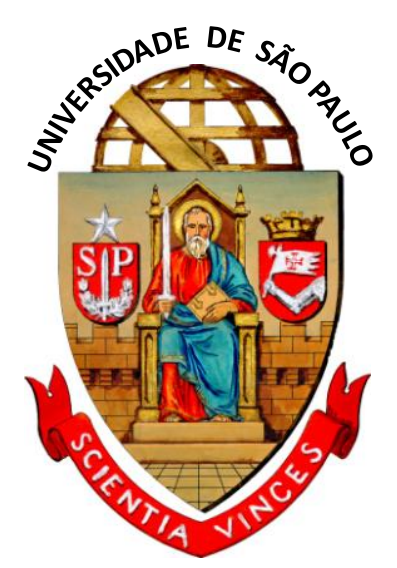

UNIVERSIDADE DE SÃO PAULO

ESCOLA DE ENGENHARIA DE SÃO CARLOS

DEPARTAMENTO DE ENGENHARIA ELÉTRICA

PROGRAMA DE PÓS-GRADUAÇÃO EM ENGENHARIA ELÉTRICA

\title{
Projeto, Fabricação e Caracterização Experimental de Metamateriais Quirais para Biossensoriamento na Faixa de Micro-ondas
}

\author{
AUTOR: Leone Veiga Muniz \\ ORIENTADOR: Prof. Dr. Ben-Hur Viana Borges \\ Dissertação apresentada à Escola de \\ Engenharia de São Carlos da USP como \\ parte dos requisitos para a obtenção do \\ título de Mestre em Ciências, Programa \\ de Engenharia Elétrica com ênfase em \\ Telecomunicações.
}

São Carlos - SP 
AUTORIZO A REPRODUÇÃO TOTAL OU PARCIAL DESTE TRABALHO, POR QUALQUER MEIO CONVENCIONAL OU ELETRÔNICO, PARA FINS DE ESTUDO E PESQUISA, DESDE QUE CITADA A FONTE.

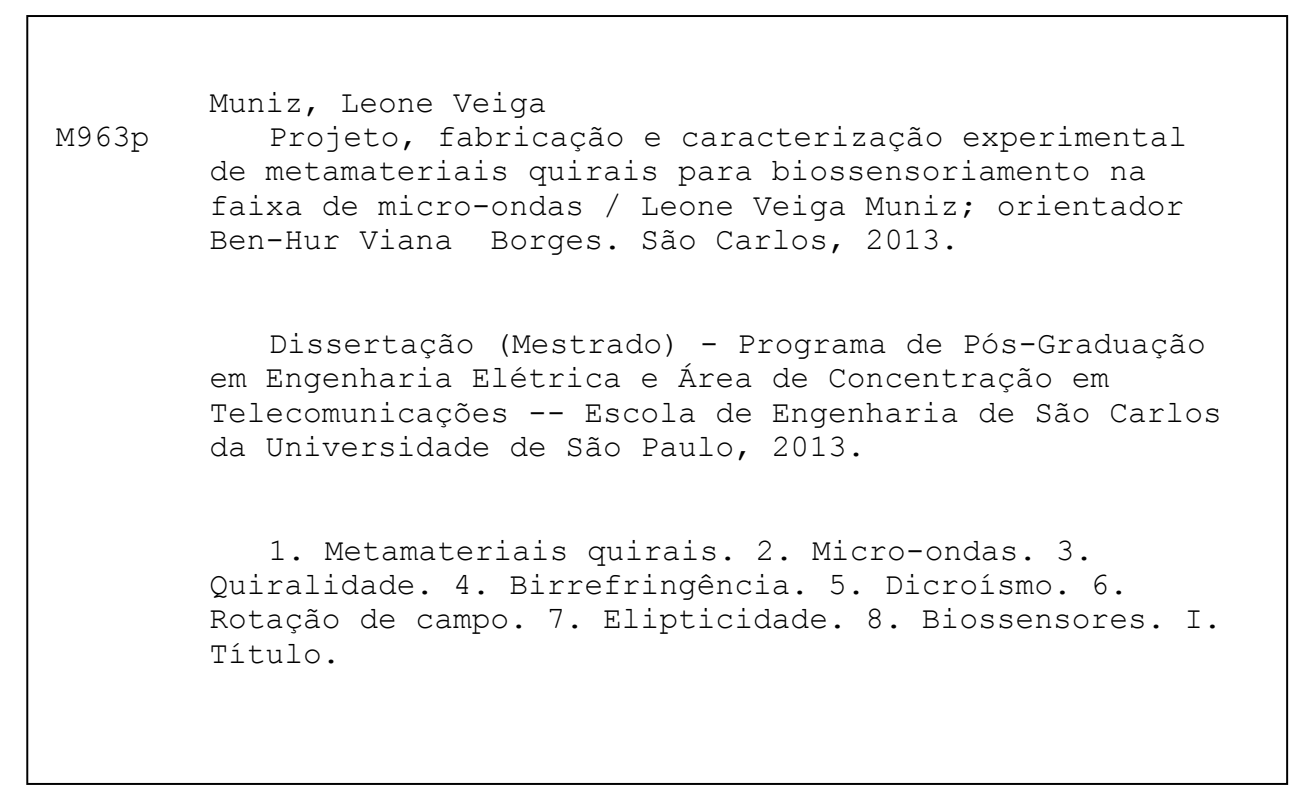




\section{FOLHA DE IULGAMENTO}

Candidato: Engenheiro LEONE VEIGA MUNIZ.

Título da dissertação: "Projeto, fabricação e caracterização experimental de metamateriais quirais para biossensoriamento na faixa de micro-ondas".

Data da defesa: 28/08/2013

\section{Comissão Julgadora:}

Prof. Associado Ben-Hur Viana Borges (Orientador)

(Escola de Engenharia de São Carlos/EESC)

Prof. Dr. Daniel Varela Magalhães

(Escola de Engenharia de São Carlos/EESC)

Dr. Joaquim José Barroso de Castro

(Instituto Nacional de Pesquisas Espaciais/INPE)
Resultado:

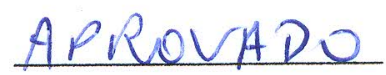

AprouARO

aprovado.

Coordenador do Programa de Pós-Graduação em Engenharia Elétrica e Presidente da Comissão de Pós-Graduação:

Prof. Titular Denis Vinicius Coury 


\section{AGRADECIMENTOS}

Agradeço a Deus, por tudo.

À minha mãe (Maria Dolores Veiga) e ao meu pai (Aliomar Lelis), pelo importante apoio e por sempre confiarem mim e investirem em meus estudos.

Aos meus irmãos (Laiane e Leonardo) e a toda a minha família, pelos incentivos.

À minha namorada (Cássia) pelo companheirismo e apoio em todos os momentos.

Ao Prof. Dr. Ben-Hur Viana Borges, pelos ensinamentos e orientações durante este trabalho.

Aos meus colegas do Laboratório de Telecomunicações, Laboratório de Micro-ondas e Metamateriais pela ajuda técnica e boa amizade.

À CAPES, à FAPESP e ao CNPq pelo auxílio financeiro.

Aos professores, funcionários e técnicos do Departamento de Engenharia Elétrica, Escola de Engenharia de São Carlos, Universidade de São Paulo (USP).

Aos demais amigos e colegas de república. 


\section{Resumo}

Muniz, L. V. (2013). "Projeto, Fabricação e Caracterização Experimental de Metamateriais Quirais para Biossensoriamento na Faixa de Micro-ondas". Dissertação (Mestrado) - Escola de Engenharia de São Carlos, Universidade de São Paulo, 2013.

Este trabalho tem como objetivos projetar, construir e caracterizar experimentalmente metamateriais quirais bi-planares para faixa de micro-ondas com o objetivo de investigar a rotação de campo como transdutor em aplicações de biossensoriamento. As estruturas metamateriais estudadas foram primeiramente modeladas e caracterizadas com o uso de aplicativos computacionais comerciais baseadas no método dos elementos finitos, onde os parâmetros geométricos das estruturas foram definidos para operarem na faixa de $8 \mathrm{GHz}$ a $12 \mathrm{GHz}$. A partir dos projetos das estruturas simuladas, os metamateriais foram construídos e caracterizados experimentalmente. No estágio de fabricação, foi desenvolvida uma técnica inédita de confecção de metamateriais em placas de circuito impresso flexível. Esta técnica, baseada no processo tradicional de fabricação de placas de circuito impresso, utiliza uma combinação de filmes finos de alumínio e folhas plásticas adesivas flexíveis formando, assim, uma folha metalizada fina e flexível. Além de ser tão eficiente quanto o método convencional, a abordagem proposta utiliza materiais de baixo custo, podendo ser adaptada a outros substratos de qualquer material, formato e espessura. Também foram projetadas e construídas placas de metamateriais com geometrias similares via método tradicional (FR4 e cobre) com o objetivo de validar os procedimentos propostos neste trabalho. A caracterização experimental dos metamateriais quirais foi realizada, por meio de antenas cornetas e analisador de redes. As propriedades efetivas do meio (quiralidade, ângulo de azimute, elipticidade, e índice de refração) foram obtidas a partir dos parâmetros-S do material, por meio de um método de extração de parâmetros. Como esperado, os resultados experimentais tiveram boa concordância com os obtidos numericamente. Por fim, foi proposta uma aplicação de metamaterial quiral utilizando suas características de rotação de campo como transdutor para a medida de glicose em amostras aquosas. No experimento proposto, o ângulo de azimute de uma onda plana polarizada que atravessa o material foi obtido 
numericamente e sua rotação de campo foi diretamente correlacionada com a concentração de glicose. Os resultados indicaram uma elevada sensibilidade mesmo para baixas concentrações de glicose, demonstrando que a rotação de campo pode realmente ser utilizada para este propósito.

Palavras-chave: metamateriais quirais, micro-ondas, quiralidade, birrefringência, dicroísmo, rotação de campo, elipticidade, biossensores 


\section{AbStRACT}

Muniz, L. V. (2013). "Design, fabrication and experimental characterization of chiral metamaterials for biosensing applications in microwave regime". M.S.c Dlssertation - Escola de Engenharia de São Carlos, Universidade de São Paulo, 2013.

This work focus on the design, fabrication and experimental characterization of bi-planar chiral metamaterials in the microwave frequency range aiming at investigating field rotation as a possible transductor for biosensig applications. First, the metamaterial structures were simulated with commercial-based finite element methods, where the structures' geometric parameters were defined to operate in the range of $8-12 \mathrm{GHz}$. Next, the metamaterials were fabricated and characterized experimentally. We have also developed a new technique for making metamaterials on flexible printed circuit boards. This proposed technique, based on traditional processes of printed circuit board's fabrication, utilizes combination of thin aluminum films and adhesive flexible plastic foils, thus forming a thin, flexible metallic foil. In addition to being as efficient as the conventional method, the proposed approach utilizes low cost materials with low insertion loss that can be adapted to substrates of any material, shape and thickness. We have also designed and fabricated metamaterials with similar geometries via the traditional circuit board method (FR4 and copper) in order to validate the procedures proposed in this work. The experimental characterization of the chiral metamaterials was carried out with antenna horns and a network analyzer. The effective medium parameters (chirality, azimuth angle, ellipticity, and refractive index) were then obtained from the $\mathrm{S}$ parameters of the material via a parameter extraction method. The experimental results were in good agreement with those obtained numerically. Finally, we proposed a new chiral metamaterial application using its field rotation characteristics as a transductor for measuring glucose concentration in aqueous solutions. In the proposed experiment, the azimuth angle of a polarized plane wave propagating through the material was numerically calculeted and its polarization field rotation was directly correlated with the glucose concentration. The results indicated a very high sensitivity even for very low glucose concentrations, indicating that field rotation can indeed be used for this purpose. 
Keywords: chiral metamaterials, microwave, chirality, birefringence, dichroism, rotatory power, ellipticity, biosensors. 


\section{ÍNDICE}

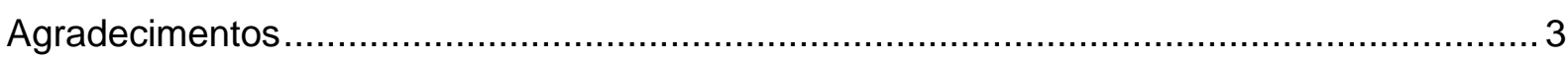

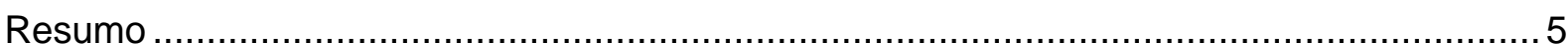

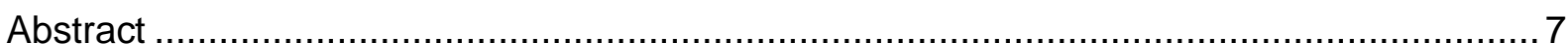

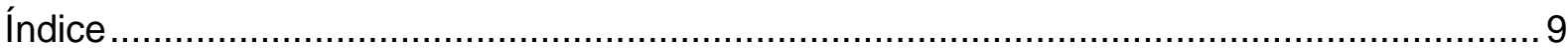

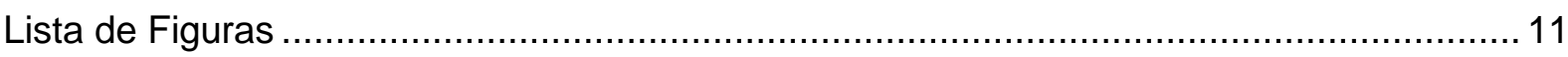

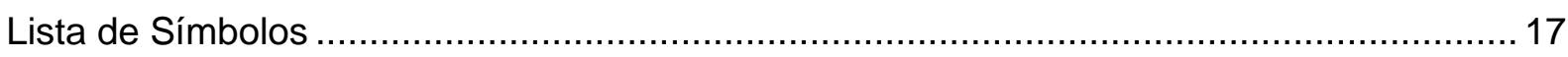

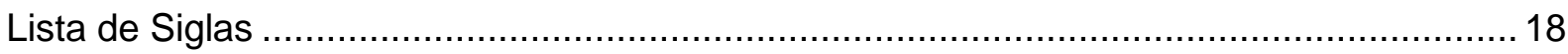

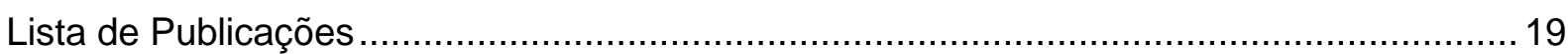

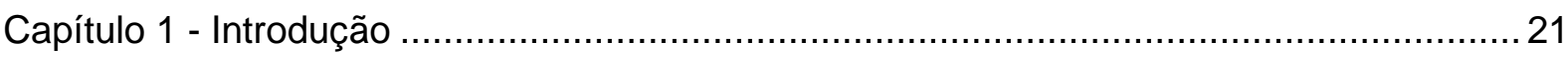

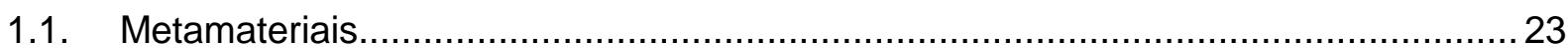

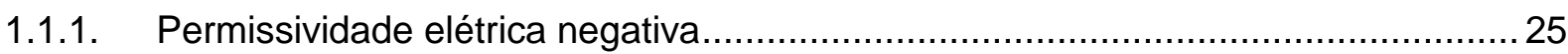

1.1.2. Permeabilidade Magnética Negativa ............................................................... 26

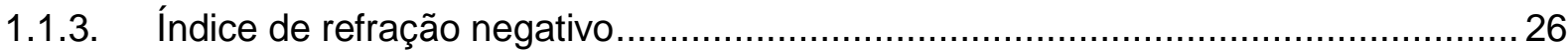

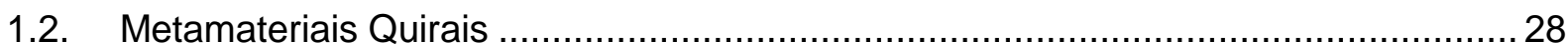

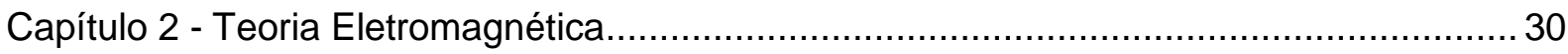

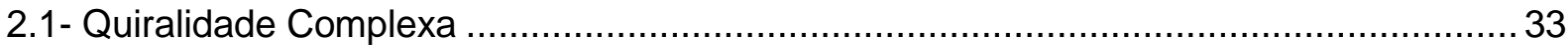

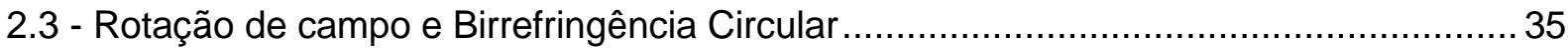

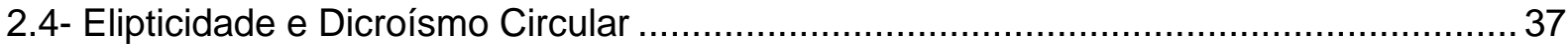

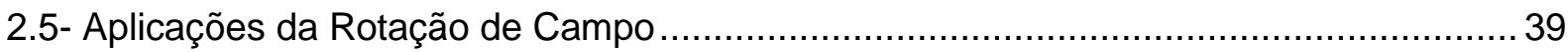

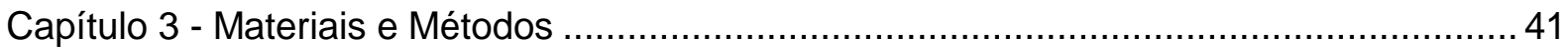

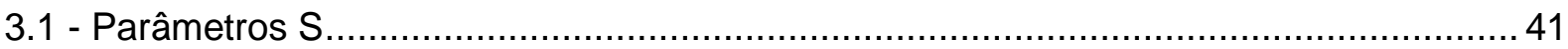

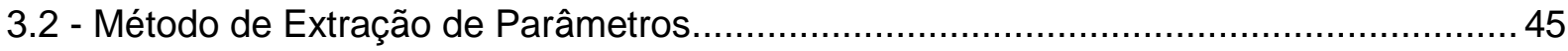

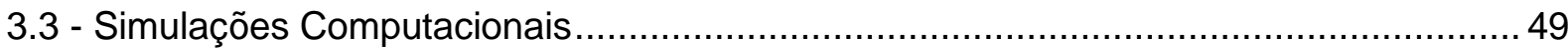

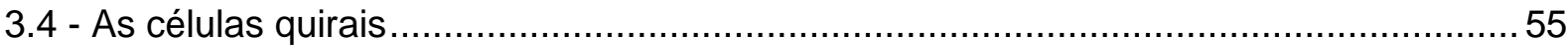

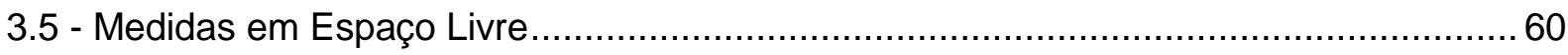

3.6 - Setup

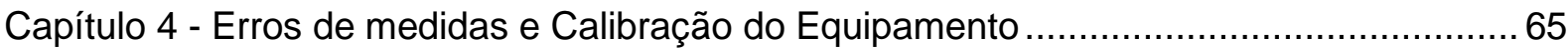

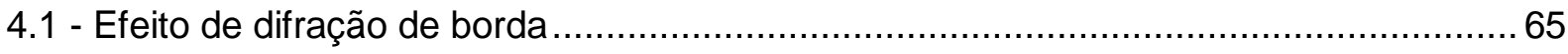

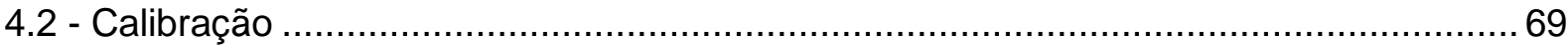

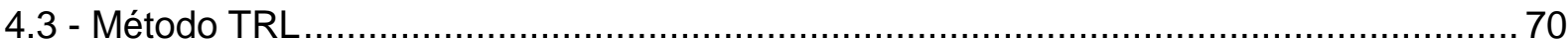

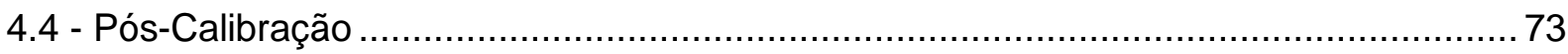

4.5 - Medidas de co-polarização e polarização cruzada............................................... 74 
Capítulo 5 - Resultados

5.1 - Ressoadores em "U”" em substrato de FR4 …....................................................... 77

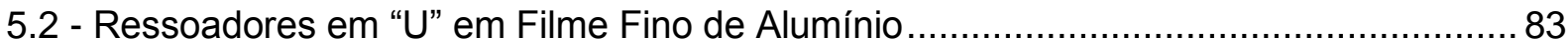

5.3 - Ressoadores em “Cruz" em substrato de FR4 ….................................................... 89

5.4 - Ressoadores em “Cruz” em Filme fino de Alumínio ................................................... 95

5.5 - Ressoadores de três hastes curvadas em FR4 ..................................................... 101

5.6 - Ressoadores de três hastes curvadas em Filme de Alumínio ................................... 107

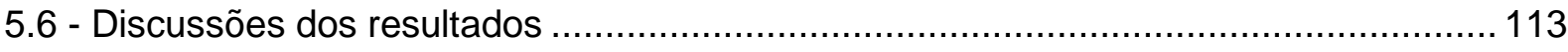

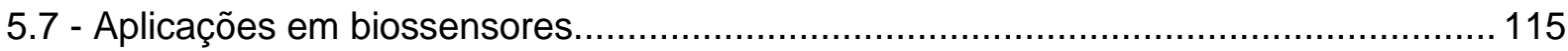

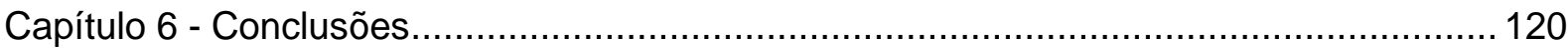

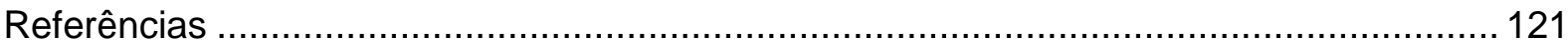

Apêndice I - Confecção das placas meta-materiais planares ........................................ 127

Apêndice II - Placas em Filme flexível de alumínio ....................................................... 130

Apêndice III - Calibração TRL no analisador de Redes HP8720C.................................... 133 


\section{LISTA DE FIGURAS}

Figura 1- Arranjo de condutores paralelos para obtenção de permissividade elétrica negativa

Figura 2 - Arranjo de ressoadores metálicos para obtenção de permeabilidade magnética negativa

Figura 3 - Arranjo de ressoadores e condutores paralelos para obtenção de valores negativos de permeabilidade magnética e permissividade elétrica e, consequentemente,

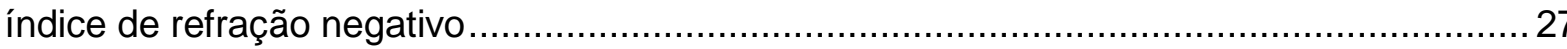

Figura 4 - Exemplo de ressoador quiral, com sua imagem espelhada assimétrica..............28

Figura 5 - Exemplos de estruturas metamateriais quirais planares para micro-ondas. ........ 29

Figura 6 - Rotação de campo e elipticidade da onda transmitida pelo metamaterial quiral.. 34

Figura 7 - Rotação de campo em um meio quiral........................................................... 35

Figura 8 - - Representação de uma onda linear como a sobreposição de duas ondas RCP e LCP

Figura 9 - Rotação de campo devido à mudança de fase entre as ondas RCP e LCP ........ 36

Figura 10 - Onda elíptica formada pela sobreposição de ondas RCP e LCP de diferentes amplitudes

Figura 11 - Cálculo da elipticidade da onda transmitida: (a) Onda linearmente polarizada como uma combinação de ondas RCP e LCP; (b) Elipticidade devido ao efeito de dicroísmo

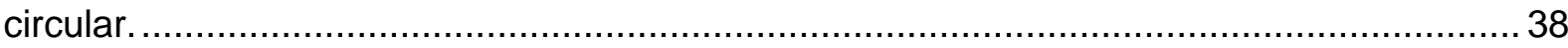

Figura 12 - Esquema de uma rede de duas portas para obtenção dos Parâmetros S........ 41

Figura 13 - Esquema simplificado da obtenção dos parâmetros S em Metamateriais ......... 43

Figura 14 - Onda plana circular incidente em um metamaterial quiral e seus coeficientes de reflexão e transmissão.

Figura 15 - Representação do arranjo periódico de ressoadores por uma célula unitária: (a)

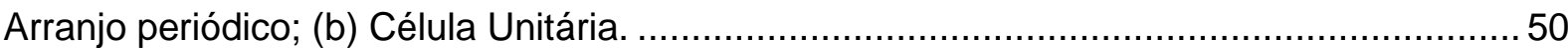

Figura 16 - Desenho e configurações de uma célula unitária no programa de simulação. ..51 Figura 17 - Condições de contorno periódicas da célula unitária no HFSS: (a) Periodicidade em y; (b) Periodicidade em $\mathrm{x}$.

Figura 18 - Configuração das portas para obtenção dos parâmetros S do sistema periódico

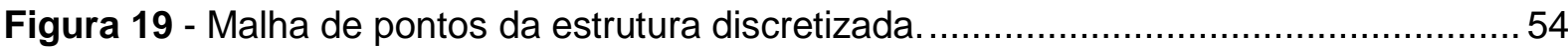

Figura 20 - Modelos de ressoadores quirais utilizados neste trabalho ...............................55

Figura 21- Estruturas projetadas em filmes de alumínio................................................ 58

Figura 22 - Esquema do sistema montado para medida experimental dos parâmetros $S$ do

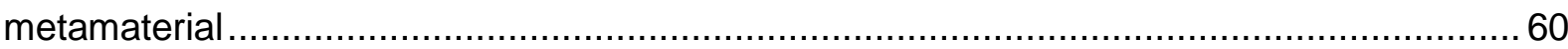

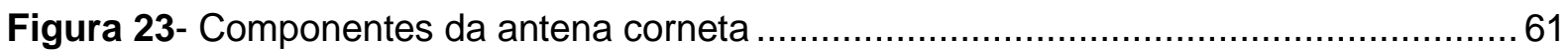

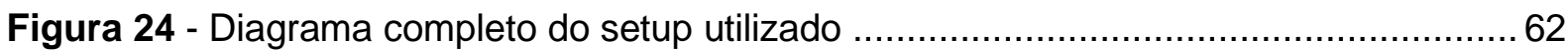

Figura 25 - Antena corneta utilizada nas medidas experimentais ...................................... 63

Figura 26 - Analisador de Redes (HP 8720C) utilizado para as medidas dos Parâmetros S63

Figura 27 - Montagem do experimento para medidas em espaço livre ...............................64 64

Figura 28 - Placas metamateriais construídas em FR4 (a, c, e) e em filme de alumínio (b, d,

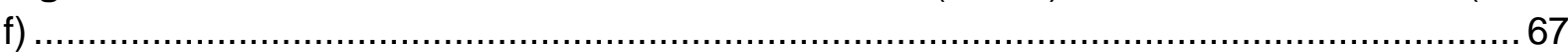

Figura 29 - Configurações das antenas em cada etapa do método de calibração TRL ........71 
Figura 30 - Gráficos da transmissão direta $\left(S_{21}\right)$ pós-calibração: (a) Magnitude em dB; (b) fase em graus

Figura 31 - Configurações de medidas de co-polarização e polarização cruzada ................74

Figura 32 - Transmissão em polarização cruzada ........................................................ 75

Figura 33 - Célula quiral unitária baseada em ressoadores em "U" com substrato em FR4.

(a) Vista frontal: Dimensões: $a_{x}=a_{y}=9 \mathrm{~mm} ; s=3,6 \mathrm{~mm} ; g=0,9 \mathrm{~mm} ; w=0,6 \mathrm{~mm}$; (b) Vista em perspectiva: $\mathrm{t}=1,6 \mathrm{~mm}$; (c) Célula em placa construída em FR4

Figura 34 - Medidas numéricas e experimentais da magnitude $(\mathrm{dB})$ dos coeficientes de transmissão lineares para ressoadores em "U" em FR4:: (a) Valores simulados de $T_{x x}$ (azul, contínua) e $\mathrm{T}_{y y}$ (vermelha, tracejada); (b) Valores experimentais de $\mathrm{T}_{\mathrm{xx}}$ (azul, contínua) e $\mathrm{T}_{\mathrm{yy}}$ (vermelha, tracejada); (c) Valores simulados de $T_{y x}$ (azul, contínua) e $T_{x y}$ (vermelha, tracejada); (d) Valores experimentais de $\mathrm{T}_{\mathrm{yx}}$ (azul, contínua) e $\mathrm{T}_{\mathrm{xy}}$ (vermelha, tracejada) ....78 Figura 35 - Valores simulados e experimentais da magnitude $(\mathrm{dB})$ e da fase dos coeficientes de transmissão circulares para ressoadores em "U" em FR4:(a) Valores simulados da magnitude de $\mathrm{T}_{++}(\mathrm{RCP})$ (azul, contínua) e $\mathrm{T}_{\text {.- }}(\mathrm{LCP})$ (vermelha, tracejada); (b) Valores experimentais da magnitude de $T_{++}$(RCP) (azul, contínua) e $T_{\text {.- }}$ (LCP) (vermelha, tracejada); (c) Valores simulados da fase de $T_{++}$(RCP) (azul, contínua) e $T_{--}$(LCP) (vermelha, tracejada); (d) Valores experimentais da fase de $T_{++}(R C P)$ (azul, contínua) e $T_{\text {.- }}$ (LCP) (vermelha, tracejada).

Figura 36 - Valores simulados e experimentais do ângulo de azimute $\theta$ e da elipticidade $\eta$ para a estrutura em ressoadores em "U" em FR4:(a) Valores simulados do ângulo de azimute $\theta$; (b) Valores experimentais do ângulo de azimute $\theta$; (c) Valores simulados da elipticidade $\eta$; (d) Valores experimentais da elipticidade $\eta$.

Figura 37 - Valores simulados e experimentais da quiralidade complexa para a estrutura em ressoadores em "U" em FR4:(a) Valores simulados parte real da quiralidade; (b) Valores experimentais parte real da quiralidade; (c) Valores simulados da parte imaginária da quiralidade; (d) Valores experimentais da parte imaginária da quiralidade.

Figura 38 - Valores simulados da parte real e imaginária dos índices de refração para ondas RCP e LCP da estrutura em ressoadores em "U" em FR4:(a) Parte real dos índices de refração para RCP e LCP; (b) Parte imaginária dos índices de refração para RCP e LCP .. 82 Figura 39 - Célula quiral unitária baseada em ressoadores em "U" com substrato em FR4.(a) Vista frontal: Dimensões: $a_{x}=a_{y}=14 \mathrm{~mm} ; \mathrm{s}=5,6 \mathrm{~mm} ; \mathrm{g}=1,4 \mathrm{~mm} ; \mathrm{w}=0,9 \mathrm{~mm}$; (b) Vista em perspectiva: $\mathrm{t}=4 \mathrm{~mm}$; (c) Uma célula da placa construída em filme fino de alumínio.

Figura 40- Medidas numéricas e experimentais da magnitude dos coeficientes de transmissão lineares para ressoadores em "U" em filme fino de alumínio:(a) Valores simulados de $T_{x x}$ (azul, contínua) e $T_{y y}$ (vermelha, tracejada); (b) Valores experimentais de $\mathrm{T}_{\mathrm{xx}}$ (azul, contínua) e Tyy (vermelha, tracejada); (c) Valores simulados de $\mathrm{T}_{\mathrm{yx}}$ (azul, contínua) e $T_{x y}$ (vermelha, tracejada); (d) Valores experimentais de $T_{y x}$ (azul, contínua) e $T_{x y}$ (vermelha, tracejada).....

Figura 41 - Valores simulados e experimentais da magnitude $(\mathrm{dB})$ e da fase dos coeficientes de transmissão circulares para ressoadores em "U" em filme de alumínio: (a) Valores simulados da magnitude de $\mathrm{T}_{++}$(RCP) (azul, contínua) e $\mathrm{T}_{\text {.- }}$ (LCP) (vermelha, tracejada); (b) Valores experimentais da magnitude de $T_{++}(R C P)$ (azul, contínua) e $T_{\text {.- }}$ (LCP) (vermelha, tracejada); (c) Valores simulados da fase de $T_{++}(R C P)$ (azul, contínua) e $T_{\text {.- }}$ (LCP) (vermelha, tracejada); (d) Valores experimentais da fase de $T_{++}(R C P)$ (azul, contínua) e $T_{-.}$ (LCP) (vermelha, tracejada); 
Figura 42 - Valores simulados e experimentais do ângulo de azimute $\theta$ e da elipticidade $\eta$ para a estrutura em ressoadores em "U" em filme de alumínio: (a) Valores simulados do ângulo de azimute $\theta$; (b) Valores experimentais do ângulo de azimute $\theta$; (c) Valores simulados da elipticidade $\eta$; (d) Valores experimentais da elipticidade $\eta$.

Figura 43 - Valores simulados e experimentais da quiralidade complexa para a estrutura em ressoadores em "U" em filme de alumínio: (a) Valores simulados parte real da quiralidade; (b) Valores experimentais parte real da quiralidade; (c) Valores simulados da parte imaginária da quiralidade; (d) Valores experimentais da parte imaginária da quiralidade. $\ldots 87$ Figura 44 - Valores simulados da parte real e imaginária dos índices de refração para ondas RCP e LCP da estrutura em ressoadores em "U" em filme de alumínio:(a) Parte real dos índices de refração para RCP e LCP; (b) Parte imaginária dos índices de refração para RCP e LCP

Figura 45 - Célula quiral unitária baseada em ressoadores em cruz com substrato em

FR4:(a) Vista frontal: Dimensões: $a_{x}=a_{y}=11 \mathrm{~mm} ; L=10,2 \mathrm{~mm} ; w=0,8 \mathrm{~mm} ; \varphi_{0}=30^{\circ} ; \varphi=$ $40^{\circ}$ (b) Vista em perspectiva: $\mathrm{t}=1,6 \mathrm{~mm}$; (c) Célula em placa construída em FR4

Figura 46 - Medidas numéricas e experimentais da magnitude dos coeficientes de transmissão lineares para ressoadores em forma de cruz em substrato de FR4:(a) Valores simulados de $T_{x x}$ (azul, contínua) e $T_{y y}$ (vermelha, tracejada); (b) Valores experimentais de $\mathrm{T}_{\mathrm{xx}}$ (azul, contínua) e $\mathrm{T}_{\mathrm{yy}}$ (vermelha, tracejada); (c) Valores simulados de $\mathrm{T}_{\mathrm{yx}}$ (azul, contínua) e $T_{x y}$ (vermelha, tracejada); (d) Valores experimentais de $T_{y x}$ (azul, contínua) e $T_{x y}$ (vermelha, tracejada) 90

Figura 47 - Valores simulados e experimentais da magnitude e da fase dos coeficientes de transmissão circulares para ressoadores em forma de cruz em substrato de FR4:(a) Valores simulados da magnitude de $T_{++}$(RCP) (azul, contínua) e $T_{\text {.- }}$ (LCP) (vermelha, tracejada); (b) Valores experimentais da magnitude de $T_{++}(R C P)$ (azul, contínua) e $T_{\text {.. }}$ (LCP) (vermelha, tracejada); (c) Valores simulados da fase de $\mathrm{T}_{++}$(RCP) (azul, contínua) e $\mathrm{T}_{-.}$(LCP) (vermelha, tracejada); (d) Valores experimentais da fase de $T_{++}(R C P)$ (azul, contínua) e $T_{-.}$ (LCP) (vermelha, tracejada);

Figura 48 - Valores simulados e experimentais do ângulo de azimute $\theta$ e da elipticidade $\eta$ para a estrutura em ressoadores em forma de cruz em substrato de FR4:(a) Valores simulados do ângulo de azimute $\theta$; (b) Valores experimentais do ângulo de azimute $\theta$; (c) Valores simulados da elipticidade $\eta$; (d) Valores experimentais da elipticidade $\eta$.

Figura 49 - Valores simulados e experimentais da quiralidade complexa para ressoadores em forma de cruz em substrato de FR4:(a) Valores simulados parte real da quiralidade; (b) Valores experimentais parte real da quiralidade; (c) Valores simulados da parte imaginária da quiralidade; (d) Valores experimentais da parte imaginária da quiralidade.

Figura 50 - Valores simulados da parte real e imaginária dos índices de refração para ondas RCP e LCP da estrutura com ressoadores em forma de cruz em substrato de FR4:(a) Parte real dos índices de refração para RCP e LCP; (b) Parte imaginária dos índices de refração para RCP e LCP

Figura 51- Célula quiral unitária baseada em ressoadores em cruz com substrato em FR4:

(a) Vista frontal: Dimensões: $a_{x}=a_{y}=17 \mathrm{~mm} ; L=15,3 \mathrm{~mm} ; w=0,8 \mathrm{~mm} ; \varphi_{0}=45^{\circ} ; \varphi=10^{\circ}$

(b) Vista em perspectiva: $\mathrm{t}=4 \mathrm{~mm}$; (c) Célula construída em filme de alumínio com substrato de baixa densidade.

Figura 52 - Medidas numéricas e experimentais da magnitude dos coeficientes de transmissão lineares para ressoadores em forma de cruz em filme de alumínio:(a) Valores simulados de $T_{x x}$ (azul, contínua) e $T_{y y}$ (vermelha, tracejada); (b) Valores experimentais de 
$T_{x x}$ (azul, contínua) e $T_{y y}$ (vermelha, tracejada); (c) Valores simulados de $T_{y x}$ (azul, contínua) e $T_{x y}$ (vermelha, tracejada); (d) Valores experimentais de $T_{y x}$ (azul, contínua) e $T_{x y}$ (vermelha, tracejada).

Figura 53 - Valores simulados e experimentais da magnitude e da fase dos coeficientes de transmissão circulares para ressoadores em forma de cruz em filme fino de alumínio:(a) Valores simulados da magnitude de $T_{++}$(RCP) (azul, contínua) e T.. (LCP) (vermelha, tracejada); (b) Valores experimentais da magnitude de $T_{++}$(RCP) (azul, contínua) e $T_{\text {.- }}$ (LCP) (vermelha, tracejada); (c) Valores simulados da fase de $T_{++}$(RCP) (azul, contínua) e $T_{\text {.- }}$ (LCP) (vermelha, tracejada); (d) Valores experimentais da fase de $T_{++}$(RCP) (azul, contínua) e T.. (LCP) (vermelha, tracejada);

Figura 54 - Valores simulados e experimentais do ângulo de azimute $\theta$ e da elipticidade $\eta$ para a estrutura em ressoadores em forma de cruz em filme fino de alumínio: (a) Valores simulados do ângulo de azimute $\theta$; (b) Valores experimentais do ângulo de azimute $\theta$; (c) Valores simulados da elipticidade $\eta$; (d) Valores experimentais da elipticidade $\eta$.

Figura 55 - Valores simulados e experimentais da quiralidade complexa para ressoadores em forma de cruz em filme de alumínio: (a) Valores simulados parte real da quiralidade; (b) Valores experimentais parte real da quiralidade; (c) Valores simulados da parte imaginária da quiralidade; (d) Valores experimentais da parte imaginária da quiralidade.

Figura 56 - Valores simulados da parte real e imaginária dos índices de refração para ondas RCP e LCP da estrutura com ressoadores em forma de cruz em filme de alumínio:(a) Parte real dos índices de refração para RCP e LCP; (b) Parte imaginária dos índices de refração para RCP e LCP.

Figura 57 - Célula quiral unitária baseada em ressoadores de hastes curvadas em FR4: (a) Vista frontal: Dimensões: $a_{x}=a_{y}=7,5 \mathrm{~mm} ; L=1,5 \mathrm{~mm} ; r=1,5 \mathrm{~mm}, w=0,7 \mathrm{~mm} ; \varphi=30^{\circ} ;(b)$ Vista em perspectiva: $\mathrm{t}=1,6 \mathrm{~mm}$; (c) Célula na placa construída em FR4.

Figura 58 - Medidas numéricas e experimentais da magnitude dos coeficientes de transmissão lineares para ressoadores em forma de hastes triplas curvadas em substrato de FR4: (a) Valores simulados de $T_{x x}$ (azul, contínua) e $T_{y y}$ (vermelha, tracejada); (b) Valores experimentais de $T_{x x}$ (azul, contínua) e $T_{y y}$ (vermelha, tracejada); (c) Valores simulados de $\mathrm{T}_{\mathrm{yx}}$ (azul, contínua) e $\mathrm{T}_{\mathrm{xy}}$ (vermelha, tracejada); (d) Valores experimentais de $\mathrm{T}_{\mathrm{yx}}$ (azul, contínua) e $T_{x y}$ (vermelha, tracejada)....

Figura 59 - Valores simulados e experimentais da magnitude e da fase dos coeficientes de transmissão circulares para ressoadores em forma de hastes triplas curvadas em substrato de FR4:(a) Valores simulados da magnitude de $\mathrm{T}_{++}$(RCP) (azul, contínua) e $\mathrm{T}_{\text {.. }}$ (LCP) (vermelha, tracejada); (b) Valores experimentais da magnitude de $T_{++}(R C P)$ (azul, contínua) e T.. (LCP) (vermelha, tracejada); (c) Valores simulados da fase de $T_{++}(R C P)$ (azul, contínua) e T.. (LCP) (vermelha, tracejada); (d) Valores experimentais da fase de $T_{++}(R C P)$ (azul, contínua) e T.. (LCP) (vermelha, tracejada);

Figura 60 - Valores simulados e experimentais do ângulo de azimute $\theta$ e da elipticidade $\eta$ para a estrutura em ressoadores em forma de hastes triplas curvadas em substrato de FR4:(a) Valores simulados do ângulo de azimute $\theta$; (b) Valores experimentais do ângulo de azimute $\theta$; (c) Valores simulados da elipticidade $\eta$; (d) Valores experimentais da elipticidade

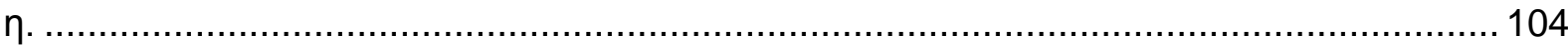

Figura 61- Valores simulados e experimentais da quiralidade complexa para a estrutura em ressoadores em forma de hastes triplas curvadas em substrato de FR4: (a) Valores simulados parte real da quiralidade; (b) Valores experimentais parte real da quiralidade; (c) 
Valores simulados da parte imaginária da quiralidade; (d) Valores experimentais da parte imaginária da quiralidade.

Figura 62 - Valores simulados da parte real e imaginária dos índices de refração para ondas RCP e LCP da estrutura em ressoadores em forma de hastes triplas curvadas em substrato de FR4:(a) Parte real dos índices de refração para RCP e LCP; (b) Parte imaginária dos índices de refração para RCP e LCP.

Figura 63 - Célula quiral unitária baseada em ressoadores de hastes curvadas em filme de alumínio:(a) Vista frontal: Dimensões: $a_{x}=a_{y}=12 \mathrm{~mm} ; L=2,4 \mathrm{~mm} ; r=2,4 \mathrm{~mm}, w=0,6 \mathrm{~mm}$; $\varphi=30^{\circ}$; (b) Vista em perspectiva: $t=4 \mathrm{~mm}$; (c) Célula construída em placa de filme de alumínio.

Figura 64 - Medidas numéricas e experimentais da magnitude dos coeficientes de transmissão lineares para ressoadores em forma de hastes triplas curvadas em filme fino de alumínio:(a) Valores simulados de $\mathrm{T}_{\mathrm{xx}}$ (azul, contínua) e $\mathrm{T}_{\mathrm{yy}}$ (vermelha, tracejada); (b) Valores experimentais de $\mathrm{T}_{\mathrm{xx}}$ (azul, contínua) e $\mathrm{T}_{\mathrm{yy}}$ (vermelha, tracejada); (c) Valores simulados de $\mathrm{T}_{\mathrm{yx}}$ (azul, contínua) e $\mathrm{T}_{\mathrm{xy}}$ (vermelha, tracejada); (d) Valores experimentais de $T_{y x}$ (azul, contínua) e $T_{x y}$ (vermelha, tracejada)

Figura 65 - Valores simulados e experimentais da magnitude e da fase dos coeficientes de transmissão circulares para ressoadores em forma de hastes triplas curvadas em filme fino de alumínio:(a) Valores simulados da magnitude de $T_{++}$(RCP) (azul, contínua) e T.- (LCP) (vermelha, tracejada); (b) Valores experimentais da magnitude de $T_{++}$(RCP) (azul, contínua) e T.. (LCP) (vermelha, tracejada); (c) Valores simulados da fase de $T_{++}(R C P)$ (azul, contínua) e T.. (LCP) (vermelha, tracejada); (d) Valores experimentais da fase de $T_{++}(R C P)$ (azul, contínua) e T.- (LCP) (vermelha, tracejada); .

Figura 66 - Valores simulados e experimentais do ângulo de azimute $\theta$ e da elipticidade $\eta$ para a estrutura em ressoadores em forma de hastes triplas curvadas em filme fino de alumínio:(a) Valores simulados do ângulo de azimute $\theta$; (b) Valores experimentais do ângulo de azimute $\theta$; (c) Valores simulados da elipticidade $\eta$; (d) Valores experimentais da elipticidade $\eta$.

Figura 67 - Valores simulados e experimentais da quiralidade complexa para a estrutura com ressoadores em forma de hastes triplas curvadas em filme fino de alumínio:(a) Valores simulados parte real da quiralidade; (b) Valores experimentais parte real da quiralidade; (c) Valores simulados da parte imaginária da quiralidade; (d) Valores experimentais da parte imaginária da quiralidade.

Figura 68 - Valores simulados da parte real e imaginária dos índices de refração para ondas RCP e LCP da estrutura em forma de hastes triplas curvadas em filme fino de alumínio:(a) Parte real dos índices de refração para RCP e LCP; (b) Parte imaginária dos índices de refração para RCP e LCP.

Figura 69 - Vista em 3D das células unitárias de hastes triplas curvadas, cujas dimensões são: $s=1.6 \mathrm{~mm}$ e $d=1.2 \mathrm{~mm}$.

Figura 70 - Vista em 3D das células unitárias de fios cruzados, cujas dimensões são: $s=$ $1.6 \mathrm{~mm}$ e $d=1.8 \mathrm{~mm}$.

Figura 71 - Vista superior da célula de hastes triplas curvadas, cujas dimensões são: $L=1.6$ $\mathrm{mm}, D=3.2 \mathrm{~mm}, a_{x}=a_{y}=8 \mathrm{~mm}, w=0.5 \mathrm{~mm}, \varphi=30^{\circ}$.

Figura 72 - Vista superior da célula de fios cruzados, cujas dimensões são: $I=16 \mathrm{~mm}, \mathrm{w}=$ $1 \mathrm{~mm}, \varphi=30^{\circ}, \varphi_{0}=45^{\circ}$.

Figura 73 - Ângulo de azimute $\theta$ em função da concentração de glicose de 0 a $300 \mathrm{mg} / \mathrm{ml}$ para a configuração de hastes triplas. 
Figura 74 - Ângulo de azimute $\theta$ em função da concentração de glicose de 0 a $300 \mathrm{mg} / \mathrm{ml}$ para a configuração de fios cruzados.

Figura 75 - Transferência térmica- (a) Papel transfer e placa de FR4 metalizada; (b)

Posicionamento do papel transfer na placa e transferência térmica, (c) placa com o layout transferido.

Figura 76 - Prensa térmica manual utilizada no processo de transferência em duas posições de operação.(a) prensa com mesa de compressão aberta; (b) mesa de compressão fechada durante o processo de transferência térmica 128

Figura 77 - Processo de corrosão: (a) placa a ser corroída; (b) placa imersa no ácido; (c) placa após a corrosão. 129

Figura 78 - Placa metamaterial pronta (a) Placa metamaterial pronta; (b) Detalhe ampliado. 129

Figura 79 - Processo de confecção da placa de circuito impresso flexível: (a) filme de alumínio $(50 \mu \mathrm{m})$; (b) plástico auto-adesivo; (c) placa pronta ........................................ 130

Figura 80 - Filme de alumínio com layout transferido .................................................... 131

Figura 81 - Placa de metamaterial com filme de alumínio ............................................. 132 


\section{LISTA DE SímBOLOS}

$\varepsilon \quad$ Permissividade elétrica

$\varepsilon_{0} \quad$ Permissividade elétrica do vácuo

$\mu \quad$ Permeabilidade magnética

$\mu_{0} \quad$ Permeabilidade magnética do vácuo

n I Índice de refração

n+ Índice de refração para ondas RCP

n- I Índice de refração para ondas LCP

z Impedância

K Quiralidade

$\theta \quad$ Ângulo de azimute

$\eta \quad$ Elipticidade 


\section{LISTA DE SigLAS}

EPS - Poliestireno Expandido

FR4 - Flame Retardant \#4

GPIB - General Purpose Interface Bus

$\mathrm{GHz}$ - Giga hertz $\left(10^{9} \mathrm{~Hz}\right)$

HFSS - High Frequency Structure Simulator

LCP - polarização circular à esquerda, Left Circularly Polarized

RCP - polarização circular à direita, Right Circularly Polarized

PEC - Perfect Electric Conductor 


\section{Lista de Publicações}

L. V. Muniz, L. C. P. S. Lima, T. C. Vasconcelos, F. D. Nunes and B. V. Borges, "Rotação do Azimute de Polarização em Metamateriais Quirais como um Transdutor para Aplicações em Biossensores". MOMAG 2012 - 15 SBMO Simpósio Brasileiro de Micro-ondas e Optoeletrônica e o 10 CBMag Congresso Brasileiro de Eletromagnetismo (MOMAG 2012), João Pessoa, PB, 2012.

L. C. P. S. Lima, L. V. Muniz, T. C. Vasconcelos, F. D. Nunes and B. V. Borges, "Design of a dual-band monopole antenna enclosed in a 2D-chiral metamaterial shell", Metamaterials'2012: The Sixth International Congress on Advanced Electromagnetic Materials in Microwaves and Optics, 2012, Saint Petersburg. Proceedings of the Metamaterials 2012 Congressp. 730-732, 2012. 


\section{CAPÍtULO 1 - INTROdUÇÃo}

Desde o surgimento da tecnologia dos metamateriais, a ciência tem buscado aplicar esse conceito nas mais diversas áreas. A possibilidade de manipular as propriedades eletromagnéticas nestes materiais despertou um grande interesse na comunidade científica, uma vez que abriu novas portas para o desenvolvimento de dispositivos inéditos e o aprimoramento dos tradicionais. Desde então, tem-se procurando inovar e aperfeiçoar as técnicas de obtenção destes meios para que seja possível aproveitar suas vantagens ao máximo.

Os metamateriais são materiais artificiais compostos por uma combinação de ressoadores metálicos em camadas dielétricas. A geometria de tais ressoadores é então cuidadosamente projetada de forma que, ao interagir com as ondas eletromagnéticas de frequências específicas, suas propriedades efetivas apresentem valores previamente desejados. Por conta dessa tecnologia, tornou-se possível obter materiais com valores incomuns das principais propriedades eletromagnéticas, quais sejam: permissividade elétrica, permeabilidade magnética e índice de refração, possibilitando até mesmo valores não encontrados em materiais naturais. Uma vez que a propagação de campos eletromagnéticos em um meio depende dessas características, ter o poder de controlá-las adiciona novos graus de liberdade no desenvolvimento de novos dispositivos eletromagnéticos.

Essa inovação tecnológica causou uma verdadeira quebra de paradigmas, proporcionando um grande impacto em setores como telecomunicações, sensores e dispositivos (ópticos e em micro-ondas) e no estudo da propagação de ondas de um modo geral, de forma que o número de pesquisas e publicações nessa área específica cresceu muito desde então. Além disso, têm surgido até mesmo congressos científicos internacionais exclusivos para o tema, possibilitando a divulgação científica e aplicações notadamente nas áreas de óptica e micro-ondas.

As propriedades de um metamaterial estão diretamente relacionadas com os parâmetros geométricos de seus ressoadores (células unitárias) ou "átomos artificiais". Um caso especial de geometria (de interesse particular neste trabalho) 
consiste em empregar uma célula unitária que não apresenta simetria em relação à sua imagem-espelho. Esta configuração apresenta algumas características adicionais que não são encontradas nos metamateriais convencionais, ou seja, a rotação do plano de polarização de ondas eletromagnéticas. Essa nova classe de metamateriais é denominada "Metamateriais Quirais", por apresentarem propriedades importantes, como: quiralidade, birrefringência e dicroísmo circular. Devido a esses fenômenos, uma onda eletromagnética linearmente polarizada que atravessa este material terá seu plano de polarização rotacionado de um determinado ângulo de azimute podendo inclusive se tornar elíptica.

Este trabalho visa o projeto, fabricação e caracterização de metamateriais quirais para a faixa de frequência de micro-ondas. Para isso, é proposta uma nova técnica de confecção desses materiais, a qual é comparada e validada com métodos tradicionais. Adicionalmente, será também investigada a adoção da rotação do plano de polarização de ondas que se propagam em metamateriais quirais como um novo transdutor para a medida de concentração de glicose em amostras aquosas. Isso será feito via medida do ângulo de azimute $\theta$, resultante da birrefringência do meio quiral. Quando a composição de uma das camadas dielétricas do substrato metamaterial é modificada, ocorrem alterações no comportamento eletromagnético de todo o conjunto influenciando, assim, sua capacidade de rotação de campo em determinadas frequências. Portanto, a partir do valor do ângulo de azimute será possível extrair informações a respeito da composição de uma amostra inserida no substrato.

A tecnologia dos metamateriais associada à praticidade dos sensores em micro-ondas, por exemplo, constitui uma área promissora. As possibilidades advindas dessa técnica prometem aprimorar novos dispositivos na área de sensoriamento, novos transdutores e novas aplicações com o uso de sensores mais modernos com desempenho superior aos convencionais.

De uma forma geral, os metamateriais constituem uma área emergente, muito rica em possibilidades e o objetivo deste trabalho é explorar o desafio de contribuir com a expansão dessa promissora tecnologia. 


\subsection{Metamateriais}

Os metamateriais são definidos como materiais artificiais projetados para terem propriedades eletromagnéticas incomuns, previamente projetadas. Em alguns casos, essas propriedades podem apresentar valores exóticos, não encontrados na natureza, tais como: valores reais negativos de permissividade elétrica $(\varepsilon<0)$, permeabilidade magnética $(\mu<0)$ e índice de refração $(n<0)[1]$

Essa poderosa tecnologia gerou uma verdadeira revolução em aplicações eletromagnéticas, uma vez que tornou possível a manipulação das características constitutivas da matéria em nível macroscópico. Adicionalmente, rompeu o paradigma segundo o qual tais propriedades nunca poderiam apresentar valores negativos. Embora valores reais de $\varepsilon<0$ já pudessem ser verificados naturalmente em metais para frequências ópticas, os mesmos nunca tinham sido observados em frequências mais baixas, na faixa de micro-ondas, por exemplo. Tal fato, associado às demais propriedades incomuns para todo o espetro eletromagnético, representaram então uma grande novidade.

Construídos a partir de materiais comuns, como metais e dielétricos, os metamateriais são compostos por um arranjo de partículas ressoadoras que desempenham o papel de "átomos macroscópicos" do material artificial. Nesse arranjo (geralmente periódico) o tamanho dos elementos básicos deve ser muito menor que o comprimento de onda de operação (em torno de 1/10 do comprimento e onda) [2], de forma que uma onda eletromagnética propagante interaja com esse meio discreto como se estivesse em um meio homogêneo [1]. Com isso, o material pode ser descrito e estudado em termos de suas propriedades efetivas como o índice de refração, permissividade, permeabilidade e impedância. [1]

Para que entrem em ressonância com o campo eletromagnético, as dimensões dos ressoadores devem ter a mesma ordem de grandeza de frações do comprimento de onda da frequência de operação. Sendo assim, para a faixa de micro-ondas $(0,3 \mathrm{GHz}$ a $300 \mathrm{GHz})$ cujo comprimento de onda é da ordem de dezenas de milímetros, as inclusões também serão nessa escala. Pela mesma 
razão, dispositivos para frequências ópticas (400THz a $800 \mathrm{THz}$ ) apresentam, consequentemente, escala nanométrica.

Os metamateriais para a faixa de micro-ondas $(\mathrm{GHz})$ em particular, possuem a vantagem de serem de fácil construção, pois suas células em escala milimétrica e ressoadores metálicos podem ser fabricadas por meio de técnicas simples de confecção de placas de circuito impresso. Por outro lado, metamateriais projetados para frequências ópticas são mais complexos de serem produzidos uma vez que, devido à escala nanométrica de suas inclusões, exigem uso de métodos mais avançados de litografia e nanofabricação. Por esse motivo, os primeiros experimentos na história dos metamateriais foram feitos para frequências de microondas e só depois, aos poucos, as pesquisas foram evoluindo para a faixa óptica [2, $3,4,5]$.

Apesar de ser considerada uma tecnologia recente, os primeiros experimentos de manipulação das propriedades de um meio para propagação de ondas ocorreram em 1898, quando Bose utilizou arranjos de estruturas metálicas para propagação de micro-ondas [6, 7]. Em 1948, Kock [7] construiu lentes a partir de estruturas periódicas para obter diferentes índices de refração. Porém, até então, meios com permissividade elétrica e permeabilidade magnética simultaneamente negativas ainda não haviam sido idealizados.

A primeira ideia a respeito de tais materiais surgiu em 1968, quando o cientista russo Victor Veselago propôs uma análise teórica da propagação de ondas eletromagnéticas nesse meio e discutiu suas possíveis implicações [8]. Veselago previu que um material com $\varepsilon<0$ e $\mu<0$, simultaneamente, resultaria em um índice de refração negativo, $\mathrm{n}<0$ e, com isso, uma série de fenômenos interessantes seriam passíveis de obtenção, como: velocidade de fase negativa, refração negativa, efeito Doppler invertido e lentes não usuais. Essa publicação foi um marco na história dos metamateriais, sendo sempre uma importante referência para qualquer estudo na área.

As ideias teóricas de Veselago só foram colocadas em prática vários anos mais tarde, no início dos anos 2000, quando a partir dos trabalhos de Pendry et al. $[9,10,11]$ foram demonstradas maneiras práticas de se obter experimentalmente materiais $\operatorname{com} \varepsilon<0$ e $\mu<0$, cujo princípio é baseado na formação de um material 
composto por inclusões discretas menores que o comprimento de onda, como será visto a seguir.

\subsubsection{Permissividade elÉtrica negativa}

A permissividade elétrica relativa $\varepsilon$ de um meio é uma grandeza complexa, em que a parte real está relacionada à formação de dipolos elétricos na matéria na presença de um campo eletromagnético e a parte imaginária às perdas de energia desse campo por dissipação no material.

A permissividade negativa pode ser alcançada a partir de arranjos periódicos tridimensionais de fios metálicos condutores colocados em paralelo, cujo esquema é ilustrado na Figura 1. Ajustando-se a geometria e a distância entre os condutores, é possível determinar a faixa de frequência de ressonância desejada, onde $\varepsilon<0$. Verificou-se que, se a polarização do campo elétrico for orientada na mesma direção dos condutores, essa estrutura apresenta o comportamento semelhante ao de um plasma, porém, para frequências da ordem de $\mathrm{GHz}$, como as de micro-ondas [9, 10].

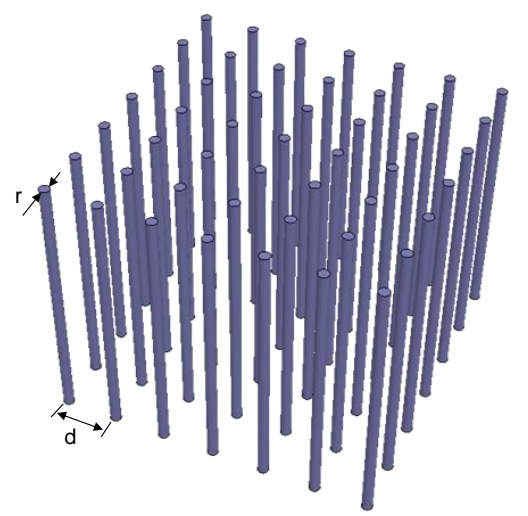

Figura 1- Arranjo de condutores paralelos para obtenção de permissividade elétrica negativa 


\subsubsection{Permeabilidade Magnética Negativa}

A permeabilidade magnética relativa $\mu$ também é uma grandeza complexa, em que a parte real está relacionada à formação de dipolos magnéticos na matéria na presença de um campo eletromagnético e a parte imaginária às perdas de energia desse campo por dissipação no material.

A obtenção de $\mu<0$, por sua vez, pode ser conseguida por meio de arranjos periódicos de anéis ressoadores muito menores com relação ao comprimento de onda [11] como ilustrado na Figura 2. Mesmo se tratando de materiais não magnéticos, a resposta do conjunto se deve às correntes induzidas nos anéis condutores. Capacitâncias e indutâncias associadas à geometria da estrutura dos anéis concêntricos permitem que, na frequência de ressonância, o metamaterial apresente valores de permeabilidade magnética incomuns, podendo até mesmo ser sintonizado para que produza um valor negativo [11].
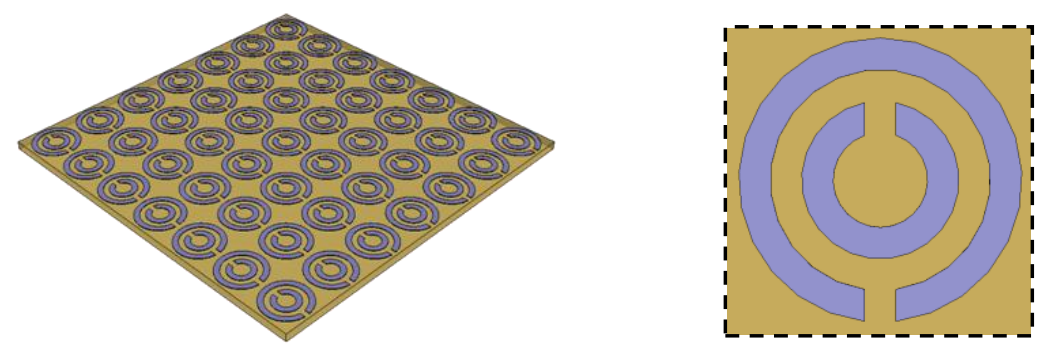

Figura 2 - Arranjo de ressoadores metálicos para obtenção de permeabilidade magnética negativa

\subsection{3. ÍNDICE DE REFRAÇÃo NEGATIVO}

O índice de refração $n$ também é uma grandeza complexa. Sua parte real está relacionada à velocidade de propagação da onda no meio e sua parte imaginária à atenuação da amplitude do campo propagante.

Para que um metamaterial tenha índice de refração negativo em determinada frequência, é preciso que sua permissividade elétrica e permeabilidade magnética sejam ambas, simultaneamente, negativas. Isso acontece porque 0 índice de refração é definido como mostrado na equação (1), e em casos de $\varepsilon<0$ e $\mu<0$, deve-se utilizar o sinal negativo da equação (1) 


$$
n= \pm \sqrt{\varepsilon \mu}
$$

Esse efeito foi obtido experimentalmente pela primeira vez por Smith et al.[12], que fizeram a combinação de arranjos periódicos de condutores paralelos (com $\varepsilon<0)$ e anéis ressoadores (com $\mu<0$ ), como ilustrado na Figura 3. Desta forma, as propriedades efetivas do meio, tais como $\varepsilon<0$ e $\mu<0$, puderam ser projetadas para que ocorresse na mesma faixa de frequência, resultando em $n<0$ para frequências de micro-ondas.
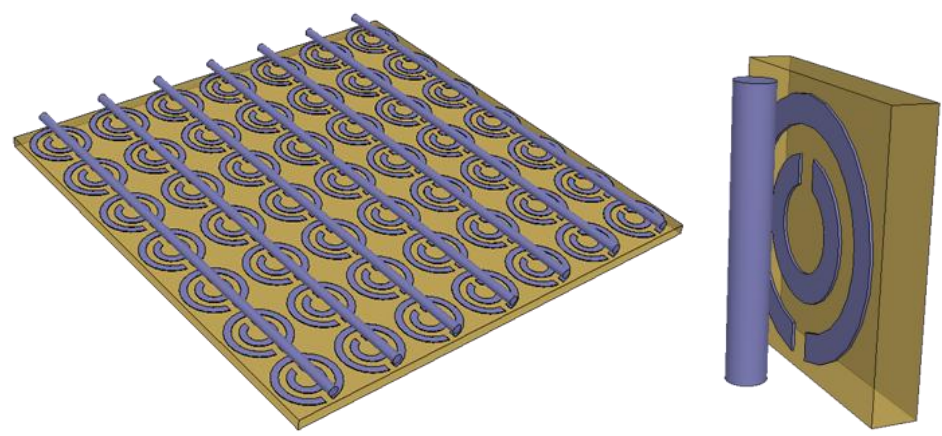

Figura 3 - Arranjo de ressoadores e condutores paralelos para obtenção de valores negativos de permeabilidade magnética e permissividade elétrica e, consequentemente, índice de refração negativo

A possibilidade de fabricação desse tipo de material é de extrema importância, uma vez que a manipulação das propriedades eletromagnéticas tornou possível a obtenção de novos dispositivos, que antes eram apenas analisados teoricamente. Desde então, diversas aplicações têm sido propostas, como superlentes [13, 14], mantas de invisibilidade eletromagnética [15, 16, 17, 18], antenas $[19,20,21]$ e sensores $[22,23]$.

Além dessas configurações, se as células unitárias do metamaterial forem especialmente assimétricas em relação à sua imagem espelhada, o meio efetivo formado por elas passa a apresentar algumas características adicionais e propriedades particulares, o que gera uma nova classe de meios artificiais denominados “Metamateriais Quirais”, descritos em mais detalhes a seguir. 


\subsection{Metamateriais Quirais}

Os denominados "metamateriais quirais" compõem uma nova classe de materiais artificiais que vêm despertando grande interesse da comunidade científica. Esse tipo de metamaterial tem como característica a ausência de simetria espelho na geometria de suas inclusões [24, 25], ou seja, o ressoador quiral e a sua imagem espelhada não se sobrepõem coincidentemente. Um exemplo de ressoador quiral, é ilustrado na Figura 2.

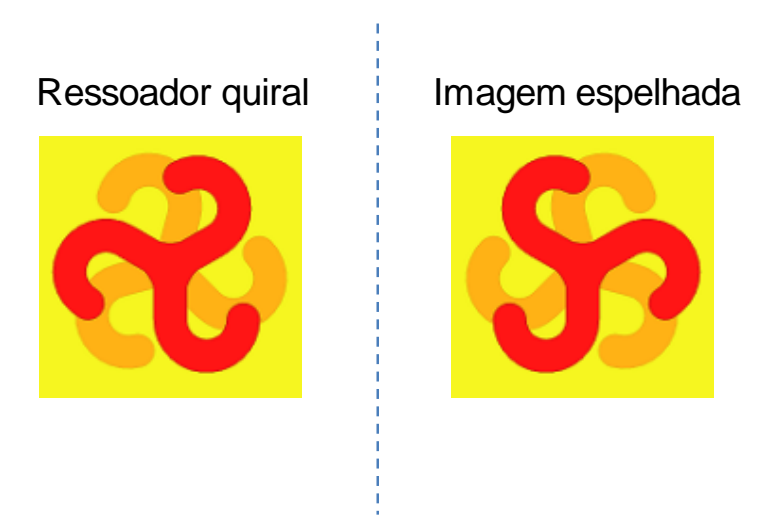

Figura 4 - Exemplo de ressoador quiral, com sua imagem espelhada assimétrica.

A primeira análise de um metamaterial quiral foi realizada por Tretyakov et al. [26], e baseava-se em uma estrutura helicoidal para as inserções. Mais recentemente, metamateriais quirais planares foram introduzidos por Fedotov et al. [27], consistindo de inclusões planares sem simetria em seu plano espelho (Figura 5-a). Essa nova configuração (planar) representou um passo importante na massificação desta estrutura por permitir que as mesmas sejam obtidas via processos tradicionais de fabricação de placas de circuito impresso (em frequências na faixa de micro-ondas). Desde então, diversas configurações desta classe de metamateriais vêm surgindo, tais como estruturas de fios cruzados [24] (Figura 5-c) e anéis divididos em "U" [25] (Figura 5-d) capazes de produzir grande rotação de campo e dicroísmo circular; ressoadores em anel assimetricamente segmentados [30] (Figura 5-b) são também capazes de produzir grande, e ao mesmo tempo sintonizável, rotação de campo, entre outros efeitos. 


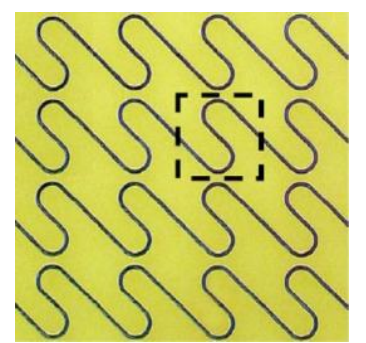

(a)

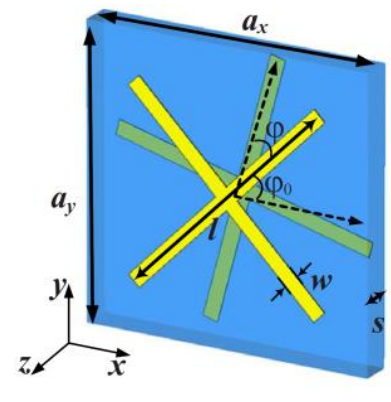

(c)

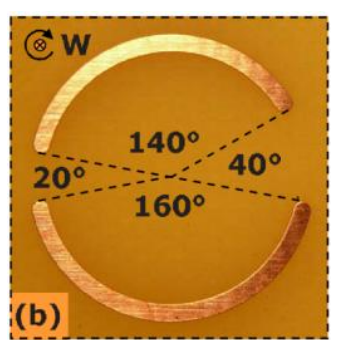

(b)

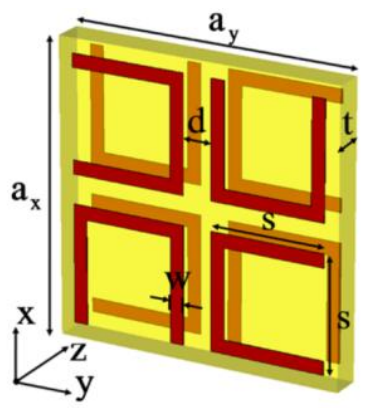

(d)

Figura 5 - Exemplos de estruturas metamateriais quirais planares para micro-ondas.

Devido a essa assimetria característica, um metamaterial quiral possui o parâmetro denominado "quiralidade", responsável por respostas eletromagnéticas diferentes para ondas de polarização circular à direita (RCP) ou à esquerda (LCP), tendo índices de refração diferentes para cada polarização [24, 25].

Por consequência da quiralidade, o metamaterial quiral apresenta propriedades de birrefringência e dicroísmo circular. A principal consequência desses fenômenos é o fato de que se uma onda de polarização linear atravessa o metamaterial quiral, ela terá seu plano de polarização rotacionado por um ângulo (ângulo de azimute devido ao efeito da birrefringência) e se tornará elíptica (efeito do dicroísmo circular) [24, 25, 31].

Além disso, como será mostrado a seguir, o efeito de quiralidade faz com que os metamateriais quirais sejam capazes de apresentar índice de refração negativo sem a necessidade de $\varepsilon<0$ e $\mu<0$ simultaneamente [28, 29], sendo um importante diferencial em relação aos metamateriais usuais. 


\section{CAPítulo 2 - TeOria EletromagnÉtica}

Todos os fenômenos eletromagnéticos, incluindo a propagação de ondas, podem ser descritos e estudados a partir das Equações de Maxwell. Essas quatro leis fundamentais do eletromagnetismo mostram, dentre outras coisas, a dependência entre os campos elétrico e magnético [32].

Para uma onda eletromagnética que se propaga no espaço livre ou em um meio dielétrico qualquer, longe de fontes de excitação e cargas livres, as Equações de Maxwell se resumem a:

$$
\begin{gathered}
\nabla \times \boldsymbol{E}=-\frac{\partial \boldsymbol{B}}{\partial t} \\
\nabla \times \boldsymbol{H}=\frac{\partial \boldsymbol{D}}{\partial t} \\
\nabla \cdot \boldsymbol{D}=0 \\
\nabla \cdot \boldsymbol{B}=0
\end{gathered}
$$

em que $\mathbf{E}$ é vetor campo elétrico, $\mathbf{H}$ é o vetor campo magnético, $\mathbf{D}$ é a densidade de fluxo elétrico e $\mathbf{B}$ é a densidade de fluxo magnético $[33,34]$

Para a completa descrição da propagação de ondas em um determinado meio, são necessárias, além das equações de Maxwell, algumas importantes relações constitutivas que trazem informações sobre as propriedades do material em questão. Essas relações, também chamadas de "Equações do Material", dão as relações entre as densidades de fluxo $\mathbf{D}$ e $\mathbf{B}$ com os respectivos campos elétrico $\mathbf{E}$ e magnético $\mathrm{H}$ quando a onda se propaga através da matéria [32, 33, 34]. 
No caso mais comum, de meios homogêneos e isotrópicos em que a propagação da onda é igual para qualquer polarização e sentido da onda, as duas relações constitutivas são [32, 34]:

$$
\begin{aligned}
& \boldsymbol{D}=\varepsilon_{0} \varepsilon \boldsymbol{E} \\
& \boldsymbol{B}=\mu_{0} \mu \boldsymbol{H}
\end{aligned}
$$

em que $\varepsilon_{0}$ é a permissividade do vácuo, $\varepsilon$ é a permissividade relativa do meio, $\mu_{0}$ é a permeabilidade do vácuo $\mu$ é a permeabilidade relativa do meio. Com isso, o índice de refração do meio é definido como [33]:

$$
n=\sqrt{\varepsilon \mu}
$$

No caso especial de materiais quirais, utilizados nesse trabalho, que se classificam como meios bi-isotrópicos [35], as relações constitutivas são:

$$
\begin{aligned}
& \boldsymbol{D}=\varepsilon_{0} \varepsilon \boldsymbol{E}+i \frac{\kappa}{c} \boldsymbol{H} \\
& \boldsymbol{B}=\mu_{0} \mu \boldsymbol{H}-i \frac{\kappa}{c} \boldsymbol{E}
\end{aligned}
$$

em que $i=\sqrt{-1}, c$ é a velocidade da luz no vácuo, e $k$ é o parâmetro de "quiralidade". O parâmetro $\kappa$ é responsável pelo acoplamento cruzado dos campos elétricos e magnéticos que se propagam pelo meio e faz com que, nas frequências de ressonância, o metamaterial quiral apresente índices de refração diferentes para ondas com polarização circular: à direita $(\mathrm{RCP}=$ polarização circular à direita, right circularly polarized) ou à esquerda (LCP = polarização circular à esquerda, left circularly polarized) [36].

De acordo com [36], aplicando essas relações constitutivas às equações de Maxwell (com dependência temporal de $\exp (-\mathrm{i} \omega \mathrm{t})$ ), obtém-se a seguinte equação para o campo elétrico: 


$$
\mathbf{k} \times(\mathbf{k} \times \mathbf{E})=-k_{0}{ }^{2}\left(\varepsilon \mu-\kappa^{2}\right) \mathbf{E}-2 \mathrm{i} \kappa k_{0}(\mathbf{k} \times \mathbf{E})
$$

onde $\mathrm{k}_{0}$ é o número de onda do espaço livre, e $\mathbf{k}=\mathrm{k}_{0} \hat{\mathbf{z}}$ é o vetor de onda que se propaga na direção do eixo $z$ no metamaterial quiral. Resolvendo a equação de onda acima, tem-se:

$$
k_{ \pm}=k_{0}(\sqrt{\varepsilon \mu} \pm \kappa)
$$

que pode ser escrita como:

$$
k_{ \pm}=k_{0} n_{ \pm}
$$

onde

$$
n_{ \pm}=\sqrt{\varepsilon \mu} \pm \kappa
$$

ou ainda

$$
n_{ \pm}=n \pm \kappa
$$

sendo $n_{+} \mathrm{O}$ índice de refração do quiral para ondas RCP e $n_{-}$para LCP; sabendo que $n$ é o índice de refração do material sem considerar a quiralidade [36].

Pode-se notar pela equação (15) que é o fator quiralidade que faz com que o material apresente índices de refração diferentes para cada tipo de polarização circular (RCP ou LCP). O índice de refração é uma grandeza complexa e suas partes real e imaginária são responsáveis, respectivamente, pela velocidade e atenuação da onda no metamaterial. Como essas características são diferentes para ondas RCP e LCP, o metamaterial quiral apresenta as propriedades de birrefringência e dicroísmo circular, responsáveis respectivamente pelos efeitos de rotação de campo e elipticidade. Cada uma dessas propriedades será discutida com mais detalhes a seguir. 


\section{1- Quiralidade CompleXa}

O fator quiralidade $k$ é uma grandeza complexa cuja parte real é responsável por proporcionar a birrefringência circular (rotação de campo), enquanto a parte imaginária determina o dicroísmo circular (elipticidade) [31, 35]. Isso pode ser entendido analisando-se o efeito da quiralidade no valor do índice de refração complexo do metamaterial quiral.

No índice de refração complexo de um meio, a parte real é a responsável pela velocidade da onda no material, ou seja, pela mudança na fase da onda transmitida. Já a parte imaginária do índice de refração está associada às perdas no material e atenuação da amplitude da onda. É fácil notar que, separando cada equação nas partes real e imaginária, temos:

$$
\begin{gathered}
n=n^{\prime}-i n^{\prime \prime} \\
\kappa=\kappa^{\prime}-i \kappa^{\prime \prime} \\
n_{ \pm}=\left(n^{\prime}-i n^{\prime \prime}\right) \pm\left(\kappa^{\prime}-i \kappa^{\prime \prime}\right) \\
n_{ \pm}=\left(n^{\prime} \pm \kappa^{\prime}\right)-i\left(n^{\prime \prime} \pm \kappa^{\prime \prime}\right)
\end{gathered}
$$

Logo, pode-se ver por (19) que a parte real e imaginária da quiralidade atua diferentemente sobre as respectivas partes do índice de refração para ondas RCP ou LCP.

Além disso, por estar relacionado ao índice de refração do material, um valor de quiralidade alto o suficiente pode proporcionar refração negativa [24, 36], como pode ser verificado na equação (15).

A quiralidade é uma grandeza que depende da frequência do campo electromagnético. Logo, o que se espera na caracterização do metamaterial é uma curva de seu comportamento em função da frequência. Os valores da quiralidade 
complexa podem ser obtidos utilizando-se diretamente os coeficientes de transmissão do material para ondas RCP e LCP, uma vez que essa fração do campo eletromagnético transmitido possui informações sobre atenuação de amplitude e atraso de fase. Sendo assim, a quiralidade pode ser calculada diretamente pelos valores complexos dos coeficientes de transmissão $T_{++}$e $T_{--}$[37], para ondas RCP e LCP, respectivamente, como mostra a equação (20):

$$
\kappa=\frac{-i}{2 k_{0} d} \ln \left(\frac{T_{++}}{T_{--}}\right)
$$

em que $d$ é a espessura do metamaterial.

Por fim, pode-se concluir que devido à quiralidade complexa, uma onda de polarização linear que atravessa um metamaterial quiral, terá seu plano de polarização rotacionado por um ângulo de azimute e se tornará elíptica. Como ilustrado na Figura 6.

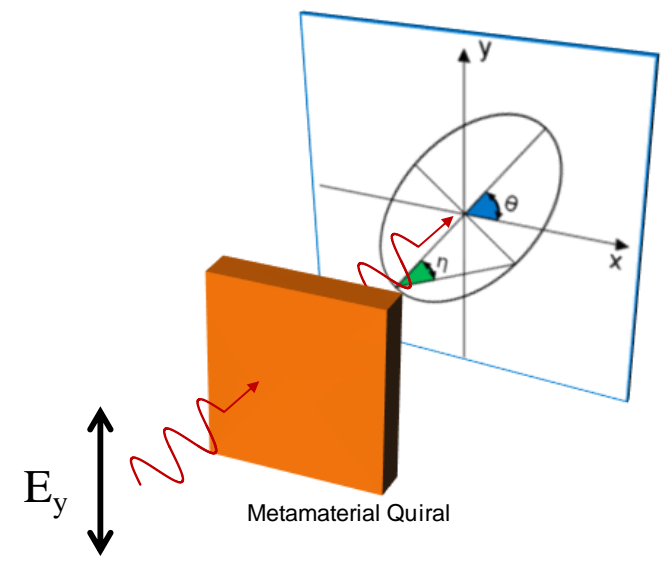

Figura 6 - Rotação de campo e elipticidade da onda transmitida pelo metamaterial quiral

Obviamente, se a quiralidade for puramente real, haverá apenas efeitos de birrefringência circular e rotação de campo da onda transmitida. Por outro lado, se houver só parte imaginária, devido ao efeito do dicroísmo circular, a onda ficará elíptica e seu maior eixo continuará no mesmo plano de polarização da onda 
incidente. Cada um desses fenômenos característicos dos quirais será explicado a seguir.

\section{3 - ROTAÇÃo de CAMPO E BiRREFRINGÊNCIA CirCULAR}

Como foi visto, devido às suas características assimétricas, os metamateriais quirais possuem índices de refração diferentes para ondas RCP e LCP nas frequências de ressonância. Esse efeito, denominado de Birrefringência Circular [33], faz com que uma onda eletromagnética (plana) linearmente polarizada que atravesse o metamaterial tenha seu plano de polarização rotacionado de um ângulo de azimute $\theta[24,25]$, como mostrado na Figura 7.

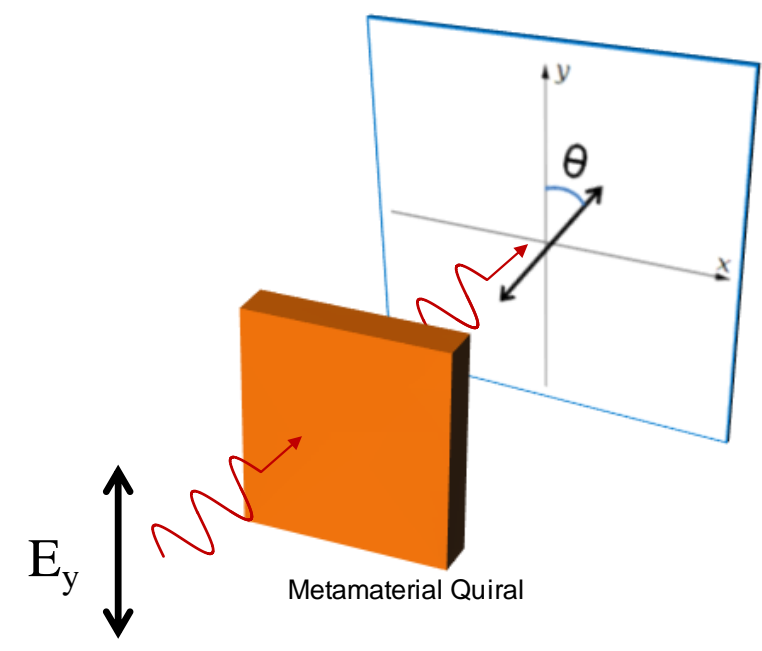

Figura 7 - Rotação de campo em um meio quiral.

Isso acontece porque uma onda de polarização linear pode ser representada pela superposição de duas ondas de polarização circular (direita e esquerda), de mesma amplitude e frequência, como mostrado na Figura 8. 


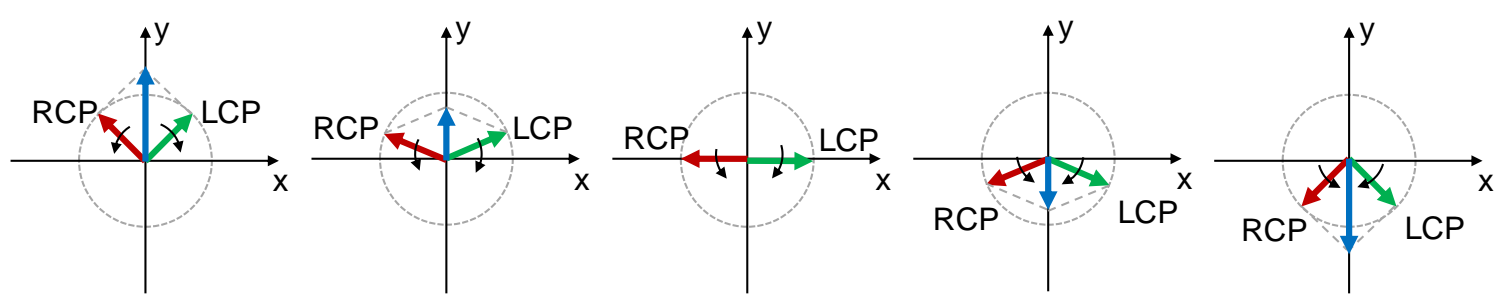

Figura 8 - - Representação de uma onda linear como a sobreposição de duas ondas RCP e LCP

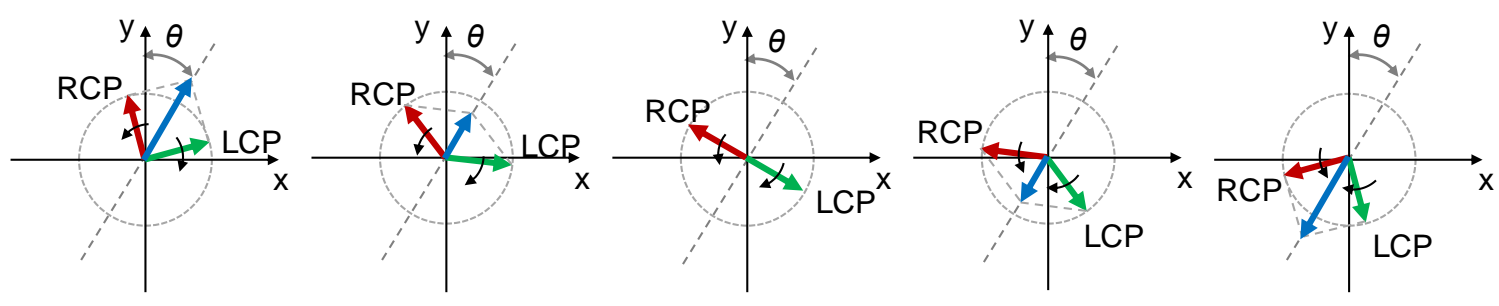

Figura 9 - Rotação de campo devido à mudança de fase entre as ondas RCP e LCP

A diferença de fase entra as duas ondas (RCP e LCP) determina o ângulo de azimute $\theta$ da onda linear. Portanto, se por algum motivo essa diferença de fase variar, o ângulo $\theta$ também irá mudar, proporcionando assim uma rotação do plano de polarização da onda linearmente polarizada, como ilustrado na Figura 9.

No metamaterial quiral, os diferentes índices de refração $\left(n_{+}\right.$e $\left.n_{-}\right)$farão com que as ondas RCP e LCP se propaguem com velocidades diferentes, causando uma defasagem entre elas e, com isso, a rotação de campo.

Analisando a onda transmitida através do metamaterial, pode-se saber o atraso de fase de cada uma dessas ondas. Assim, o ângulo de azimute pode ser calculado a partir da diferença de fase entre as ondas de polarização circular $\mathrm{RCP}(+)$ e LCP(-) que atravessaram o metamaterial e foram transmitidas, sendo definido como $[24,25,33,36]$

$$
\theta=\frac{\arg \left(T_{++}\right)-\arg \left(T_{--}\right)}{2}
$$

onde $T_{++}$e $T_{--}$são os coeficientes complexos de transmissão de ondas RCP e LCP, respectivamente, que atravessam o metamaterial. 


\section{4- ELIPTICIDADE E Dicroísmo CiRCULAR}

Outra importante característica dos metamateriais quirais é o dicroísmo circular, que faz com que o material apresente atenuações diferentes para cada tipo de polarização circular (RCP e LCP) [33]. Sendo assim, a amplitude de cada componente circular é atenuada de forma diferente. Essa absorção diferenciada acontece devido à parte imaginária dos índices de refração $n_{+}$e $n_{\text {, diferentes para as }}$ ondas $\mathrm{RCP}(+)$ e LCP(-).

Portanto, considerando que uma onda de polarização linear seja composta por duas ondas circulares de mesma amplitude e frequência, ao se propagar através do metamaterial quiral, a diferença entre as amplitudes fará com que a onda deixe de ser puramente linear e se torne elíptica como ilustrado na Figura 10.

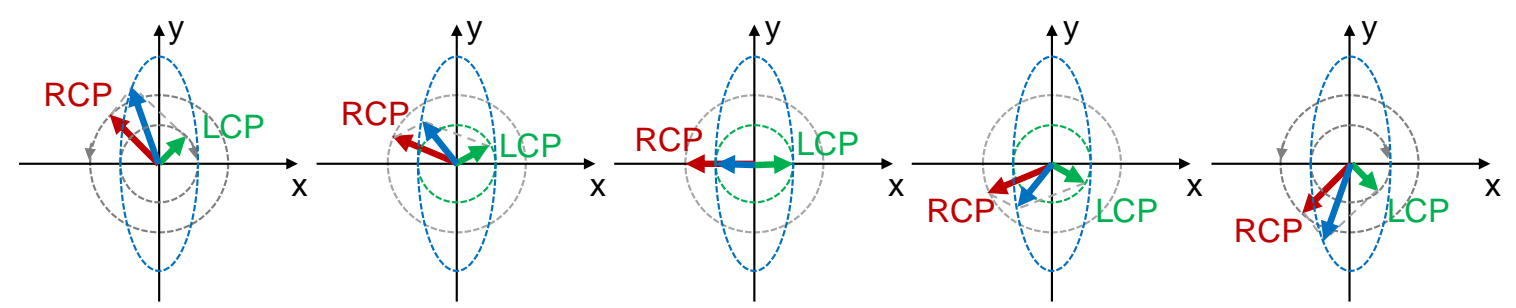

Figura 10 - Onda elíptica formada pela sobreposição de ondas RCP e LCP de diferentes amplitudes

O parâmetro quantitativo da elipticidade é representado pela letra $\eta$ e é dado pelo ângulo entre o maior e menor eixo da elipse, como ilustrado na Figura 11-a. Sendo assim, o cálculo da elipticidade $\eta$ é feito por meio dos catetos do triângulo formado por esses eixos, como mostrado na Figura 11-b. 


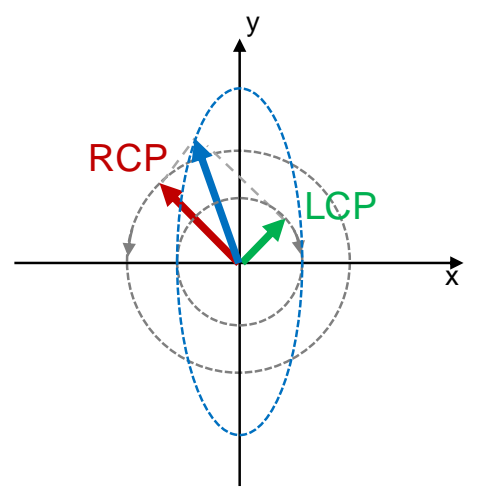

(a)

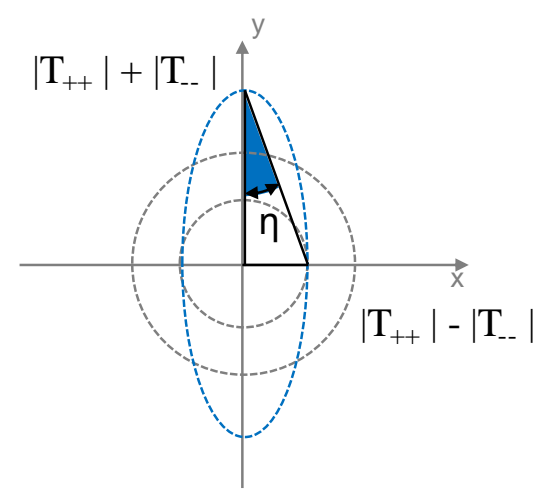

(b)

Figura 11 - Cálculo da elipticidade da onda transmitida: (a) Onda linearmente polarizada como uma combinação de ondas RCP e LCP; (b) Elipticidade devido ao efeito de dicroísmo circular.

Dessa forma, analisando a Figura 11, a elipticidade $\eta$ pode ser calculada como:

$$
\tan (\eta)=\frac{\left|T_{++}\right|-\left|T_{--}\right|}{\left|T_{++}\right|+\left|T_{--}\right|}
$$

Assim,

$$
\eta=\tan ^{-1}\left(\frac{\left|T_{++}\right|-\left|T_{--}\right|}{\left|T_{++}\right|+\left|T_{--}\right|}\right)
$$

onde $T_{++}$e $T_{--}$são os coeficientes complexos de transmissão de ondas RCP e LCP, respectivamente, que atravessam o metamaterial [25].

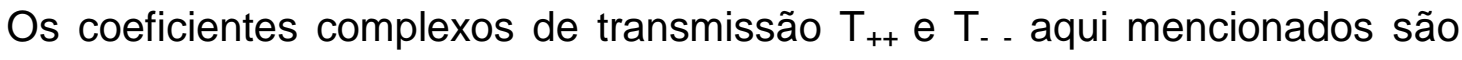
obtidos por meio da incidência de ondas RCP e LCP através do metamaterial quiral e das medidas do campo transmitido para cada polarização. Entretanto, devido à relativa complexidade de se trabalhar com fontes de excitação de polarização circular, tais coeficientes podem ser obtidos por meio da combinação de medidas de polarização linear em x e y. Para isso, inicialmente são feitas medidas dos coeficientes de transmissão lineares do metamaterial quiral com co-polarização (x-x e $y-y)$ e de polarização cruzada (x-y e $y-x)$ entre a fonte de excitação e detecção. 
Com isso, obtêm-se quatro coeficientes lineares $T_{x x}, T_{x y}, T_{y x}$ e $T_{y y}$, que combinados podem ser convertidos em coeficientes de transmissão circulares $T_{++}$e $T_{--}$[24] como mostrado em (24) e (25)

$$
\begin{gathered}
T_{++}=\frac{1}{2}\left[\left(T_{x x}+T_{y y}\right)+i\left(T_{x y}-T_{y x}\right)\right] \\
T_{--}=\frac{1}{2}\left[\left(T_{x x}+T_{y y}\right)-i\left(T_{x y}-T_{y x}\right)\right]
\end{gathered}
$$

A notação de sub-índices dos parâmetros de transmissão indica o tipo de polarização do campo elétrico, em que o primeiro sub-índice se refere ao sentido de polarização do campo elétrico na porta de detecção e o segundo, na porta de excitação [24]. A obtenção desses coeficientes, assim como a extração de demais parâmetros, será mostrada com mais detalhes mais adiante.

\section{5- APLICAÇões da RotaÇÃo de CAMPo}

A partir dos efeitos da quiralidade complexa, este trabalho propõe a aplicação de metamateriais quirais planares na construção de biossensores. Diferente dos sensores em micro-ondas convencionais (baseados em variações de intensidade de transmissão), aqui se propõe a utilização do poder de rotação de campo, empregando-se o ângulo de azimute $\theta$ como transdutor desta classe de sensores para, com isso, detectar e medir variações na composição de amostras biológicas inseridas nas camadas do metamaterial.

A resposta em frequência de um metamaterial depende da sua geometria e também das propriedades dielétricas dos materiais que compõem a estrutura. Assim, para uma inclusão de dimensões fixas, se a composição de uma das camadas de substrato é modificada, haverá alterações no comportamento 
eletromagnético de todo o conjunto como, por exemplo, de seu poder de rotação de campo. Isso faz do metamaterial quiral um ótimo candidato para aplicações na área de sensores. Se um analito for adequadamente inserido entre os ressoadores do material é possível ter informações a respeito da composição a partir da resposta eletromagnética do metamaterial como um todo.

O biossensor metamaterial proposto consiste em inserir a amostra biológica entre as camadas de ressoadores quirais. Dependendo da concentração de glicose, o poder de rotação de campo proporcionada pelo metamaterial se altera. Desse modo, a partir do ângulo de azimute $(\theta)$ da onda transmitida através do meta-sensor, é possível inferir o valor da concentração de glicose. Sendo assim, a medida consiste em se obter as curvas do ângulo de azimute $(\theta)$ em função da concentração de glicose da solução.

De uma maneira geral, sensores baseados em dispositivos tradicionais de micro-ondas já têm sido largamente utilizados em diversas áreas. Eles possuem grandes vantagens sobre sensores físico-químicos, pelo fato de não interferirem com as amostras por eles analisadas. Eles possibilitam a medição da grandeza sem alterar a composição do analito em questão. Além disso, devido à sua rapidez de resposta, esses sensores possibilitam até mesmo medidas em tempo real. 


\section{CAPítulo 3 - MateriaIS e MÉtodos}

\section{1 - PARÂMETROS S}

Para a caracterização do material artificial, é necessária a obtenção das suas propriedades eletromagnéticas efetivas: permissividade elétrica $(\varepsilon)$, permeabilidade magnética $(\mu)$, índice de refração $(n)$, impedância $(z)$ e, no caso dos metamateriais quirais, também o fator de quiralidade $(\kappa)$, o ângulo de azimute $(\theta)$ e a elipticidade $(\eta)$. Todas essas características podem ser obtidas a partir dos parâmetros de espalhamento, que são os coeficientes de reflexão e transmissão do material, também conhecidos como "Parâmetros S" (do inglês, scattering parameters). Esse método é utilizado na modelagem de diversos sistemas lineares passivos como circuitos elétricos, transistores, filtros e tem sido o mais adequado para caracterização de estruturas metamateriais. Em todos os casos, o princípio utilizado é o mesmo: excitar o sistema "desconhecido" e, a partir da sua resposta, obter as características que o represente e descreva.

O esquema geral do método de obtenção dos Parâmetros $S$ de um sistema genérico de duas portas é mostrado na Figura 12.

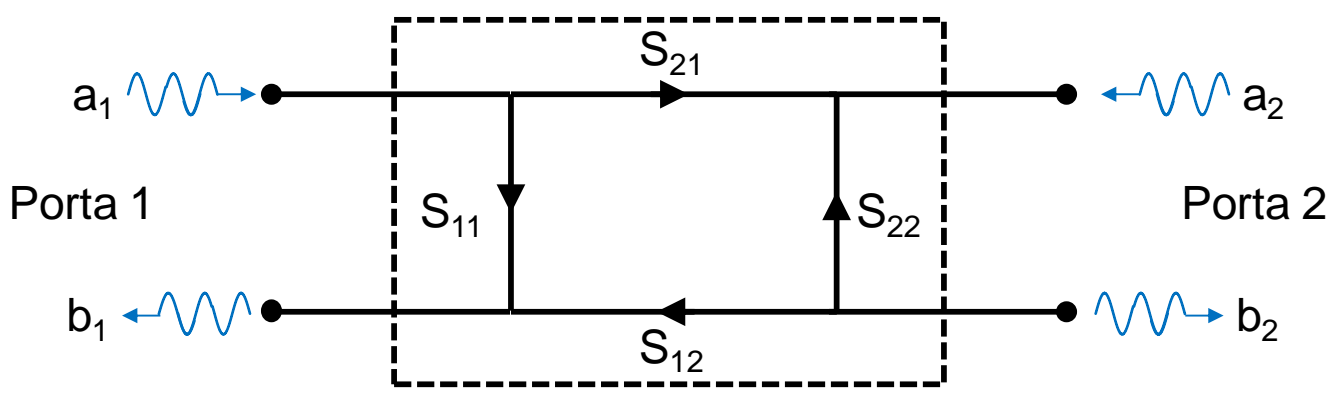

Figura 12 - Esquema de uma rede de duas portas para obtenção dos Parâmetros S

Neste método, as portas do sistema emitem um sinal sobre a amostra e captam de volta a amplitude e fase do que foi refletido e do que foi transmitido. Os Parâmetros $S$ são então obtidos pelas seguintes relações [38, 39]: 


$$
\begin{aligned}
& b_{1}=S_{11} a_{1}+S_{12} a_{2} \\
& b_{2}=S_{21} a_{1}+S_{22} a_{2}
\end{aligned}
$$

ou, escrevendo na forma matricial,

$$
\left[\begin{array}{l}
b_{1} \\
b_{2}
\end{array}\right]=\left[\begin{array}{ll}
S_{11} & S_{12} \\
S_{21} & S_{22}
\end{array}\right]\left[\begin{array}{l}
a_{1} \\
a_{2}
\end{array}\right]
$$

em que a matriz S é chamada de Matriz de Espalhamento e os fatores a's e b's são valores complexos (magnitude e fase) dos sinais de entrada e saída da rede. Os parâmetros $S_{11}$ e $S_{22}$ são os coeficientes de reflexão e são definidos como as relações entre o sinal refletido e o emitido na mesma porta. Os parâmetros $S_{21}$ e $S_{12}$, por sua vez, são coeficientes de transmissão e são as relações entre o sinal transmitido e sinal emitido entre as duas portas do sistema [38, 39]:

$$
\begin{aligned}
& S_{11}=\left.\frac{b_{1}}{a_{1}}\right|_{a_{2}=0} \\
& S_{22}=\left.\frac{b_{2}}{a_{2}}\right|_{a_{1}=0} \\
& S_{21}=\left.\frac{b_{2}}{a_{1}}\right|_{a_{2}=0} \\
& S_{12}=\left.\frac{b_{1}}{a_{2}}\right|_{a_{1}=0}
\end{aligned}
$$

Nessa notação, o primeiro sub-índice representa a porta receptora, enquanto o segundo sub-índice representa a porta emissora. Sendo assim, por exemplo, o coeficiente de transmissão $S_{21}$ indica que o sinal saiu da porta 1 e chegou à porta 2 . 
Os Parâmetros S são coeficientes complexos, possuindo parte real e parte imaginária (magnitude e fase) e que dependem da frequência do campo electromagnético. A partir deles são calculadas todas as demais propriedades efetivas do metamaterial, obtidas por meio de equações do método de recuperação de parâmetros que serão mostradas mais adiante no texto. Em geral, todos esses parâmetros também são dependentes da frequência e o que se espera na caracterização do metamaterial é uma curva de seu comportamento em função da frequência numa faixa definida.

No processo de extração de parâmetros de metamateriais, o sinal aplicado pelas portas é uma onda plana que se propaga no espaço livre até a incidência normal à superfície do material. $\mathrm{Na}$

Figura 13 é mostrado o esquema simplificado da obtenção dos parâmetros $S$ em Metamateriais, que segue o mesmo princípio, medindo-se o quanto foi refletido e o quanto foi transmitido.

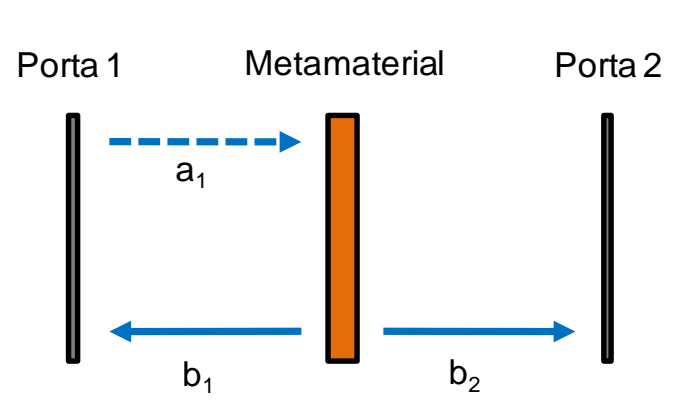

(a)

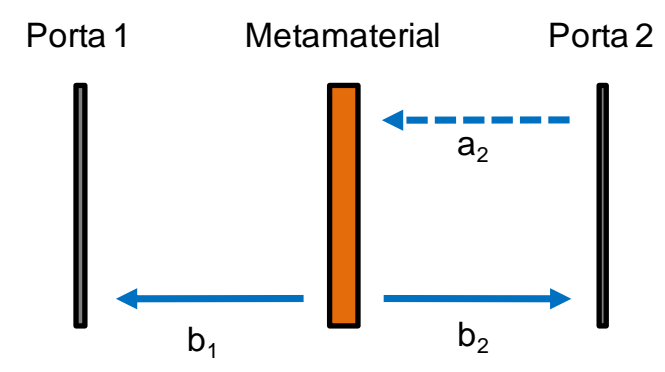

(b)

$$
\begin{aligned}
& S_{11}=\left.\frac{b_{1}}{a_{1}}\right|_{a_{2}=0} \\
& S_{21}=\left.\frac{b_{2}}{a_{1}}\right|_{a_{2}=0}
\end{aligned}
$$

$$
\begin{aligned}
& S_{12}=\left.\frac{b_{1}}{a_{2}}\right|_{a_{1}=0} \\
& S_{22}=\left.\frac{b_{2}}{a_{2}}\right|_{a_{1}=0}
\end{aligned}
$$

Figura 13 - Esquema simplificado da obtenção dos parâmetros S em Metamateriais 
A título de simplificação, em algumas análises, os parâmetros de REFLEXÃO $\left(S_{11}\right.$ ou $S_{22}$ ) podem ser representados apenas pela letra $R$, enquanto que os coeficientes de TRANSMISSÃO $\left(S_{21}\right.$ ou $\left.S_{12}\right)$, representados pela letra T. Por exemplo, os parâmetros de transmissão circulares $T_{++}$e $T_{--}$, os lineares $T_{\mathrm{xx}}, \mathrm{T}_{\mathrm{yx}}$, yx e $T_{y y}$ são todos coeficientes de transmissão $S_{21}$ (ou $S_{12}$ ) com seus respectivos tipos de polarização.

A partir desses coeficientes de reflexão $(R)$ e transmissão $(T)$ é possível, então, estimar os valores das principais propriedades efetivas do metamaterial. Para isso, são utilizados métodos específicos de extração de parâmetros que recuperam os valores de índice de refração, impedância, quiralidade, permissividade e permeabilidade, descritos em detalhes na próxima seção. 


\section{2 - MÉtodo de Extração de Parâmetros}

Neste capítulo é apresentado o principal método utilizado na literatura para a extração de parâmetros de metamateriais quirais [36] e que foi utilizado na caracterização dos metamateriais deste trabalho. Trata-se de um método confiável e muito utilizado nas principais publicações da área [24, 25, 36]. Entretanto, suas respostas são aproximações visto que o metamaterial é, a princípio, considerado como um meio homogêneo, entre outras considerações físicas que também devem ser feitas durante o processo, como serão devidamente mencionadas neste capítulo.

O objetivo do método é partir inicialmente dos parâmetros $S$ do metamaterial e, por meio de equações de recuperação, calcular as principais propriedades eletromagnéticas efetivas do meio artificial. $\mathrm{Na}$ análise dos parâmetros $\mathrm{S}$ (coeficientes $R$ e $T$ ) dos metamateriais quirais, considera-se que as ondas planas RCP e LCP incidem sobre o material como mostrado na Figura 14, onde os subíndices (+) e (-) correspondem, respectivamente, a ondas RCP e LCP [36].

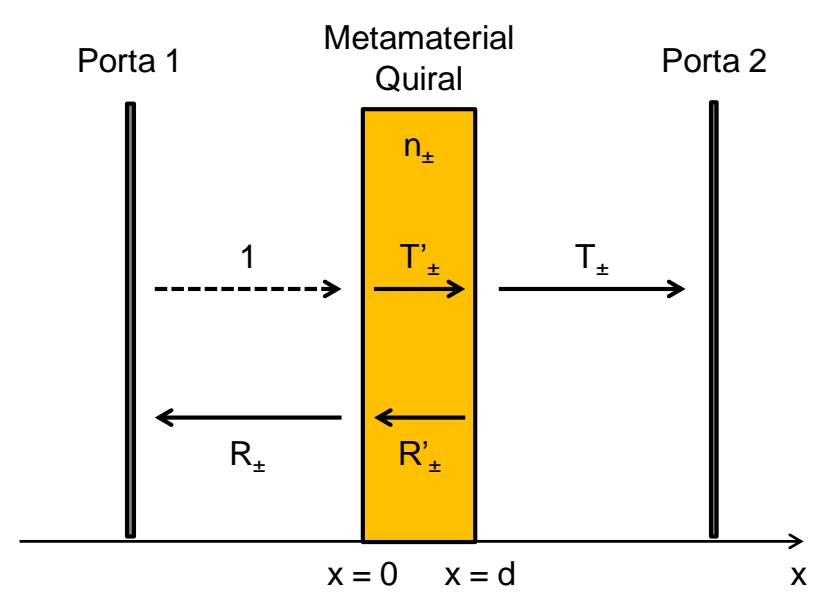

Figura 14 - Onda plana circular incidente em um metamaterial quiral e seus coeficientes de reflexão e transmissão

Pelas condições de contorno do problema, nas interfaces $x=0$ e $x=d$, deve haver a continuidade dos campos elétricos e magnéticos. 
$\operatorname{Em} x=0$ :

$$
\begin{gathered}
1+R_{ \pm}=T_{ \pm}^{\prime}+R_{ \pm}^{\prime} \\
1-R_{ \pm}=\frac{T_{ \pm}^{\prime}-R_{ \pm}^{\prime}}{z}
\end{gathered}
$$

$\operatorname{Em} x=d$ :

$$
\begin{gathered}
T_{ \pm}^{\prime} e^{i k_{ \pm} d}+R_{ \pm}^{\prime} e^{-i k_{\mp} d}=T_{ \pm} \\
\frac{T_{ \pm}^{\prime} e^{i k_{ \pm} d}-R_{ \pm}^{\prime} e^{-i k_{\mp} d}}{z}=T_{ \pm}
\end{gathered}
$$

em que $k_{ \pm}$é o numero de onda para ondas RCP/LCP, $z=Z / Z_{0}$ é a impedância normalizada, e $Z_{0}$ a impedância do espaço livre, considerando ainda que $z$ seja a mesma para ondas RCP e LCP

Pode-se então isolar os termos correspondentes aos coeficientes de transmissão $T \pm$ e reflexão $R_{ \pm}$da seguinte forma [36]:

$$
T_{ \pm}=\frac{4 z e^{i k_{ \pm} d}}{(1+z)^{2}-(1-z)^{2} e^{2 i n k_{0} d}}
$$

e

$$
R_{ \pm}=\frac{(1-z)^{2}\left(e^{2 i n k_{0} d}-1\right)}{(1+z)^{2}-(1-z)^{2} e^{2 i n k_{0} d}}
$$


Uma vez considerado que a impedância $z$ é a mesma para ondas RCP e LCP, pode-se então afirmar que $R_{+}$e $R$. são iguais: $R_{ \pm}=R$.

O índice de refração e a impedância do metamaterial, definidos em função dos parâmetros de reflexão e transmissão, são dados por [36]:

$$
\begin{gathered}
z= \pm \sqrt{\frac{(1+R)^{2}-T_{+} T_{-}}{(1-R)^{2}-T_{+} T_{-}}} \\
n_{ \pm}=\frac{i}{k_{0} d} \ln \left[\frac{1}{T_{ \pm}}\left(1-\frac{z-1}{z+1} R\right)\right]
\end{gathered}
$$

De acordo com o método [36], pelo princípio da conservação de energia, o sinal da raiz quadrada em (39) deve ser escolhido de tal forma que a parte real da impedância $z$ e a parte imaginária do índice de refração $n_{ \pm}$sejam positivas, como mostrado nas equações (41) e (42)

$$
\begin{aligned}
& R E(z)>0 \\
& I M\left(n_{ \pm}\right)>0
\end{aligned}
$$

Obtidos $z$ e $n_{ \pm}$, é possível encontrar os demais parâmetros dos metamateriais quirais, como a quiralidade $\kappa$, o índice de refração $n$, a permeabilidade magnética $\mu \mathrm{e}$ a permissividade elétrica $\varepsilon$, usando as seguintes relações [36]:

$$
\kappa=\frac{\left(n_{+}-n_{-}\right)}{2}
$$




$$
n=\frac{\left(n_{+}+n_{-}\right)}{2}
$$

$$
\mu=n z
$$

$$
\varepsilon=\frac{n}{z}
$$

Neste trabalho, a caracterização dos metamateriais quirais foi feita por meio do método descrito acima e a obtenção dos Parâmetros $S$ foi feita de duas maneiras: por meio de simulações computacionais e por medidas experimentais. Nos próximos capítulos, serão mostrados os procedimentos de cada uma delas. 


\section{3 - SimULAÇões COMPUTACIONAIS}

No processo de modelagem dos metamateriais, existe uma ferramenta de grande importância que é a Simulação Computacional. Por meio de softwares específicos, é possível obter a resposta de problemas reais utilizando um ambiente virtual em computadores, que reproduzem os princípios físicos por meio de equações matemáticas. Tais programas são baseados em Métodos Numéricos como o Método dos Elementos Finitos (MEF) ou Diferenças Finitas no Domínio do Tempo (FDTD), os quais dividem os problemas em intervalos finitos (de tempo ou espaço) e fazem uma análise iterativa aplicando as equações ponto a ponto nesse domínio discretizado.

Esses métodos numéricos já são utilizados na resolução de diversos problemas de engenharia como propagação de calor, acústica, mecânica de fluidos, entre outros e, no caso do presente trabalho, é empregado na solução problemas em eletromagnéticos, onde são as aplicadas as Equações de Maxwell. Estes são métodos já bastante difundidos e, por isso, já existem diversos softwares comerciais baseados nessas técnicas.

A simulação computacional é um recurso essencial na modelagem de metamateriais, uma vez que fornece previamente a resposta eletromagnética da estrutura antes mesmo de ela ser fabricada e testada. Isso permite que, durante o projeto, a estrutura possa ser "sintonizada" com as dimensões e configurações adequadas para que apresente a resposta pretendida na faixa de frequência desejada.

Neste trabalho, as análises computacionais foram feitas utilizando o software comercial Ansoft HFSS (High Frequency Structure Simulator) [40], baseado no Método de Elementos Finitos e que possui um ambiente gráfico em três dimensões (3D). Nessa plataforma, por meio de uma interface amigável, é possível desenhar as estruturas em 3D, configurar os materiais de sua composição, condições de contorno e portas de excitação. Assim, por meio dessa análise numérica, é possível se obter os Parâmetros S do metamaterial simulado. 
No caso específico de simulações de metamateriais formados por arranjos periódicos de ressoadores, todo esse conjunto de inclusões discretas repetidas lado a lado pode ser representado por apenas um único elemento, como ilustrado na Figura 15. Para que isso seja válido, essa célula unitária é então configurada com condições de contorno periódicas e, por conta disso, o resultado final é o mesmo de um arranjo periódico infinito. Esse é um artifício poderoso, pois diminui o tamanho do problema, reduzindo assim, o custo computacional da simulação. Isso é de grande importância, pois a análise fica mais rápida e exige menos memória e processamento do computador.

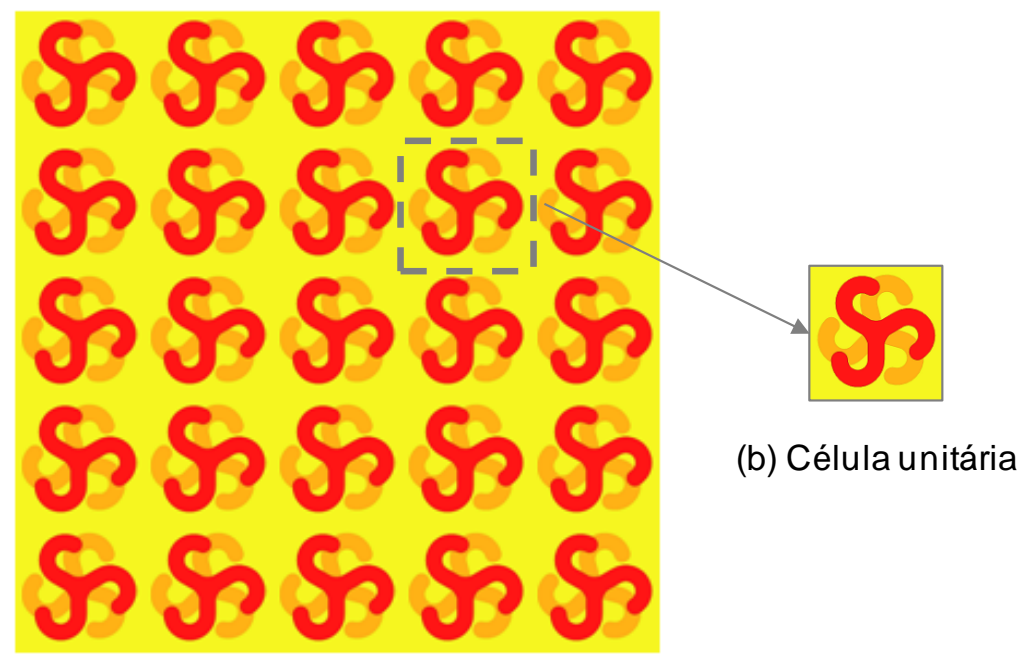

(a) Arranjo periódico

Figura 15 - Representação do arranjo periódico de ressoadores por uma célula unitária: (a) Arranjo periódico; (b) Célula Unitária.

A estrutura da célula unitária é então desenhada no próprio ambiente gráfico do programa e cada parte do objeto é configurada conforme o tipo de material da qual é constituída, como ilustrado na Figura 16. A região do substrato é configurada com suas propriedades dielétricas (permissividade e tangente de perdas) e nas regiões correspondente aos ressoadores são aplicadas as propriedades do metal em questão (permissividade e condutividade). Nas simulações deste trabalho, entretanto, o metal foi representado por um condutor elétrico perfeito (PEC - Perfect Electric Conductor), uma vez que para a faixa de frequência de micro-ondas, os metais se comportam como tal. Isso é feito a fim de diminuir o custo computacional 
da simulação, uma vez que a espessura do metal pode ser desconsiderada, diminuindo o número de pontos de discretização.

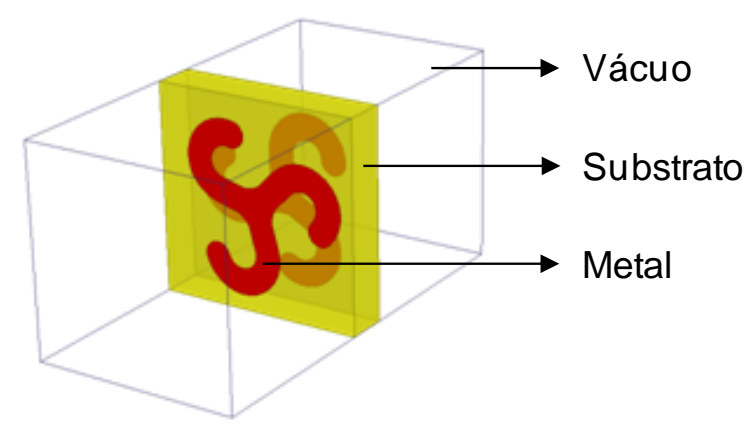

Figura 16 - Desenho e configurações de uma célula unitária no programa de simulação.

Para simular a incidência e propagação da onda eletromagnética sobre a estrutura, esta é desenhada dentro de uma caixa limitada que dá o tamanho da janela computacional da simulação. Nas paredes dessa caixa, são configuradas as condições de contorno periódicas e as portas de excitação.

\section{Condições de Contorno Periódicas}

No HFSS, as condições de contorno periódicas são baseadas no Teorema de Floquet [40] que define como os campos se igualam nas fronteiras da caixa, gerando a continuidade periódica virtual. Por isso, essas condições devem ser aplicadas nas paredes o redor da célula unitária as quais são configuradas aos pares, nas direções da periodicidade do metamaterial, como mostrado na Figura 17.

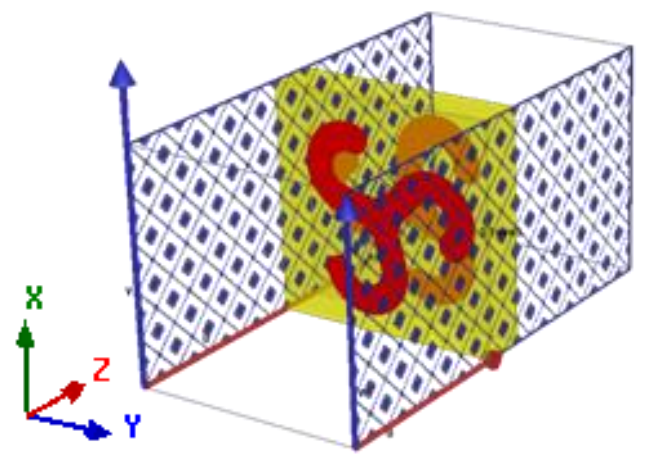

(a)

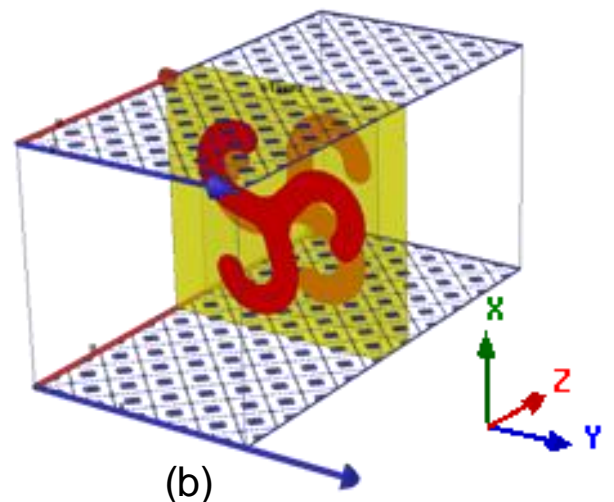

(b)

Figura 17 - Condições de contorno periódicas da célula unitária no HFSS: (a) Periodicidade em y; (b) Periodicidade em $\mathrm{x}$. 
Em cada par, enquanto uma das faces recebe a denominação de "Master", seu par correspondente recebe a de "Slave", as quais são definições do próprio software para usar o Teorema de Floquet. Essas condições são aplicadas em cada face por meio de vetores $(\mathbf{U}$ e $\mathbf{V})$, que servem para definir no desenho, o retângulo correspondente a cada uma delas.

\section{Portas de Excitação}

As portas de excitação, por sua vez, são aplicadas nas faces paralelas à célula unitária, como mostrado na Figura 18, simulando a incidência normal de uma onda plana sobre a célula.

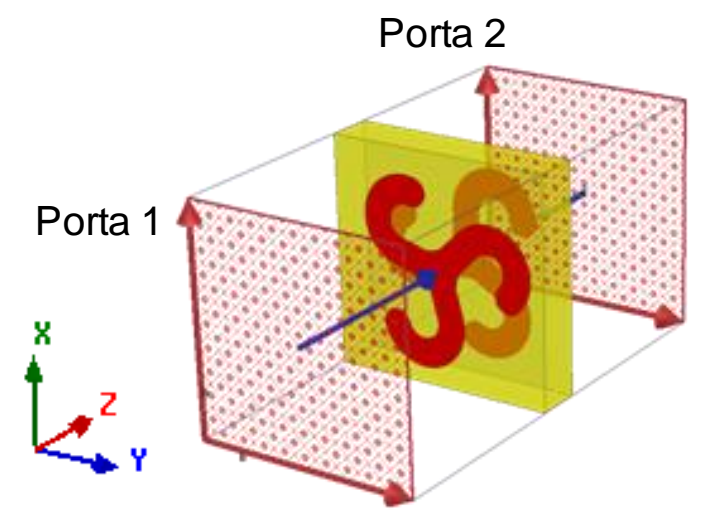

Figura 18 - Configuração das portas para obtenção dos parâmetros S do sistema periódico

Para excitação de estruturas periódicas, o HFSS possui uma opção específica chamada de "Floquet Port". As faces correspondentes às portas são definidas por meio de vetores (a e b) que também possuem a função de quantificar o tamanho do período espacial em cada direção.

A partir desse sistema de duas portas (Porta 1 e Porta 2) foram obtidos os Parâmetros $S$ simulados $\left(S_{11}, S_{12}, S_{21}, S_{22}\right)$. Nas análises realizadas neste trabalho, entretanto, considerou-se apenas a excitação na Porta 1, com propagação da onda incidente na direção positiva do eixo $z$, resultando assim apenas nos parâmetros de transmissão $T=S_{21}$ e 0 de reflexão $R=S_{11}$, suficientes para caracterizar 0 metamaterial quiral. 
As portas foram configuradas para ter duas polarizações lineares ( $x$ e $y$ ) que, analisadas separadamente, dão as quatro combinações de parâmetros de transmissão de co-polarização $\left(T_{x x}\right.$ e $\left.T_{y y}\right)$ e de polarização cruzada $\left(T_{x y}\right.$ e $\left.T_{y x}\right)$.

Nas simulações deste trabalho, a distância entre as portas e a célula foi definida e padronizada como sendo igual ao tamanho da célula. A princípio, em simulações desse tipo no HFSS, essa separação correspondente ao comprimento da linha de transmissão do sistema pode ser qualquer valor maior que zero, desde que seja feita uma correção de fase com o auxílio do vetor "De-embed". Esta é uma opção que o programa oferece nas configurações das "Floquet Ports", cuja função e "calibrar" as portas. Esse vetor é definido entre a face de cada porta Floquet até a interface da célula unitária e, baseado no valor dessa separação, o programa pode fazer os devidos cálculos. Para minimizar o tamanho da caixa computacional, recomenda-se configurar essa separação em um valor da mesma ordem de grandeza da célula.

\section{Seleção da Faixa de Frequência de Operação}

Antes de iniciar a simulação no HFSS, é necessário determinar a faixa de frequência. Para este trabalho, o intervalo utilizado foi o de $8 \mathrm{GHz}$ a $12 \mathrm{GHz}$, com 201 pontos, resultando em um passo de $0,02 \mathrm{GHz}$. Além disso, também foi preciso indicar para o software qual a frequência de operação a ser tomada como base para criação da malha. Neste caso, foi configurada a frequência central da banda: 10 $\mathrm{GHz}$.

\section{Criação da malha}

O HFSS possui uma função muito eficiente de geração dos pontos de discretização do domínio. Por meio de um refinamento automático e adaptativo da malha, a estrutura a ser simulada é então representada por um conjunto de elementos finitos, como mostrado na Figura 19. 


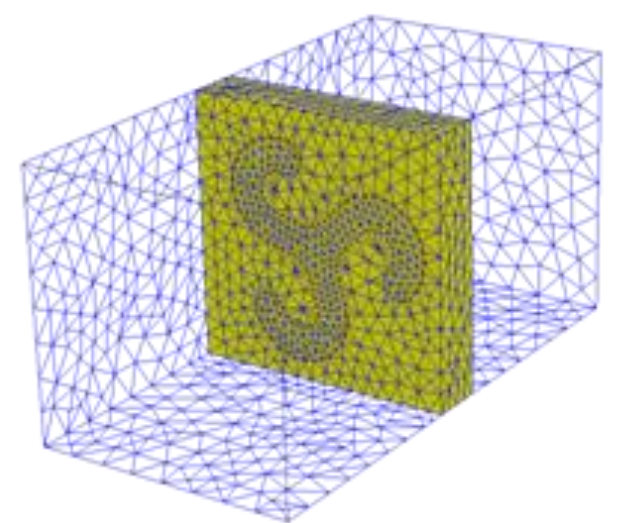

Figura 19 - Malha de pontos da estrutura discretizada.

\section{Modelagem da estrutura: "sintonizando" o ressoador}

Uma vez que a faixa de frequência de operação do metamaterial está diretamente relacionada com o tamanho da sua célula unitária, o projeto da estrutura consiste em ajustar as dimensões dos ressoadores de forma que sua ressonância ocorra na faixa desejada. Além disso, essa sintonia também visa o alcance da resposta eletromagnética desejada, como valores específicos de determinadas propriedades do metamaterial.

Essa modelagem é feita computacionalmente por meio de simulações paramétricas. Cada parâmetro geométrico da célula unitária (comprimento, largura, ângulo, raio, etc.) é representado por uma variável que recebe diferentes valores durante a simulação dentro de um intervalo determinado cuidadosamente pelo projetista. Dentre as várias respostas obtidas, são selecionadas aquelas mais próximas do esperado e, se necessário, deve ser feita novamente uma nova parametrização mais refinada para melhorar os resultados. Na modelagem das estruturas metamateriais deste trabalho, as simulações paramétricas foram feitas com o objetivo de se obter a melhor geometria possível visando maximizar os efeitos de rotação de campo dentro da faixa de $8 \mathrm{GHz}$ a $12 \mathrm{GHz}$.

Finalmente, com a estrutura modelada, esta é então caracterizada na simulação e, a partir das dimensões definidas, ela já pode ser fabricada para as medidas experimentais. 


\section{4 - AS CÉLULAS QUIRAIS}

Para a modelagem e caracterização dos metamateriais quirais planares deste trabalho, foram utilizados três modelos de células assimétricas de duas camadas, como mostrado na Figura 20. Duas delas (Figura 20-(a) e (b)) foram baseadas em publicações da área [24, 25] e tiveram suas dimensões e geometrias adaptadas para operarem na faixa de frequência utilizada neste trabalho, de 8 a $12 \mathrm{GHz}$. A terceira estrutura, mostrada na Figura 20-c, foi proposta e vem sendo analisada pelo nosso Grupo de Metamateriais.

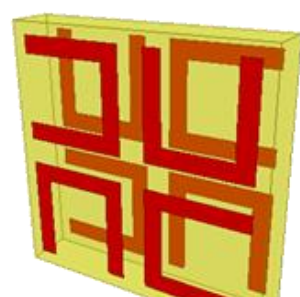

(a)

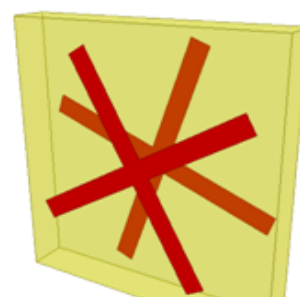

(b)

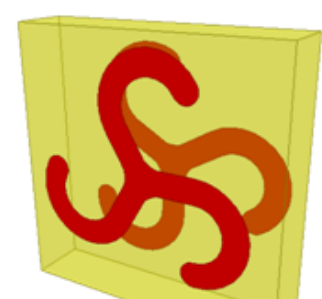

(c)

Figura 20 - Modelos de ressoadores quirais utilizados neste trabalho

A primeira célula (Figura 20-a) retirada de [25] consiste em quatro anéis ressoadores em forma de "U" distribuídos radialmente em torno do centro da célula, com uma diferença de $90^{\circ}$ entre si. Na face oposta, o mesmo padrão é repetido, porém invertido, de forma que o conjunto como um todo não possua simetria espelho e, consequentemente, apresente quiralidade.

O segundo modelo (Figura 20-b) retirado de [24] é constituído de dois ressoadores em forma de cruz, cada um disposto em uma das faces do substrato. Ambos os ressoadores são idênticos, porém, para dar a assimetria característica dos quirais, eles são posicionados com um determinado ângulo $\varphi$ de diferença entre si. $O$ valor desse ângulo deve ser otimizado durante o projeto da estrutura, sendo que se seu valor for nulo, a célula não apresentaria quiralidade.

A terceira estrutura quiral (Figura 20-c), modelada para este trabalho, é constituída de dois ressoadores idênticos posicionados em faces opostas do substrato com um determinado ângulo mútuo $\varphi$ entre si, que terá seu valor 
determinado durante 0 projeto. Os ressoadores são formados por três hastes metálicas curvadas e com um ângulo de $120^{\circ}$ entre uma haste e outra.

Cada uma das células foi projetada para ser construídas em dois tipos de substrato: na tradicional placa de circuito impresso de FR4 e cobre; e na nova técnica do filme fino de alumínio desenvolvido neste trabalho. Para cada tipo de substrato, cada modelo apresentou diferentes dimensões e configurações.

A técnica de construção de metamateriais planares em placas de circuito impresso comerciais tem sido utilizada em diversas publicações na área, devido à sua praticidade e facilidade. Nessa técnica, utilizam-se como matéria prima placas planas de substratos dielétricos cujas faces são cobertas por uma fina camada de metal. O substrato utilizado é o FR4 (Flame Retardant \#4) e o metal é o Cobre, sendo neste filme metálico o local onde as células ressoadoras são construídas. Porém, o projeto do metamaterial fica limitado às propriedades do substrato e isso traz diversas desvantagens como:

- perdas de inserção;

- espessura fixa (consequentemente, a distância entre os ressoadores fica limitada a esse valor. Por exemplo, o FR4 possui uma espessura de $1,6 \mathrm{~mm})$;

- valor fixo para permissividade elétrica relativa (do substrato, FR4: $\varepsilon=4$ );

- formato único (sempre plano),

Apesar de já existirem comercialmente alguns tipos de placas de circuito impresso flexíveis, estas ainda são de custo muito elevado, de difícil acesso e sua manipulação requer processos mais complexos. Algumas pesquisas na área de metamateriais tem utilizado métodos semelhantes para operação na faixa de terahertz [41, 42, 43] e micro-ondas [44]. Porém, devido às desvantagens e complexidades citadas, ainda se trata de uma prática muito pouco explorada.

Nesse contexto, este trabalho propõe uma nova técnica de fabricação de metamateriais quirais planares com o uso de folhas metalizadas e um substrato fino e flexível de baixo custo que apresenta ainda as seguintes vantagens:

- espessura reduzida; 
- por ser muito fino, pode ter influência desprezível na resposta do metamaterial, simulando assim uma situação em que os ressoadores pareçam estar suspensos no espaço livre;

- pode ser aplicado em metamateriais do tipo rígido ou flexível;

- pode ser adaptado a qualquer formato: plano, cilíndrico, cônico, etc..

- a distância entre os ressoadores pode ter diferentes valores, se cada cada ressoador for construído em um filme fino separado e configurada a distância desejada entre eles;

- pode ser, a princípio, facilmente adaptado a qualquer outro tipo de substrato, fazendo apenas com que o filme fino seja colado à superfície desejada;

- sua confecção é de baixo custo e semelhante à das placas de circuitos convencionais.

Para chegar a tal configuração de filme fino metalizado, inicialmente foram feitas algumas tentativas até se encontrar o melhor método.

A primeira experiência foi a de usar folhas finas de Teflon metalizadas por vaporização de alumínio. Porém, essa técnica não se mostrou eficaz, pois os testes no Laboratório de Micro-ondas demonstraram que a camada de metal depositado, de tão fina, não oferecia condutância suficiente para as correntes induzidas nos ressoadores. Verificou-se ainda que mesmo sendo feitas várias deposições a fim de aumentar a espessura da película metálica, o problema ainda persistia.

Outro teste realizado envolveu o uso de um tipo de fita adesiva de cobre que, além de ser fina, flexível e ter boa condutividade, possui aderência para qualquer superfície. Os testes iniciais indicaram que esta seria uma boa opção, porém devido ao alto preço do material, dificuldade de ser encontrada no comércio e possuir uma largura limitada $(4 \mathrm{~cm})$, essa técnica não foi utilizada.

Por fim, foi elaborada a técnica que obteve melhor desempenho e melhor custo-benefício, a qual foi definida para aplicação neste trabalho: um filme metálico formado por uma folha de papel alumínio de espessura de aproximadamente $30 \mu \mathrm{m}$ colada sobre ela uma folha de plástico adesivo flexível de espessura de $30 \mu \mathrm{m}$, resultando assim, num substrato dielétrico flexível com uma face metalizada. Tanto o 
plástico adesivo quanto a folha de alumínio são de baixíssimo custo sendo facilmente encontrados no comércio (lojas de embalagens, por exemplo). Alguns testes também foram feitos com filmes de alumínio de mesma espécie, porém mais finos. Mas estes se mostraram muito sensíveis à própria dilatação térmica devido à alta temperatura de um dos processos de confecção dos metamateriais e, portanto, ficou definido o uso apenas do papel alumínio de espessura maior ( 30 $\mu \mathrm{m})$.

Os metamateriais deste trabalho foram projetados e construídos utilizando-se os dois métodos: o tradicional com placas rígidas de FR4 e cobre; e o novo método com o filme fino de alumínio. Os metamateriais foram então caracterizados e as respostas dos dois tipos foram comparadas, validando a nova técnica.

Nas simulações das estruturas em FR4, as propriedades desse substrato foram configuradas de acordo com suas características reais: permissividade $\varepsilon=4 \mathrm{e}$ tangente de perdas dielétricas tan $\delta=0,02$ e espessura de $1,6 \mathrm{~mm}$.

As estruturas em filmes de alumínio foram projetadas inicialmente desconsiderando o seu substrato fino, simulando, assim, uma estrutura de ressoadores suspensos no espaço. Nas primeiras análises computacionais, foi configurado apenas $O$ "ar" $(\varepsilon=1$; $\tan \delta=0)$ como substrato entre os ressoadores quirais como ilustrado na Figura 21.

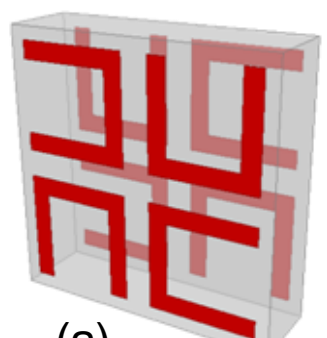

(a)

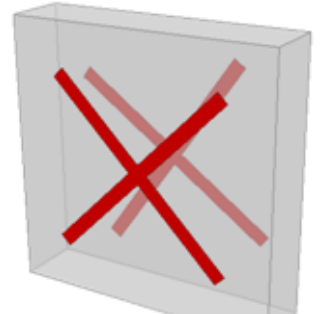

(b)

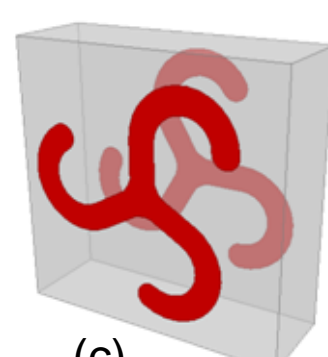

(c)

Figura 21- Estruturas projetadas em filmes de alumínio

Na fabricação das placas, porém, para dar sustentação mecânica ao filme de alumínio, foi utilizado um substrato de baixa densidade (EPS - Poliestireno Expandido, uma espécie de Isopor) de espessura de $4 \mathrm{~mm}$, cujo valor de permissividade elétrica é muito próximo à do espaço livre $(\varepsilon=1,05)[45]$. 
A partir dos primeiros testes experimentais, e da comparação com os respectivos resultados numéricos, notou-se a necessidade de um ajuste nas simulações. Verificou-se que o substrato de isopor em conjunto com a cola, e ao próprio plástico adesivo utilizado na fabricação, apresentava uma tangente de perdas de aproximadamente tan $\delta=0,02$. Sendo assim, todas as simulações com esse tipo de substrato foram configuradas com esse valor de tangente de perdas no substrato. Esse valor foi adicionado às simulações de modo a garantir uma melhor convergência com os resultados experimentais.

No Apêndice I deste trabalho, encontra-se o processo completo com mais detalhes da confecção de metamateriais pelos dois métodos utilizados neste trabalho.

Por fim, depois de feita a modelagem e fabricação das estruturas nos dois tipos de substratos, as placas dos metamateriais puderam então ser caracterizadas experimentalmente por meio de medidas em espaço livre. 


\section{5 - MedidAS Em EsPaço LivRE}

Como visto anteriormente, as principais propriedades eletromagnéticas de um metamaterial podem ser obtidas a partir de seus Parâmetros de Espalhamento S. Na prática, tais parâmetros são medidos experimentalmente utilizando-se um par de Antenas Cornetas conectadas a um Analisador de Redes em um método denominado "Medidas em Espaço Livre".

Técnicas de medidas em espaço livre já têm sido utilizadas para medidas de propriedades eletromagnéticas de materiais comuns como Teflon, PVC e cerâmicas para a faixa de micro-ondas [46, 47]. Esse método tem a vantagem de não ser destrutivo e não há necessidade de entrar em contato com a amostra, sendo o mais adequado para caracterização de metamateriais.

Nesse método, as antenas cornetas atuam como as portas de excitação e detecção do sistema, emitindo as ondas EM e medindo os campos transmitidos e refletidos pelo metamaterial. Com isso, a partir dessas informações, o Analisador de Rede calcula os Parâmetros S.

Na Figura 22 é mostrado um esquema do sistema montado.

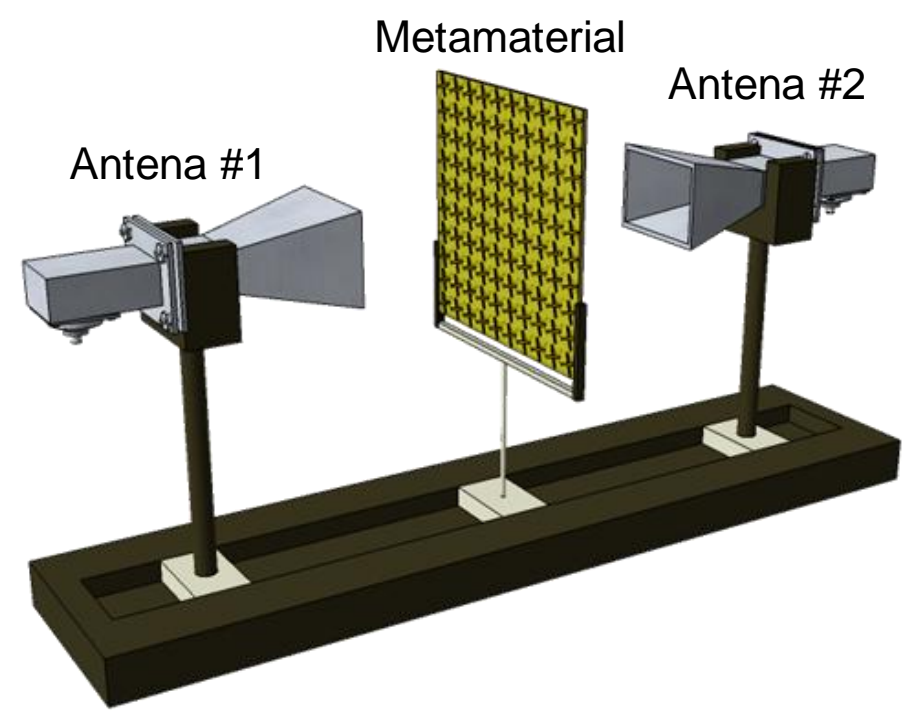

Figura 22 - Esquema do sistema montado para medida experimental dos parâmetros $S$ do metamaterial 
As antenas cornetas são as mais adequadas para esse tipo de experimento devido à sua boa diretividade, facilidade de excitação, emissão/detecção de campo linearmente polarizado, além da simplicidade de construção e versatilidade [48]. São compostas basicamente por uma antena monopolo, um guia de onda e a corneta propriamente dita, como mostrado em detalhes na Figura 23. A antena monopolo é a responsável por fazer a transição entre o cabo coaxial e o guia de onda, por onde o sinal eletromagnético se propaga até chegar à corneta, onde ocorre a transição gradual entre o guia e o espaço livre.

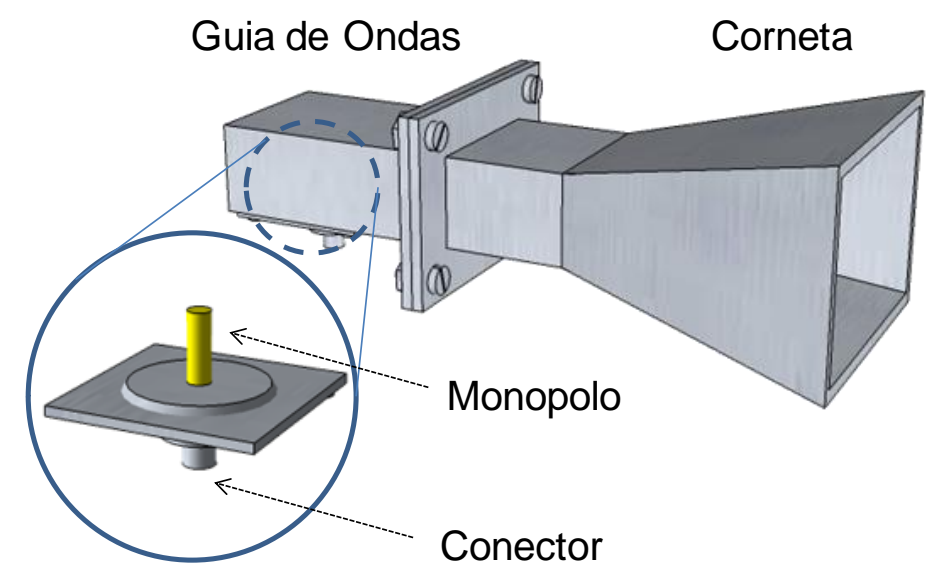

Figura 23- Componentes da antena corneta

A onda EM emitida é linearmente polarizada e seu plano de polarização tem a mesma orientação da antena monopolo que a gerou. Assim, a obtenção de polarização horizontal, vertical, em x ou em y, conforme o caso, é feita pela posição da antena. Assim sendo, a mudança de um tipo de polarização para outro é feita girando adequadamente a antena em um ângulo de noventa graus.

Uma das vantagens do método de medidas em espaço livre na faixa de micro-ondas é que, devido à ordem de grandeza de seu comprimento de onda, as dimensões dos dispositivos utilizados (antenas, guias de ondas, cabos coaxiais, amostras) são da escala de dezenas de milímetros, possibilitando que todo o experimento possa ser montado sobre uma simples mesa ou bancada de laboratório. 


\section{6 - SeTUP}

O "setup" utilizado na parte experimental deste trabalho é formado por um par de antenas cornetas, cabos coaxiais, analisador de redes e um computador, como mostrado na Figura 24. Além disso, para auxiliar na montagem e calibração, foram utilizados suportes e trilhos para posicionar as antenas e as amostras.

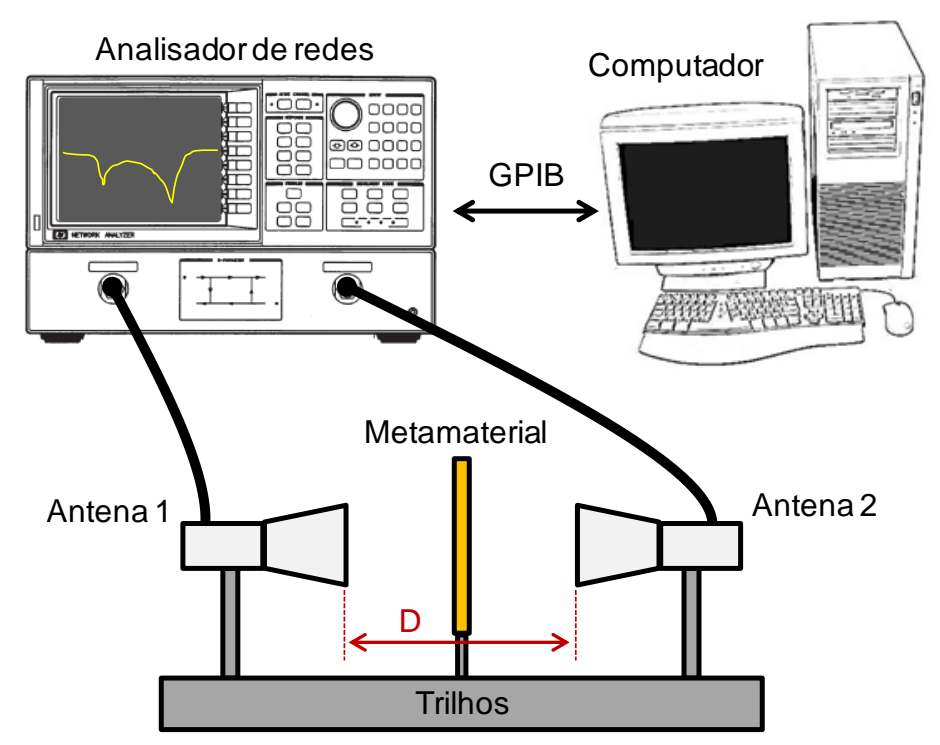

Figura 24 - Diagrama completo do setup utilizado

As antenas foram posicionadas e alinhadas uma de frente para a outra a uma distância $\mathrm{D}=140 \mathrm{~mm}$ entre si, como mostrado na Figura 24. O metamaterial a ser caracterizado foi posicionado entre as antenas, exatamente no meio, de forma que pudesse ser iluminado por uma onda de incidência normal vinda da antena transmissora. A posição da amostra se localiza no plano de referencia que será definido durante o processo de calibração, descrito mais adiante no texto. Para medida os Parâmetros $S$, as duas antenas cornetas são conectadas às portas do analisador de redes por meio de cabos coaxiais.

As antenas cornetas utilizadas nos experimentos deste trabalho são do tipo "piramidal" e operam na faixa de micro-ondas de $8 \mathrm{GHz}$ a $12 \mathrm{GHz}$, denominada de "Banda X" [48]. Na Figura 25 é mostrada fotografia com mais detalhes e dimensões 
das antenas cornetas utilizadas. Seus guias de onda são do padrão WR90, com dimensões internas de $22,86 \times 10,16 \mathrm{~mm}$.

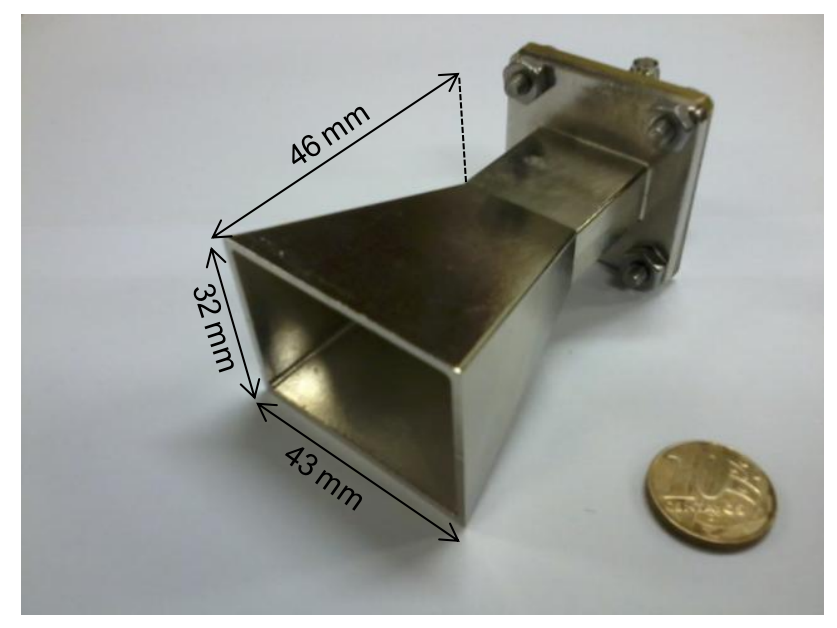

Figura 25 - Antena corneta utilizada nas medidas experimentais

As antenas foram montadas sobre um sistema de trilhos com posicionamento de precisão para auxiliarem na etapa de calibração, como será mostrado mais adiante no texto.

O Analisador de Redes utilizado foi o modelo HP 8720C, mostrado na Figura 26. $\mathrm{O}$ equipamento possui duas portas e sua faixa de frequência é de $50 \mathrm{MHz}$ a 20 $\mathrm{GHz}$.

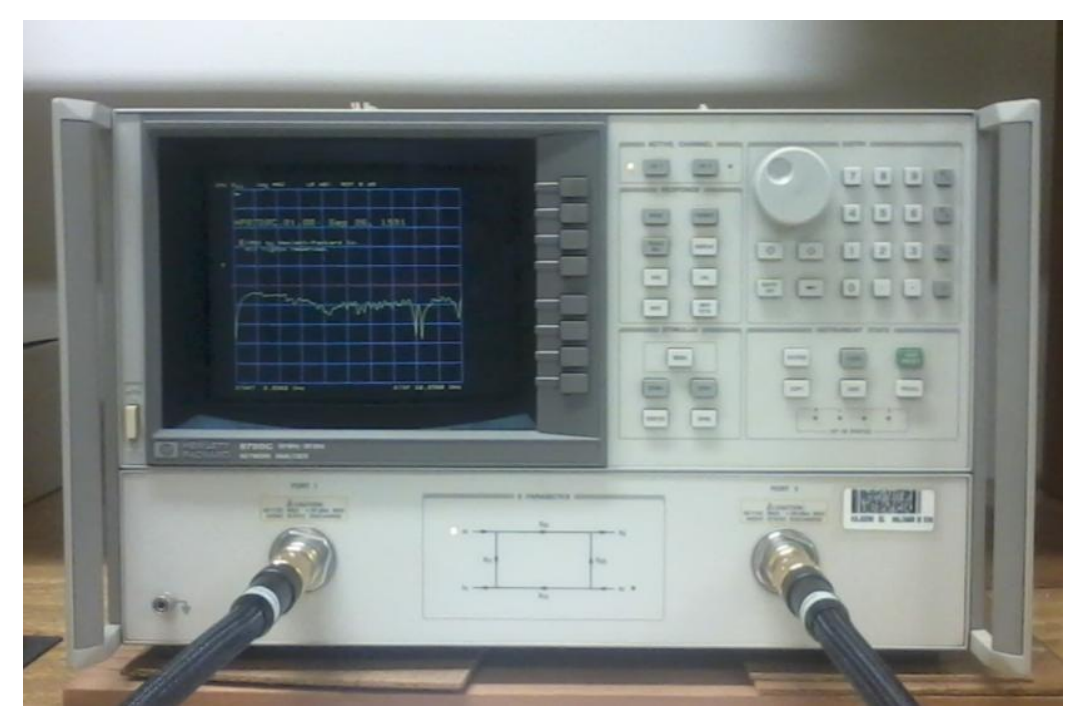

Figura 26 - Analisador de Redes (HP 8720C) utilizado para as medidas dos Parâmetros S 
A conexão entre 0 analisador de redes e o computador foi feita por meio de um cabo GPIB que transfere os parâmetros $S$ medidos para um disco rígido, possibilitando assim o armazenamento e tratamento dos dados.

$\mathrm{Na}$ Figura 27 é mostrada uma foto da montagem das antenas para 0 experimento das medidas em espaço livre.

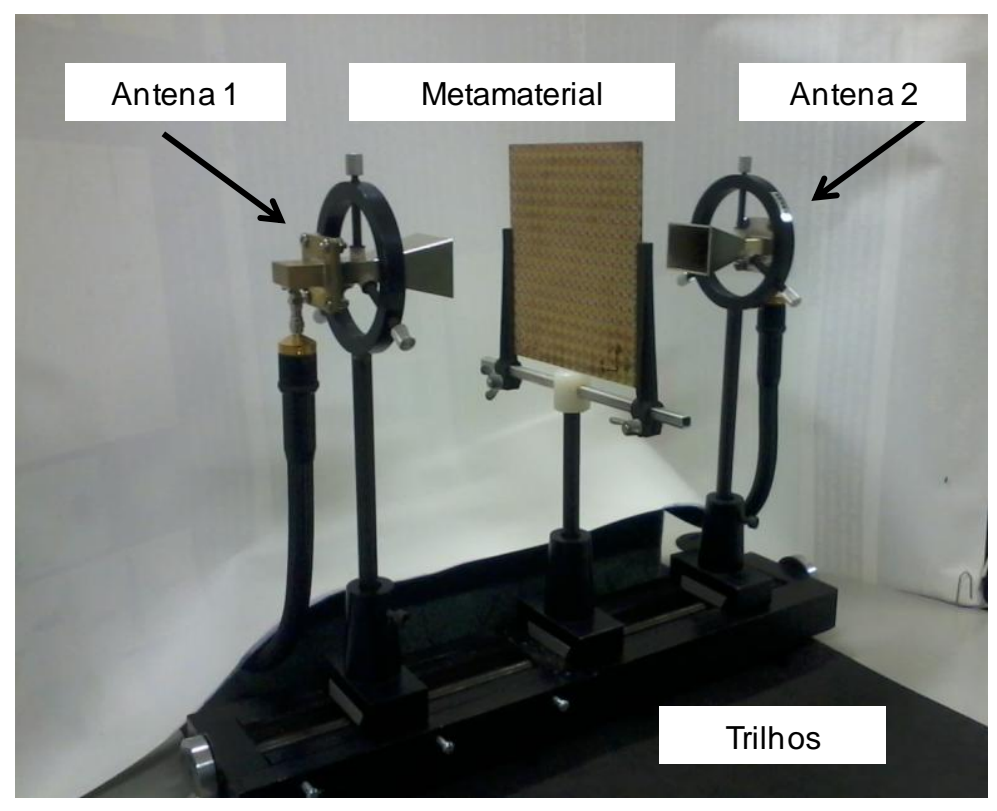

Figura 27 - Montagem do experimento para medidas em espaço livre 


\section{CAPÍtUlo 4 - ERROS de MEdidAS E CALIBRAÇÃo do EQUIPAMENTO}

O Método de Medidas em Espaço Livre, utilizado na caracterização de metamateriais, pode apresentar basicamente dois tipos de erros: difração das ondas nas bordas da placa e os erros associados à resposta eletromagnética da linha de transmissão do sistema de medidas (cabos, conectores, antenas) [46, 47]. Como será abordado a seguir, o primeiro tipo de erro é minimizado ajustando-se as dimensões do setup, enquanto que o segundo é corrigido no processo de calibração do sistema.

\section{1 - EFEITO DE DIFRAÇÃO DE BORDA}

O efeito difração de borda pode ser minimizado com o uso lentes associadas às antenas cornetas, que focalizam o feixe de micro-ondas na região central da amostra, evitando as bordas [46, 47] e permitindo o uso de amostras menores [49]. Além disso, na falta de dispositivos de focalização, existem outros métodos também confiáveis, porém mais simples.

No setup deste trabalho, não foram utilizadas lentes para corrigir o efeito de borda. Utilizou-se a alternativa de fazer com que o tamanho da amostra fosse maior ou igual a 5 comprimentos de onda da frequência de operação e as antenas cornetas fossem posicionadas próximas à placa de metamateriais a uma separação mínima o suficiente para diminuir o problema. Dessa forma, a falta das lentes não afeta a precisão da medida dos parâmetros S [50].

Por outro lado, essa distância entre cada antena e a amostra deve ser grande o suficiente para evitar a região reativa da antena, relacionada ao campo próximo do elemento irradiador. O critério para se determinar o valor dessa separação é baseado na condição de campo distante (Limite de Rayleigh ou Distância de 
Fraunhofer ) que diz que a amostra deve ficar a uma distância de pelo menos $D=$ $2 \mathrm{~A}^{2} / \lambda$, onde $\mathrm{A}$ é a maior dimensão da antena e $\lambda$ é o comprimento de onda.

Para este trabalho, foram feitas algumas considerações e aproximações a cerca desses valores. A maior dimensão da antena utilizada é de $A=43 \mathrm{~mm}$ e, considerando o comprimento de onda da frequência central da faixa de operação $\left(\mathfrak{f}_{c}\right.$ $=10 \mathrm{GHz}$ ) temos $\lambda_{c}=30 \mathrm{~mm}$. Isso implica numa separação ideal entre a antena e a amostra de pelo menos $D \geq 123,27 \mathrm{~mm}$ e, consequentemente uma separação entre as duas antenas de (o dobro) $D \geq 246,33 \mathrm{~mm}$. Contudo, devido às limitações práticas da precisão das antenas utilizadas, essa distância se mostrou muito grande para que uma antena conseguisse detectar o sinal da outra, afetando a qualidade das medidas. Verificou-se, porém, que se o Limite de Rayleigth fosse aplicado à distância entre as duas antenas (e não entre cada antena e o metamaterial) os resultados ficariam dentro do esperado. Portanto, a consideração do Limite de Rayleigh de $D \geq 123,27 \mathrm{~mm}$ foi aplicada para a separação entre as duas antenas cornetas. Por fim, após alguns testes com diferentes separações, buscando o maior valor prático, foi estabelecido que a distância utilizada fosse $D=\mathbf{1 4 0} \mathbf{~ m m}$.

O tamanho da placa de metamaterial, por sua vez, foi baseado no critério de ser maior ou igual a $5 \lambda_{c}$ [50]. Assim, como $\lambda_{c}=30 \mathrm{~mm}$, os metamateriais foram construídos em placas quadradas de 150x150 mm, como mostradas na Figura 28. 

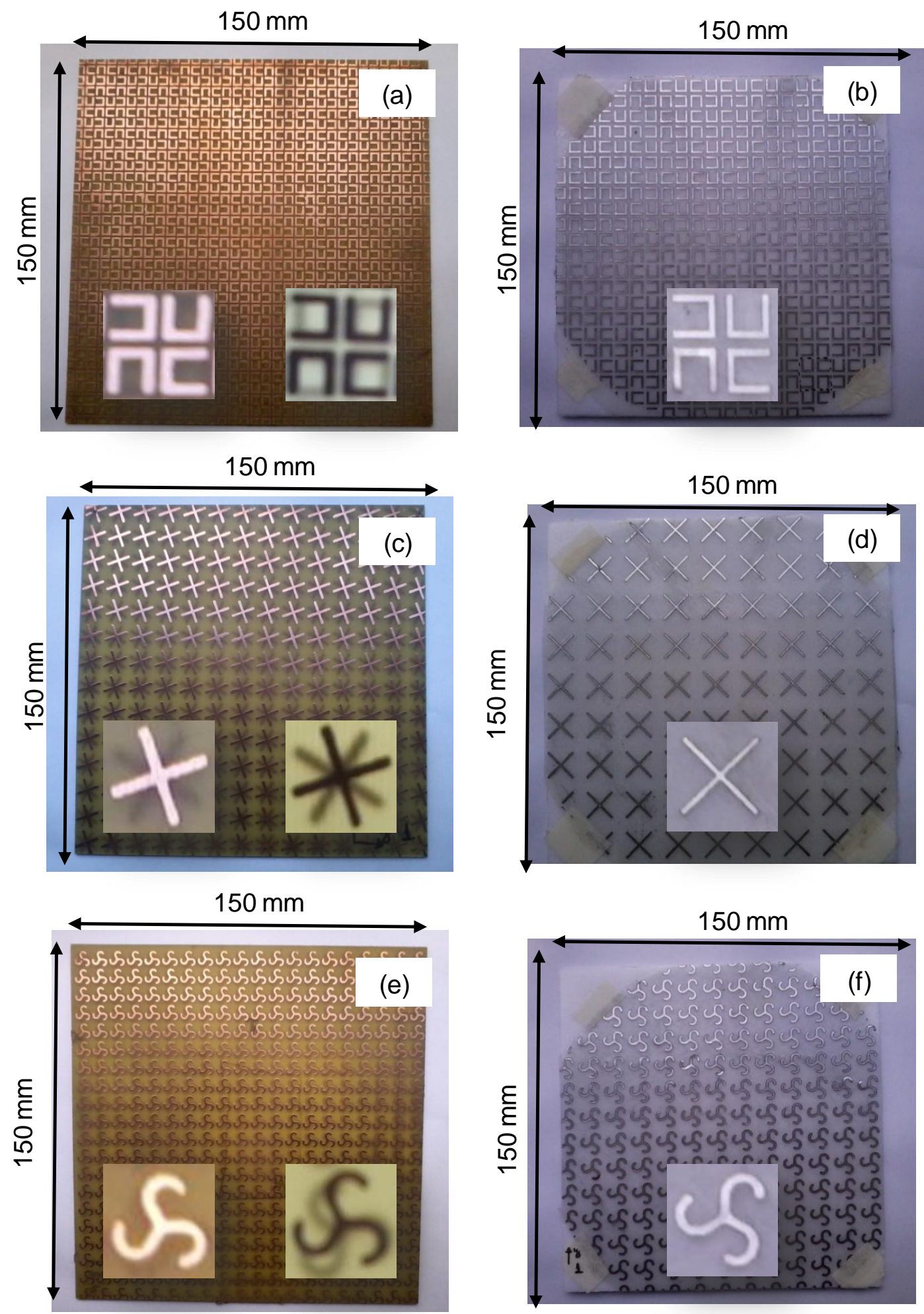

Figura 28 - Placas metamateriais construídas em FR4 (a, c, e) e em filme de alumínio (b, d, f) 


\section{2 - Calibração}

O processo de calibração tem como principal objetivo remover a resposta eletromagnética em frequência dos dispositivos auxiliares utilizados durante as medições (cabos, conectores, antenas, entre outros). Tal procedimento deve ser feito a fim de remover os efeitos do próprio sistema sobre a magnitude e fase do sinal, que podem afetar a resposta da amostra em questão. Sendo assim, em experimentos de micro-ondas que utilizam o Analisador de Redes, antes de se iniciar qualquer medida, é preciso calibrar o sistema.

Essa calibração deve ser feita a fim de corrigir possíveis "erros" ao longo da linha de transmissão entre o aparelho e o metamaterial. Isto se deve à própria resposta em frequência da linha e devido às demais imperfeições, tais como múltiplas reflexões, descasamento de impedância nas conexões, ressonâncias, transições entre dispositivos, e demais defeitos inevitáveis [46, 47, 50, 51]. Se, pelo contrário, esses efeitos indesejáveis não forem previamente corrigidos, eles poderão aparecer durante as medidas e os resultados finais estariam errados. Por esse motivo, uma boa calibração do sistema, antes de iniciar quaisquer medidas, é fundamental para o sucesso do experimento.

Devido a essa crucial importância da calibração, atualmente, a maioria dos Analisadores de Redes modernos já possuem recursos internos próprios que auxiliam nessa etapa. $O$ analisador de redes detecta possíveis erros na linha de transmissão tendo como base padrões de referência conhecidos, tais como situações de curto-circuito, circuito aberto e cargas perfeitamente casadas. Com isso, baseado na resposta esperada, o equipamento faz a correção matematicamente por meios de coeficientes internos para cada frequência da faixa de operação [51]. Os cálculos são baseados na teoria de Linhas de Transmissão [39].

Métodos tradicionais de calibração em micro-ondas, geralmente utilizados em medidas em microfitas ou dispositivos coaxiais, utilizam como padrões de referência, terminações conectadas diretamente às portas do sistema (ou cabos do analisador de redes). Esses padrões podem ser de quatro tipos: curto-circuito, circuito aberto, 
carga perfeitamente casada e transmissão direta (Método SOLT: short, open, load e transmition). Entretanto, no caso de medidas em espaço livre, que utilizam antenas cornetas e/ou guias de ondas, o método de calibração mais adequado é o denominado Thru-Reflect-Line (TRL) [46, 47, 49,51] que será descrito a seguir.

\section{3 - MÉTODO TRL}

Como o próprio nome sugere, a calibração TRL é feita em três etapas: Thru (Direto), Reflect (Reflexão), Line (Linha), que são os padrões de referência utilizados no processo [49]. Este é um método interessante para aplicações em medidas em espaço livre, sendo mais fácil e até mais preciso que os métodos tradicionais de calibração. Por isso, o TRL é o método de calibração utilizado nesse trabalho.

O setup da calibração TRL é o mesmo utilizado para medições, como ilustrado na Figura 24 com as duas antenas polarizadas em $Y$ (vertical) e sem o metamaterial entre elas. Nas etapas Thru e Line, o par de antenas é posicionado com separações específicas entre si para obtenção do padrão de transmissão livre entre as duas antenas cornetas, enquanto que na etapa Reflect, mede-se o padrão de reflexão utilizando um espelho metálico colocado em um plano de referência entre as antenas. Cada etapa será explicada com mais detalhes a seguir.

\section{THRU:}

Na primeira etapa, thru, que em português quer dizer "direto", as antenas cornetas são posicionadas diretamente uma de frente para a outra, ambas com a mesma polarização, sem nenhum obstáculo entre elas, assim como ilustrado na Figura 29-a. A distância " $D$ " entre as antenas deve a mesma usada durante as medições. Nesse passo, o analisador de redes emite um sinal e mede a transmissão e reflexão nas duas portas [52]. 
(a) Thru

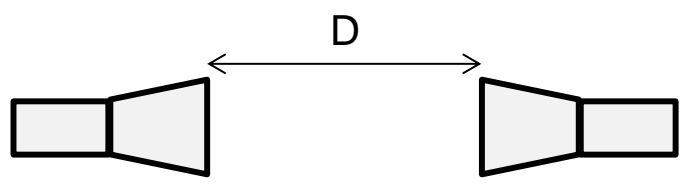

(b) Reflect

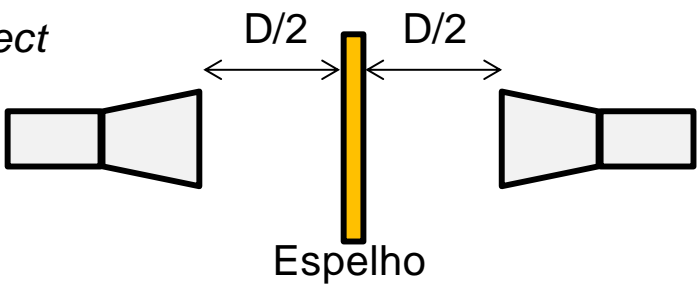

(c) Line

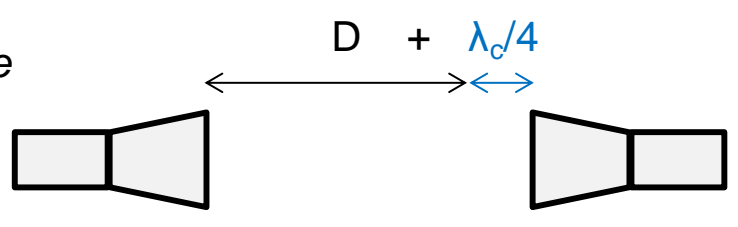

Figura 29 - Configurações das antenas em cada etapa do método de calibração TRL

\section{REFLECT:}

O padrão Reflect é obtido inserindo-se um espelho metálico entre as antenas como mostrado na Figura 29-b. A posição desse refletor deve ser a mesma onde a amostra será posicionada durante os experimentos, local este considerado o "plano de referência”, e sua localização deve ser a uma distância “ $D / 2$ ” das antenas [46, 47]. O espelho possui as mesmas dimensões das placas de metamaterial: $150 \times 150 \mathrm{mmm}$ e foi construído com as mesmas placas metalizadas para circuito impresso. Para aumentar a precisão da calibração, é recomendável ainda afastar as antenas para trás a uma distância adequada para compensar a espessura do espelho.

Assim, o analisador de redes emite um sinal e mede a reflexão nas duas portas. Terminada essa etapa, o espelho é retirado e as antenas devem voltar às suas posições iniciais para o próximo passo. 


\section{LINE:}

$\mathrm{Na}$ última etapa, Line, a separação entre as antenas é modificada a uma distância ligeiramente maior que " $D$ ". Esse acréscimo deve ser igual a um quarto do comprimento de onda da frequência central da banda [46, 47] que, para este trabalho foi de $\lambda_{c} / 4=7,5 \mathrm{~mm}$, como mostrado na Figura 29-c. Com essa nova configuração, o analisador de redes emite um sinal e mede novamente a transmissão e reflexão nas duas portas [52]. A princípio, a separação das antenas para esta etapa pode ser qualquer valor maior que " $D$ " [39], porém, por convenção, utiliza-se essa referência padrão de $\lambda_{c} / 4[46,47,51]$.

Após essa etapa, a antena deve ser voltada à posição inicial (Thru), para dar início às medidas experimentais com os metamateriais.

Para garantir a precisão dos movimentos milimétricos do setup em cada etapa da calibração deste trabalho, as antenas foram montadas em suportes móveis sobre trilhos cujo posicionamento apresentam precisão de $1 \mathrm{~mm} / 20$.

No Apêndice III deste trabalho é apresentado o procedimento detalhado para se fazer a calibração TRL no analisador de redes HP8720C, utilizado neste trabalho. 


\section{4 - Pós-Calibração}

Após a calibração, é necessário verificar se os erros do sistema e as repostas dos componentes da linha de transmissão foram removidos. Para isso, faz-se a medida da transmissão direta entre as duas antenas cornetas (configuração THRU) e o que se espera é uma resposta plana, tanto para a magnitude quanto para a fase do sinal transmitido. Em toda a faixa de frequência de operação, a magnitude do sinal deve estar corrigida para o valor máximo (1 em escala linear; $0 \mathrm{~dB}$ em escala logarítmica), enquanto a fase deve ser nula $\left(0^{\circ}\right)$.

Sendo assim, depois de feita a calibração TRL para este trabalho, foram verificadas as curvas de magnitude e fase mostradas na Figura 30 , onde pode-se observar que o resultado ficou conforme o esperado. $O$ erro residual da calibração ficou em torno de $\pm 0,18 \mathrm{~dB}$ para a magnitude $\mathrm{e} \pm 1,2^{\circ}$ para a fase.
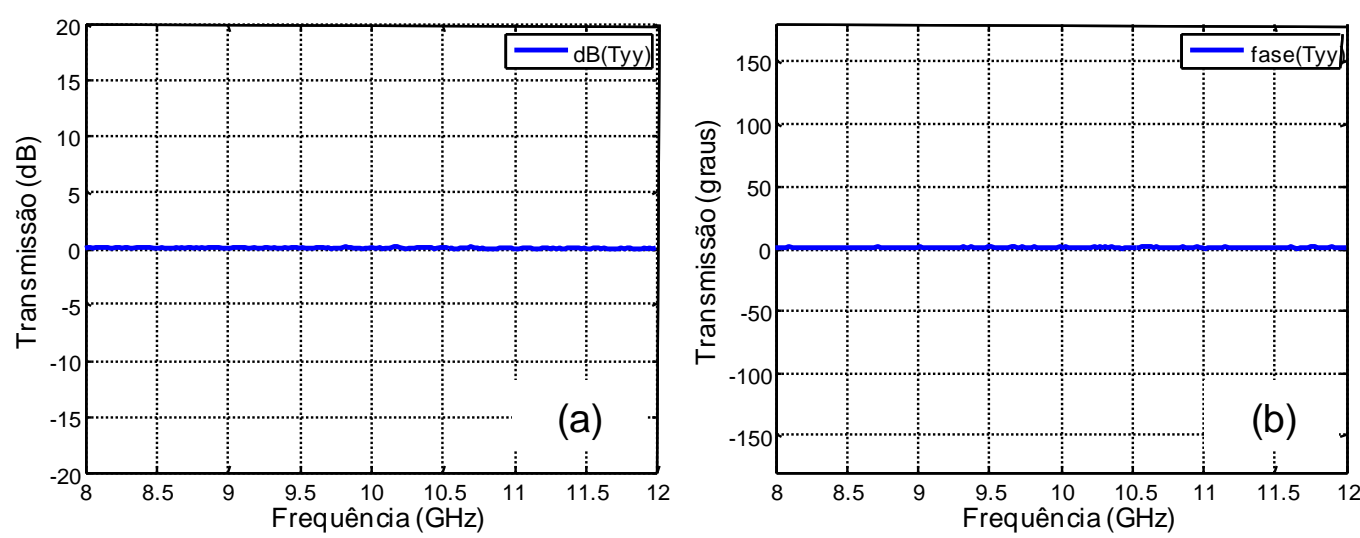

Figura 30 - Gráficos da transmissão direta $\left(\mathrm{S}_{21}\right)$ pós-calibração: (a) Magnitude em dB; (b) fase em graus

Assim, após a calibração ter sido feita e conferida, o sistema está pronto para fazer as medidas experimentais da caracterização do metamaterial. 


\section{5 - MEDIDAS DE CO-POLARIZAÇÃO E POLARIZAÇÃO CRUZADA}

Para obtenção experimental dos quatro parâmetros de transmissão lineares $T_{x x}, T_{x y}, T_{y x}$, e $T_{y y}$, as antenas cornetas foram posicionadas como mostrado na Figura 31 , onde cada seta indica o plano de polarização de cada corneta (a imagem do metamaterial foi omitida para melhor visualização apenas das antenas).

Para as medidas de polarização cruzada $\left(T_{x y}\right.$ e $\left.T_{y x}\right)$, as antenas cornetas foram posicionadas como mostrado em Figura 31 (b) e (c), enquanto que para as medidas de co-polarização $\left(T_{x x}\right.$ e $\left.T_{y y}\right)$, as antenas foram configuradas como ilustrado em Figura 31 (a) e (d).

Todas essas quatro medições foram feitas utilizando-se a mesma calibração feita em YY.

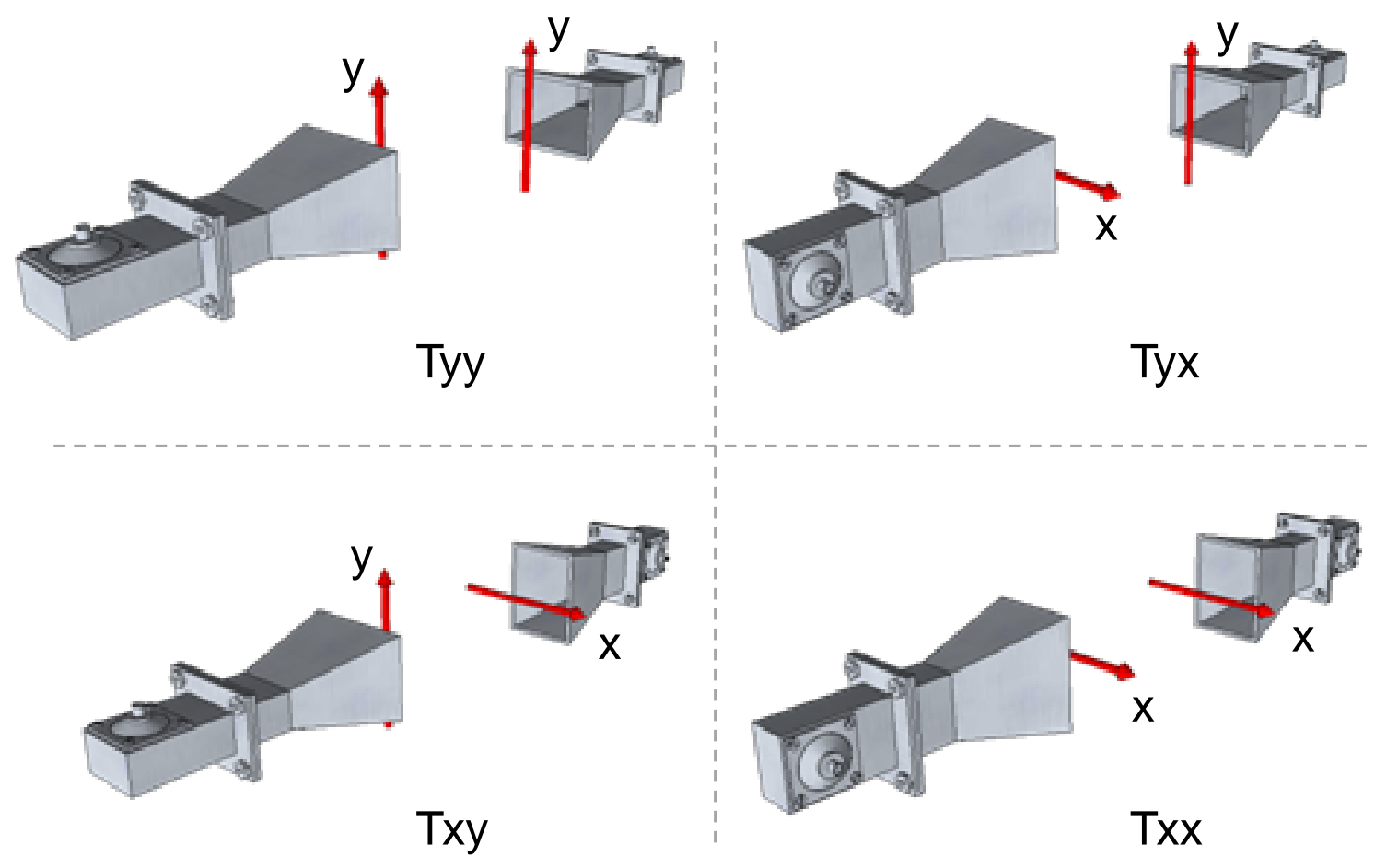

Figura 31 - Configurações de medidas de co-polarização e polarização cruzada 
Como era de se esperar, medidas de transmissão livre entre antenas de polarização cruzada devem apresentar uma magnitude de valor muito baixo, teoricamente nulo. Assim, após a calibração TRL com as antenas co-polarizadas (YY), a medida da transmissão de polarização cruzada (X-Y ou Y-X) resulta no gráfico mostrado na Figura 32. Entretanto, como será mostrado nos resultados, a presença do metamaterial quiral entre as antenas provoca uma rotação do plano de polarização da onda transmitida, aumentando o coeficiente de transmissão cruzada para valores acima de $-10 \mathrm{~dB}$ ou até mesmo $-5 \mathrm{~dB}$.

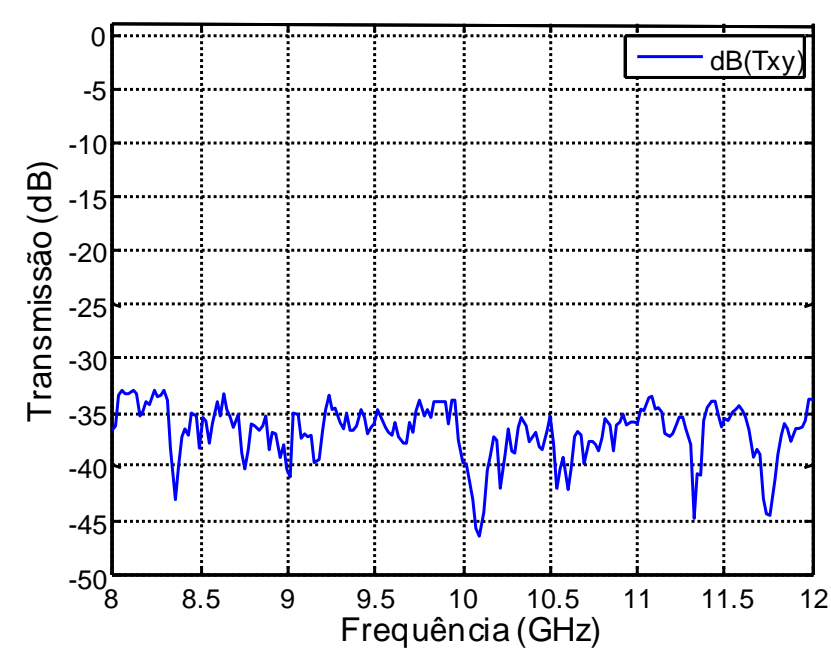

Figura 32 - Transmissão em polarização cruzada 


\section{Capítulo 5 - Resultados}

Neste capítulo são mostrados os resultados das simulações e das medidas experimentais das três estruturas metamateriais modeladas e caracterizadas neste trabalho. Além disso, são também mostrados os resultados das aplicações propostas para o metamaterial quiral como biossensor.

Primeiramente serão apresentadas as dimensões de cada célula projetada, bem como as curvas de caracterização (simulação e experimental) dos modelos de metamateriais quirais propostos. Cada modelo foi projetado e construído em dois tipos de substratos: FR4 e filme fino de alumínio. Os gráficos da caracterização simulada e experimental mostram a resposta em frequência das estruturas em termos dos coeficientes de transmissão linear $\left(T_{x x}, T_{x y}, T_{y x}\right.$ e $\left.T_{y y}\right)$, transmissão circular $\left(T_{++}\right.$e $\left.T_{--}\right)$, rotação de campo $(\theta)$, elipticidade $(\eta)$ e quiralidade complexa (к).

Além disso, por meio de métodos de recuperação de parâmetros, também foram calculados numericamente o índice de refração para ondas RCP e LCP $(n+e$ n-) de cada estrutura com seu respectivo substrato. Para este cálculo, entretanto, foram utilizados apenas dados simulados, pois para obter tal parâmetro são necessários os coeficientes de reflexão das ondas RCP e LCP do metamaterial e o setup experimental utilizado neste trabalho apresentou limitações para tal medida.

A análise de cada resultado foi feita de um modo geral verificando-se qualitativamente a presença dos fenômenos de birrefringência e dicroísmo circular. Com isso, para a validação do novo método de fabricação de metamateriais proposto neste trabalho, serão feitas comparações entre os seus resultados com os do método tradicional. Em seguida, também serão feitas discussões gerais sobre os erros de medidas e diferenças entre as curvas simuladas e experimentais.

Finalmente, serão apresentados os resultados numéricos do biossensor baseado no poder de rotação de campo dos metamateriais quirais. $O$ ângulo de azimute $(\theta)$ é utilizado como elemento transdutor para medidas de concentração de glicose em meio aquoso na faixa de micro-ondas $(1,7 \mathrm{GHz})$. 


\section{1 - RESSOADORES EM “U” EM SUBSTRATO DE FR4}

O metamaterial quiral baseado em ressoadores em "U" de cobre em substrato de FR4 foi adaptado de [25] por meio de simulações paramétricas (descritas na Seção 3.3), tendo resultado em uma célula unitária com dimensões de: $a_{x}=a_{y}=9$ $\mathrm{mm} ; \mathrm{s}=3,6 \mathrm{~mm} ; \mathrm{g}=0,9 \mathrm{~mm} ; \mathrm{w}=0,6 \mathrm{~mm} ; \mathrm{t}=1,6 \mathrm{~mm}$; como mostradas na Figura 33 (a) e (b). A estrutura foi construída na placa de FR4, como mostrado na foto da Figura 33 (c).

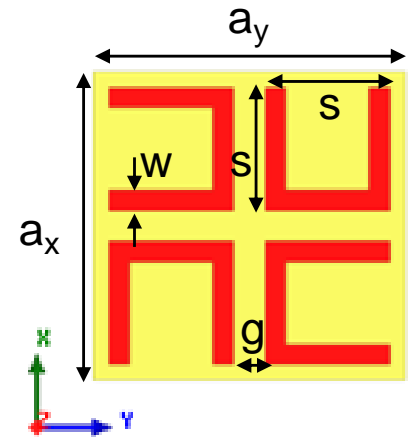

(a)

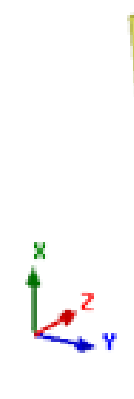

(b)

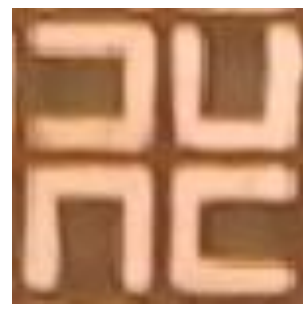

(c)

Figura 33 - Célula quiral unitária baseada em ressoadores em "U" com substrato em FR4. (a) Vista frontal: Dimensões: $a_{x}=a_{y}=9 \mathrm{~mm} ; \mathrm{s}=3,6 \mathrm{~mm} ; \mathrm{g}=0,9 \mathrm{~mm} ; \mathrm{w}=0,6 \mathrm{~mm}$; (b) Vista em perspectiva: $\mathrm{t}=1,6 \mathrm{~mm}$; (c) Célula em placa construída em FR4

Os quatro parâmetros de transmissão lineares foram obtidos por meio das simulações e das medidas experimentais e suas curvas são mostradas na Figura 34.

Nas medidas com metamateriais quirais, os coeficientes $T_{y x}$ e $T_{x y}$, que a princípio deveriam ser nulos devido à polarização cruzada, aqui apresentam valores razoáveis, indicando a rotação do plano de polarização da onda e o surgimento de uma componente de campo no eixo de polarização cruzada. 
Simulação
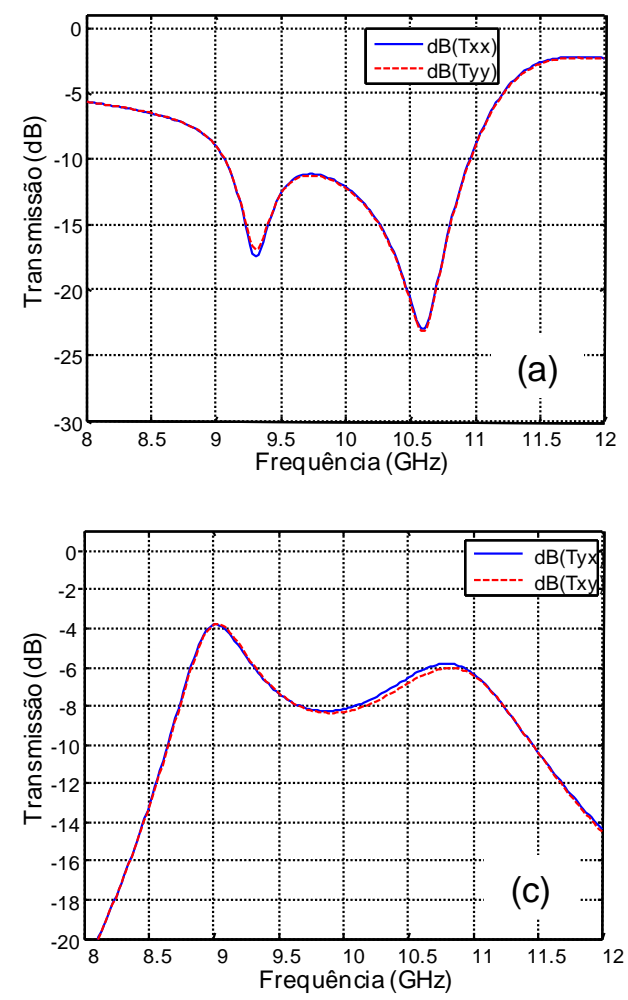

Experimental
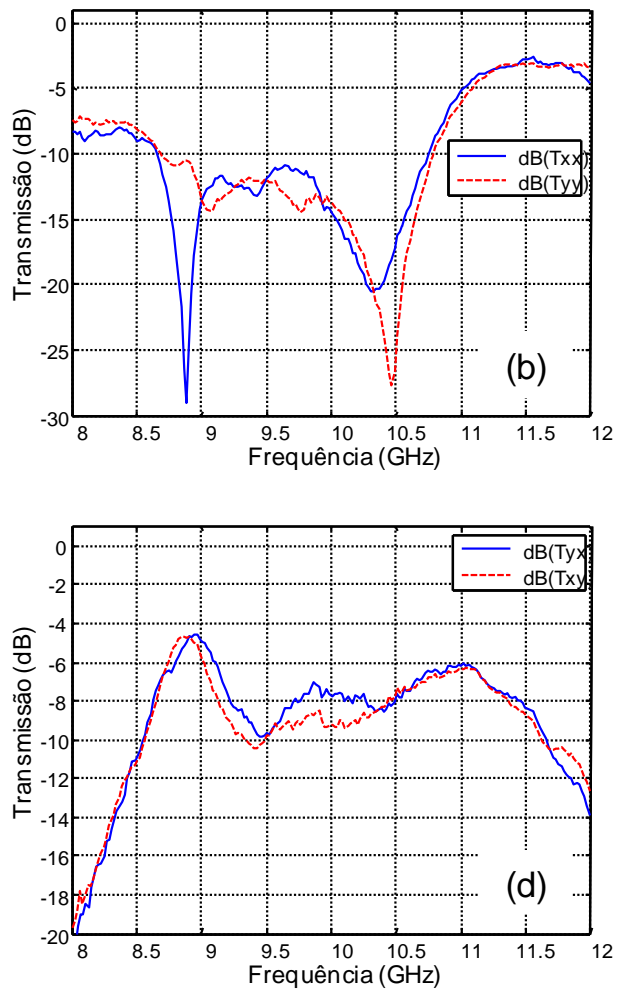

Figura 34 - Medidas numéricas e experimentais da magnitude (dB) dos coeficientes de transmissão lineares para ressoadores em "U" em FR4:: (a) Valores simulados de $\mathrm{T}_{\mathrm{xx}}$ (azul, contínua) e $\mathrm{T}_{\mathrm{yy}}$ (vermelha, tracejada); (b) Valores experimentais de $\mathrm{T}_{\mathrm{xx}}$ (azul, contínua) e $\mathrm{T}_{y y}$ (vermelha, tracejada); (c) Valores simulados de $\mathrm{T}_{\mathrm{yx}}$ (azul, contínua) e $T_{x y}$ (vermelha, tracejada); (d) Valores experimentais de $T_{y x}$ (azul, contínua) e $T_{x y}$ (vermelha, tracejada)

A partir dos parâmetros lineares foram então calculados os coeficientes de transmissão circulares $T_{++}$(RCP) e $T_{--}$(LCP) usando as equações (24) e (25), respectivamente. Os resultados das simulações e da parte experimental são mostrados na Figura 35. 
Simulação
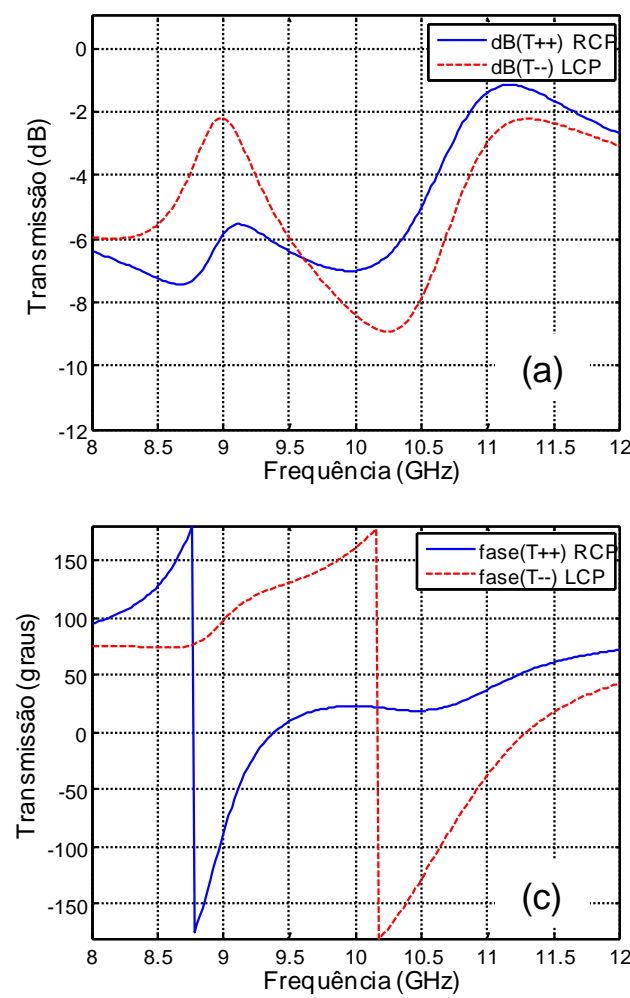

Experimental
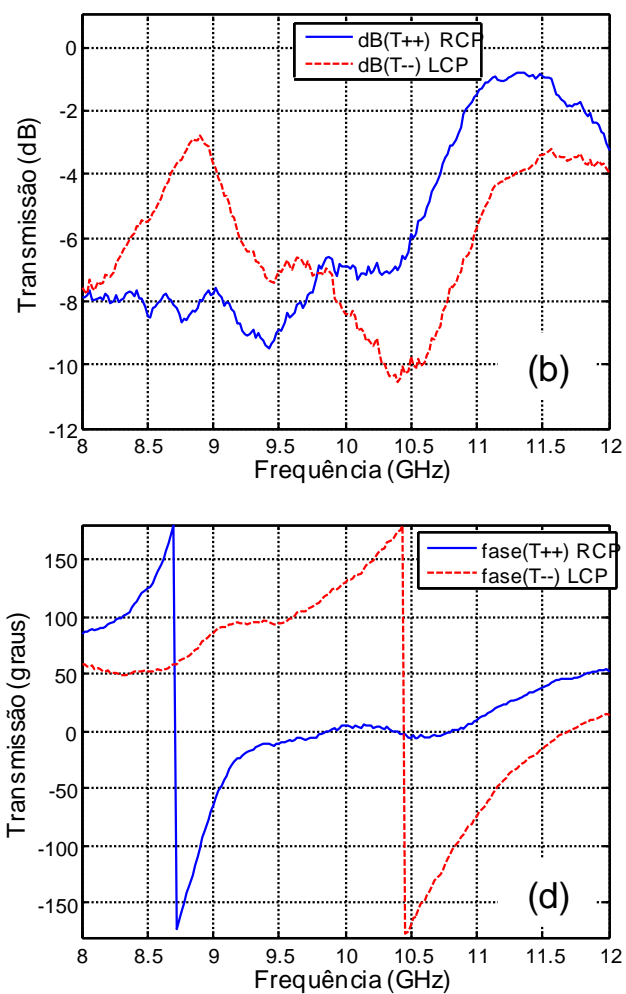

Figura 35 - Valores simulados e experimentais da magnitude $(\mathrm{dB})$ e da fase dos coeficientes de transmissão circulares para ressoadores em "U" em FR4:(a) Valores simulados da magnitude de $\mathrm{T}_{++}$(RCP) (azul, contínua) e T.. (LCP) (vermelha, tracejada); (b) Valores experimentais da magnitude de $\mathrm{T}_{++}$(RCP) (azul, contínua) e $\mathrm{T}_{\text {.. }}$ (LCP) (vermelha, tracejada); (c) Valores simulados da fase de $\mathrm{T}_{++}$(RCP) (azul, contínua) e $\mathrm{T}_{\text {.. }}$ (LCP) (vermelha, tracejada); (d) Valores experimentais da fase de $T_{++}$(RCP) (azul, contínua) e $T_{\text {.- }}$ (LCP) (vermelha, tracejada).

Por meio desses resultados pode-se verificar visualmente o efeito da birrefringência circular pela diferença entre as curvas de fase da transmissão das ondas RCP e LCP (Figura 35(c) e (d)). Da mesma forma, o efeito do dicroísmo circular pode ser notado nas diferentes curvas de magnitude da transmissão de RCP e LCP (Figura 35(a) e (b), respectivamente). A partir desses valores, utilizando-se as equaçoes (21) e (23) foram então calculadas o ângulo de azimute $\theta$ e a elipticidade $\eta$, como mostrado na Figura 36. 

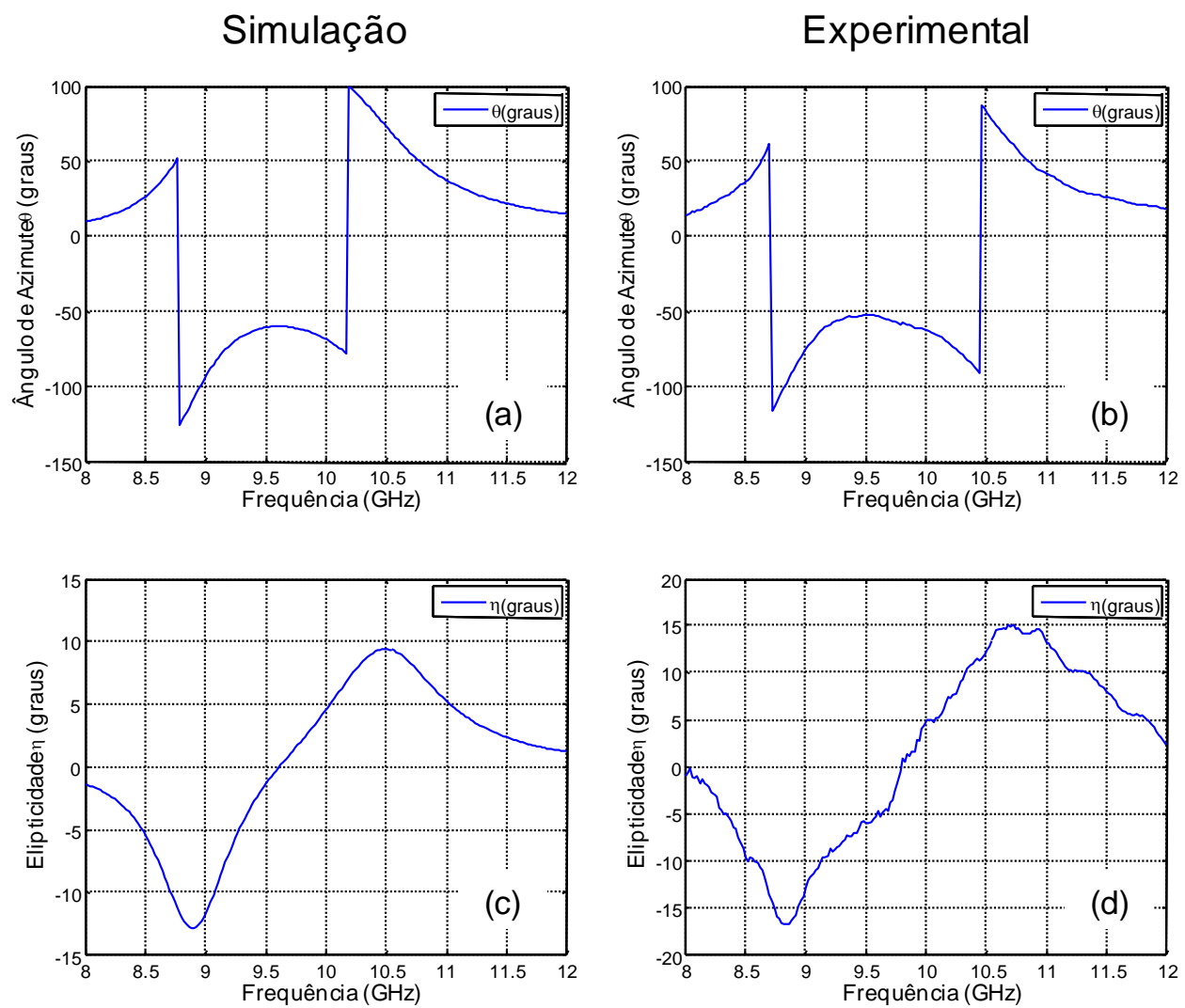

Figura 36 - Valores simulados e experimentais do ângulo de azimute $\theta$ e da elipticidade $\eta$ para a estrutura em ressoadores em "U" em FR4:(a) Valores simulados do ângulo de azimute $\theta$; (b) Valores experimentais do ângulo de azimute $\theta$; (c) Valores simulados da elipticidade $\eta$; (d) Valores experimentais da elipticidade $\eta$.

Nas Figura 36 (a) e (b), pelas curvas do ângulo de azimute $\theta$, podem ser verificados valores máximos de rotação de campo de $\theta=100^{\circ}$ nas frequências próximas a $10 \mathrm{GHz}$ e $\theta=-150^{\circ} \mathrm{em}$ torno de $8,8 \mathrm{GHz}$.

Nos resultados para a elipticidade (Figura 36 (c) e (d)), os valores máximos de elipticidade ocorrem nas frequências em torno de $9 \mathrm{GHz}$ e $10,5 \mathrm{GHz}$, apresentando os valores de $\eta=-13^{\circ}$ e $\eta=-9^{\circ}$, respectivamente.

As curvas da quiralidade complexa foram obtidas com o uso da equação (20) e os resultados simulados e experimentais das suas partes real e imaginária são mostrados na Figura 37. 
Simulação
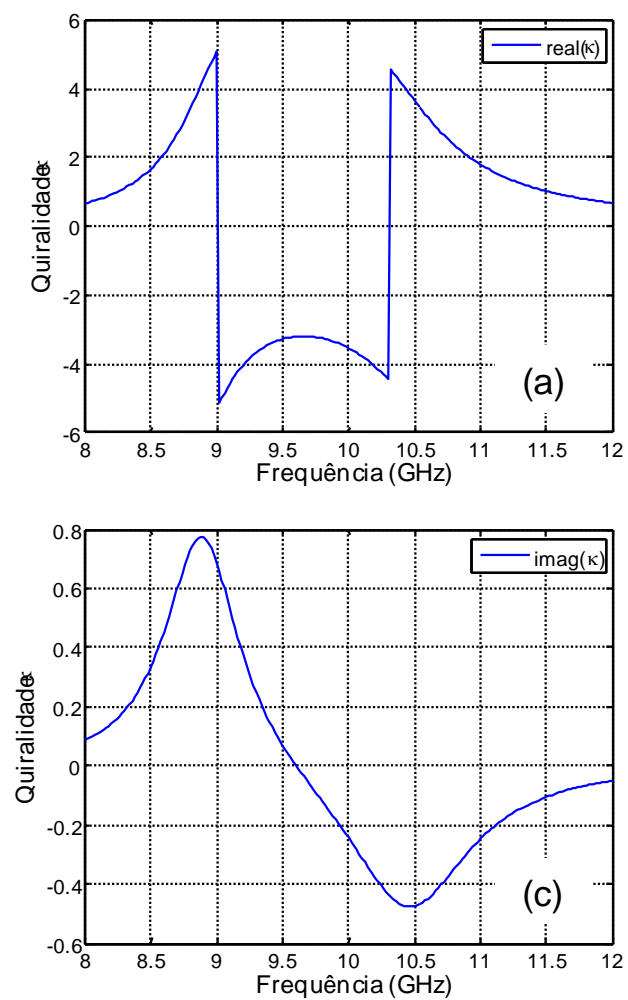

Experimental
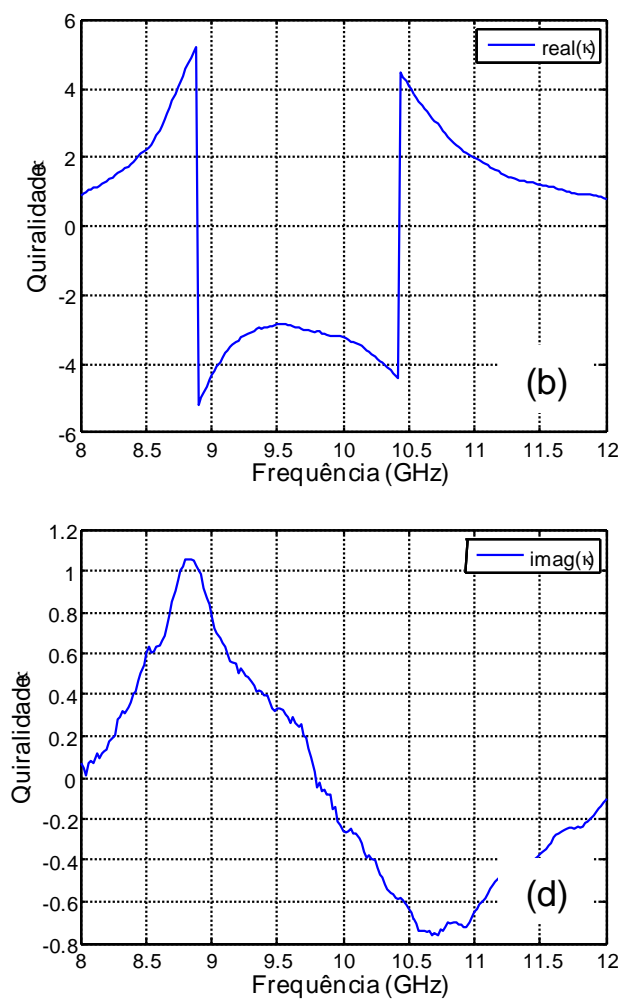

Figura 37 - Valores simulados e experimentais da quiralidade complexa para a estrutura em ressoadores em "U" em FR4:(a) Valores simulados parte real da quiralidade; (b) Valores experimentais parte real da quiralidade; (c) Valores simulados da parte imaginária da quiralidade; (d) Valores experimentais da parte imaginária da quiralidade.

Pode-se observar na Figura 37 (a) e (b) que as curvas da parte real da quiralidade possuem o mesmo comportamento das curvas do ângulo de azimute (Figura 36 (a) e (b)), indicando que a birrefringência é uma influência direta da parte real da quiralidade.

O mesmo pode ser observado para a relação entre a parte imaginária da quiralidade (Figura 37 (c) e (d)) e a curva de elipticidade (Figura 36 (c) e (d)).

O índice de refração da estrutura foi obtido a partir do método de extração de parâmetros. As curvas de suas partes real e imaginária são mostrados na Figura 38. 
Parte Real

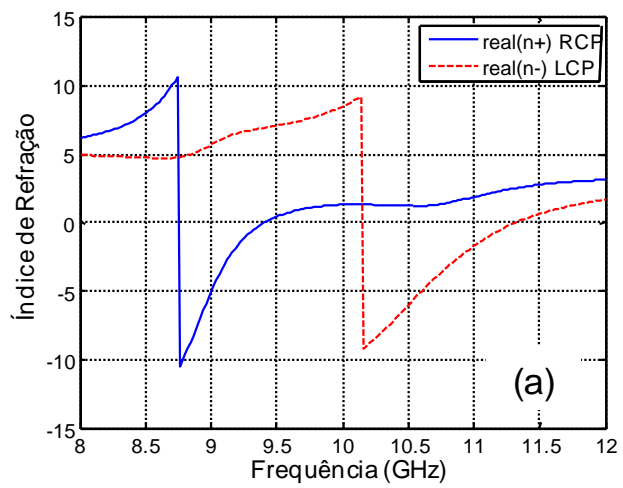

Parte Imaginária

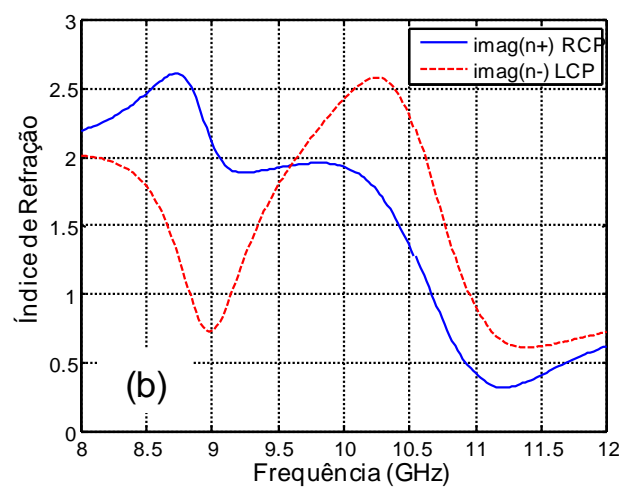

Figura 38 - Valores simulados da parte real e imaginária dos índices de refração para ondas RCP e LCP da estrutura em ressoadores em "U" em FR4:(a) Parte real dos índices de refração para RCP e LCP; (b) Parte imaginária dos índices de refração para RCP e LCP

A Figura 38-a mostra as curvas da parte real do índice de refração para ondas RCL e LCP. Pode-se notar primeiramente que $n+$ e $n$-são diferentes em toda a faixa de frequência, por consequência da birrefringência circular do meio. Esses valores distintos são os responsáveis pelas diferentes curvas de fase dos coeficientes de transmissão das ondas RCP e LCP transmitidas através do metamaterial quiral (Figura 35 (c e d)). Verifica-se, ainda, a existência de faixas de refração negativa em para $\mathrm{n}+\mathrm{e}$ - em torno de $9 \mathrm{GHz} 10,5 \mathrm{GHz}$, respectivamente.

A Figura 38-(b) apresenta os diferentes gráficos da parte imaginária no índice de refração para ondas RCP e LCP, indicando assim as diferentes absorções para cada tipo de polarização circular, devido ao efeito do dicroísmo circular. 


\section{2 - Ressoadores em “U” EM Filme Fino de Alumínio}

Após a modelagem computacional, o metamaterial quiral baseado em ressoadores em "U" no filme fino de alumínio teve sua célula unitária definida com as dimensões: $a_{x}=a_{y}=14 \mathrm{~mm} ; \mathrm{s}=5,6 \mathrm{~mm} ; \mathrm{g}=1,4 \mathrm{~mm} ; \mathrm{w}=0,9 \mathrm{~mm} ; \mathrm{t}=4 \mathrm{~mm}$; como mostradas nas Figura 39 (a) e (b). A estrutura completa foi construída com o filme fino de alumínio e, para dar suporte mecânico, utilizou-se um substrato de baixa densidade, como mostrado na foto da Figura 39 (c).

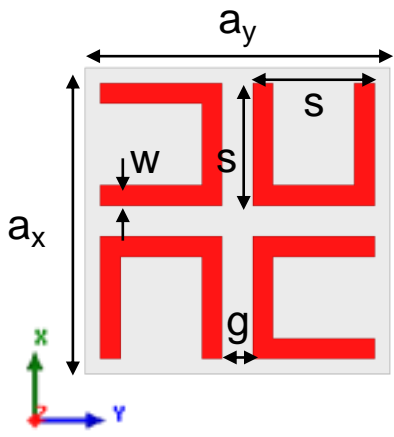

(a)

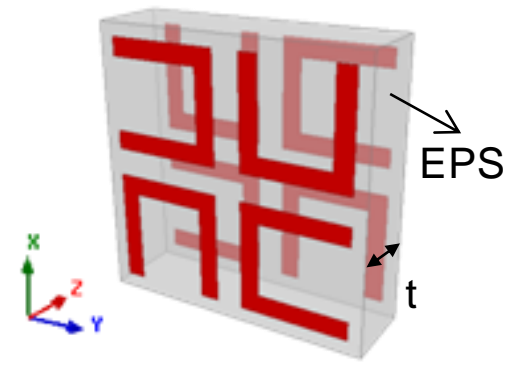

(b)

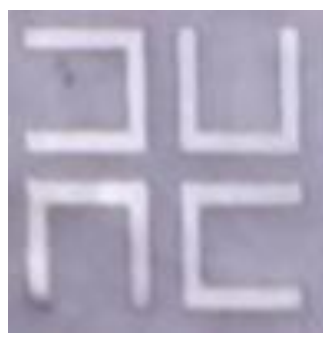

(c)

Figura 39 - Célula quiral unitária baseada em ressoadores em "U" com substrato em FR4.(a) Vista frontal: Dimensões: $a_{x}=a_{y}=14 \mathrm{~mm} ; s=5,6 \mathrm{~mm} ; g=1,4 \mathrm{~mm} ; w=0,9 \mathrm{~mm}$; (b) Vista em perspectiva: $\mathrm{t}=4 \mathrm{~mm}$; (c) Uma célula da placa construída em filme fino de alumínio.

Os quatro parâmetros de transmissão lineares foram obtidos por meio das simulações e das medidas experimentais e suas curvas são mostradas na Figura 40.

Os gráficos dos dados simulados e medidos experimentalmente estão em concordância, apesar de algumas pequenas diferenças nas curvas experimentais devido a erros de medidas que serão discutidos mais adiante. 
Simulação
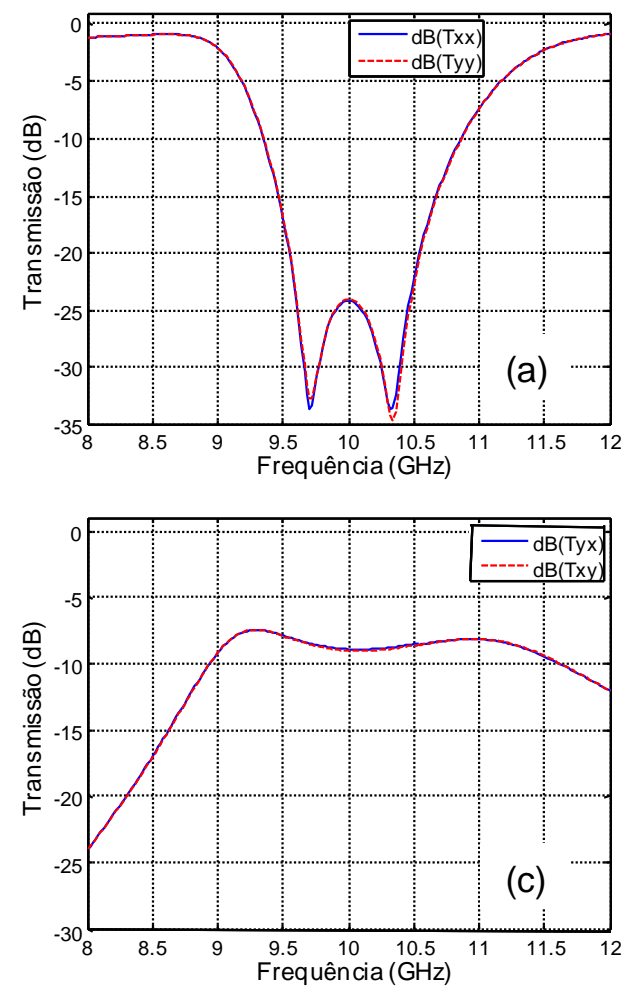

Experimental
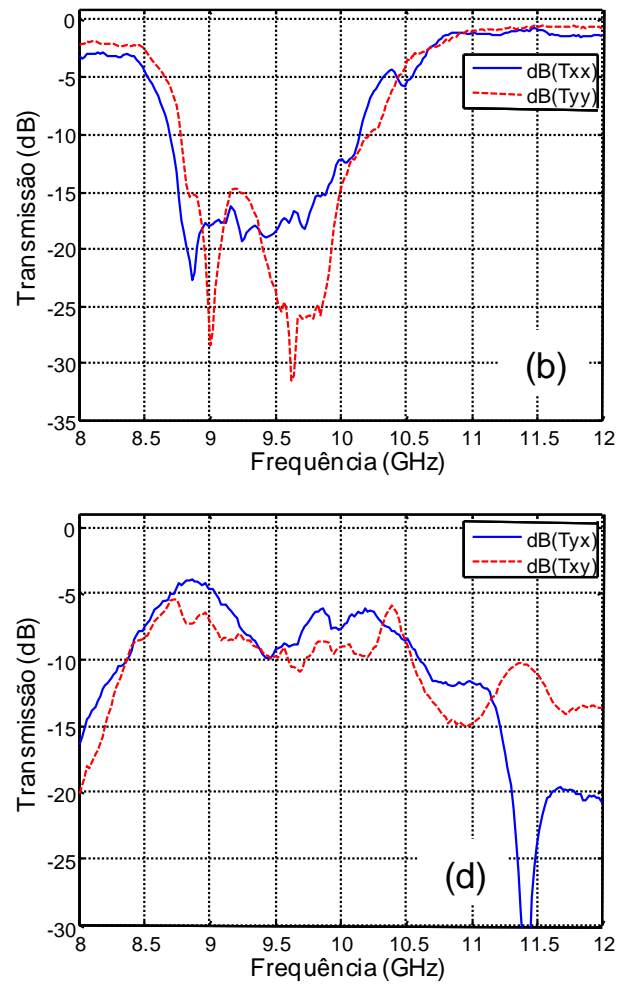

Figura 40- Medidas numéricas e experimentais da magnitude dos coeficientes de transmissão lineares para ressoadores em "U" em filme fino de alumínio:(a) Valores simulados de $T_{x x}$ (azul, contínua) e $T_{y y}$ (vermelha, tracejada); (b) Valores experimentais de $\mathrm{T}_{\mathrm{xx}}$ (azul, contínua) e Tyy (vermelha, tracejada); (c) Valores simulados de $\mathrm{T}_{\mathrm{yx}}$ (azul, contínua) e $T_{x y}$ (vermelha, tracejada); (d) Valores experimentais de $T_{y x}$ (azul, contínua) e $T_{x y}$ (vermelha, tracejada)

Nas curvas das simulações das Figura 40 (a) e (c), pode-se observar que os parâmetros de transmissão em co-polarização ( $T_{x x}$ e $\left.T_{y y}\right)$ possuem mesma magnitude em toda a faixa. O mesmo ocorre nas curvas de magnitude de $\left(T_{x y}\right.$ e $\left.T_{y x}\right)$. Isso acontece devido à simetria rotacional de $90^{\circ}$ da estrutura, ou seja, a sua imagem é a mesma para a orientação x ou y. Mesmo assim, ainda se trata de uma estrutura quiral, pois esta não apresenta simetria espelho e os efeitos de quiralidade podem ser observados nas curvas de transmissão de ondas RCP e LCP mostradas na Figura 41. 

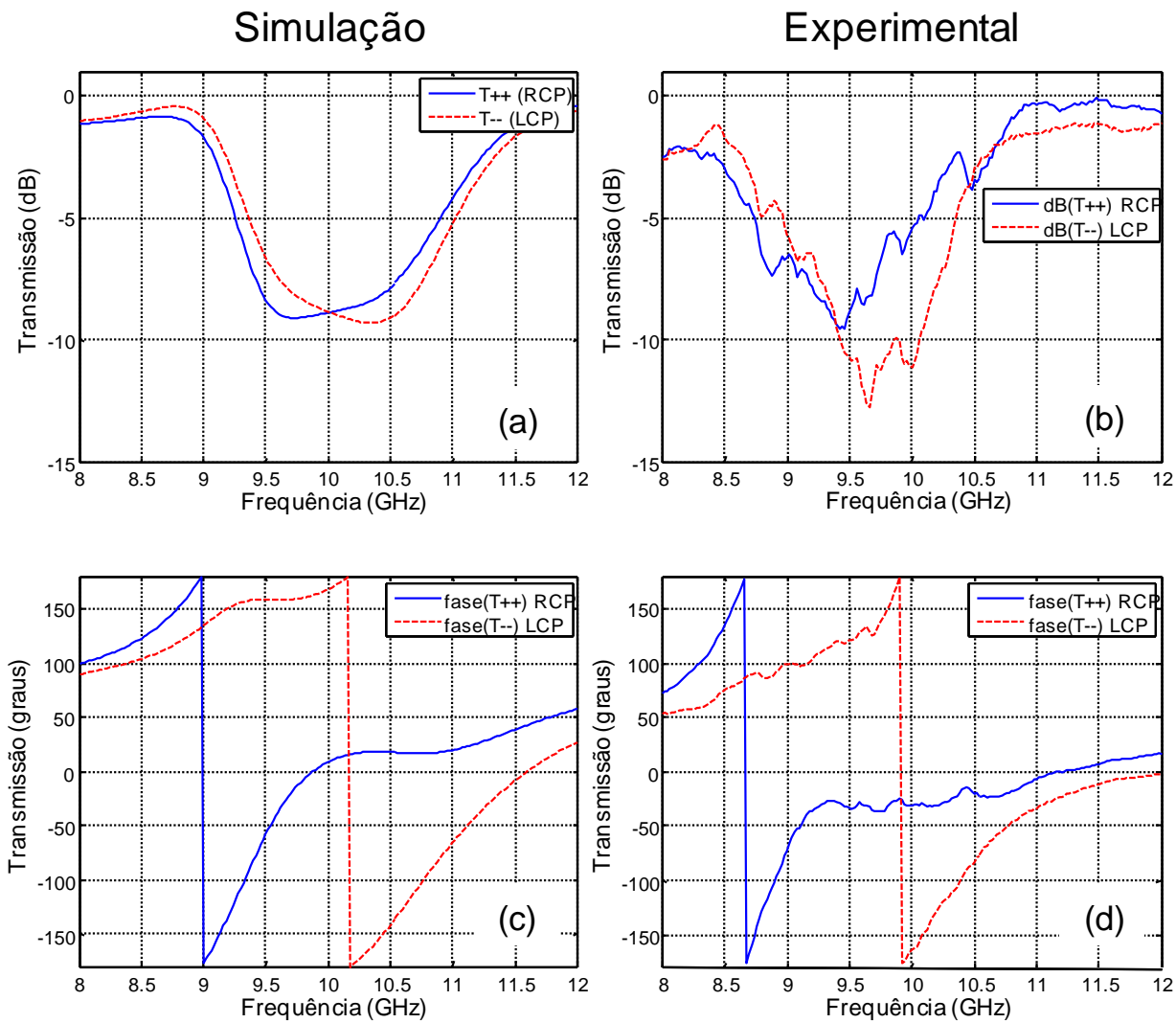

Figura 41 - Valores simulados e experimentais da magnitude $(\mathrm{dB})$ e da fase dos coeficientes de transmissão circulares para ressoadores em "U" em filme de alumínio: (a) Valores simulados da magnitude de $T_{++}$(RCP) (azul, contínua) e $T_{\text {.- }}$ (LCP) (vermelha, tracejada); (b) Valores experimentais da magnitude de $T_{++}$(RCP) (azul, contínua) e $T_{. .}$(LCP) (vermelha, tracejada); (c) Valores simulados da fase de $T_{++}$(RCP) (azul, contínua) e T... (LCP) (vermelha, tracejada); (d) Valores experimentais da fase de $\mathrm{T}_{++}(\mathrm{RCP})$ (azul, contínua) e T.. (LCP) (vermelha, tracejada);

Por meio dos gráficos da simulação, pode-se verificar visualmente o efeito da birrefringência circular pela diferença entre as curvas de fase da transmissão das ondas RCP e LCP (Figura 41(c) e (d), respectivamente).

O efeito do dicroísmo circular também se manifesta nessa estrutura, o que pode ser notado nas diferentes curvas de magnitude da transmissão de RCP e LCP (Figura 41(a) e (b)), indicando perdas diferentes para os dois tipos de polarização circular, e fazendo com que haja elipticidade na onda transmitida. A partir desses valores, utilizando-se as equações (21) e (23) foram então calculadas o ângulo de azimute $\theta$ e a elipticidade $\eta$, como mostrado na Figura 42. 
Simulação
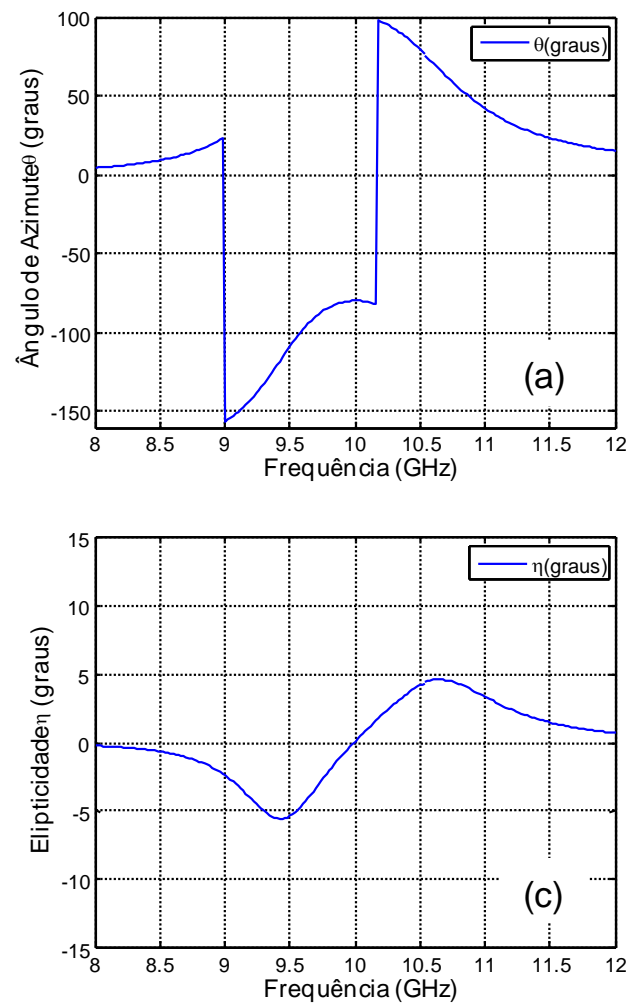

Experimental
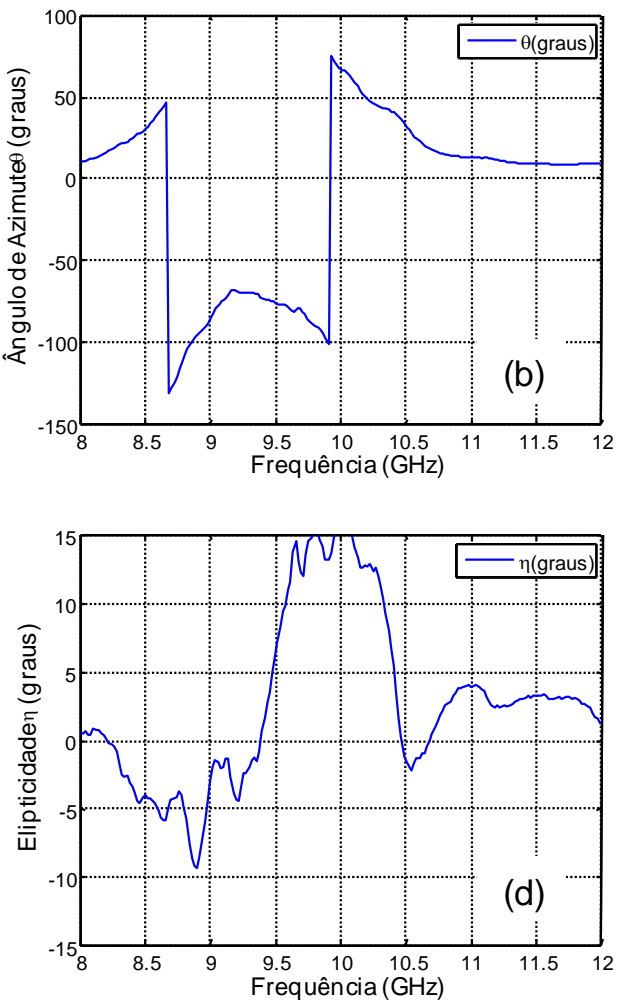

Figura 42 - Valores simulados e experimentais do ângulo de azimute $\theta$ e da elipticidade $\eta$ para a estrutura em ressoadores em "U" em filme de alumínio: (a) Valores simulados do ângulo de azimute $\theta$; (b) Valores experimentais do ângulo de azimute $\theta$; (c) Valores simulados da elipticidade $\eta$; (d) Valores experimentais da elipticidade $\eta$.

Nas Figura 42 (a) e (b), observando-se as curvas do ângulo de azimute $\theta$, podem ser verificados valores máximos de rotação de campo da ordem de $100^{\circ}$ nas frequências próximas a $10 \mathrm{GHz}$ e $\theta=-150^{\circ} \mathrm{em}$ torno de $9 \mathrm{GHz}$.

As Figura 42 (c) e (d) mostram as curvas de elipticidade simuladas e experimentais, respectivamente. Nos resultados simulados verificam-se valores de elipticidade entre $-5^{\circ}$ e $5^{\circ}$, enquanto que nos resultados experimentais os valores extremos estão entre $-10^{\circ}$ e $15^{\circ}$. A diferença entre essas curvas está associada aos erros de medidas que fizeram com que a diferença entre os coeficientes $T_{++}$e $T$.. se acentuasse proporcionando, assim, maiores valores medidos de elipticidade.

A partir da equação (20) foram obtidas as curvas da quiralidade complexa, e os gráficos simulados e experimentais das suas partes real e imaginária são mostrados na Figura 43. 
Simulação
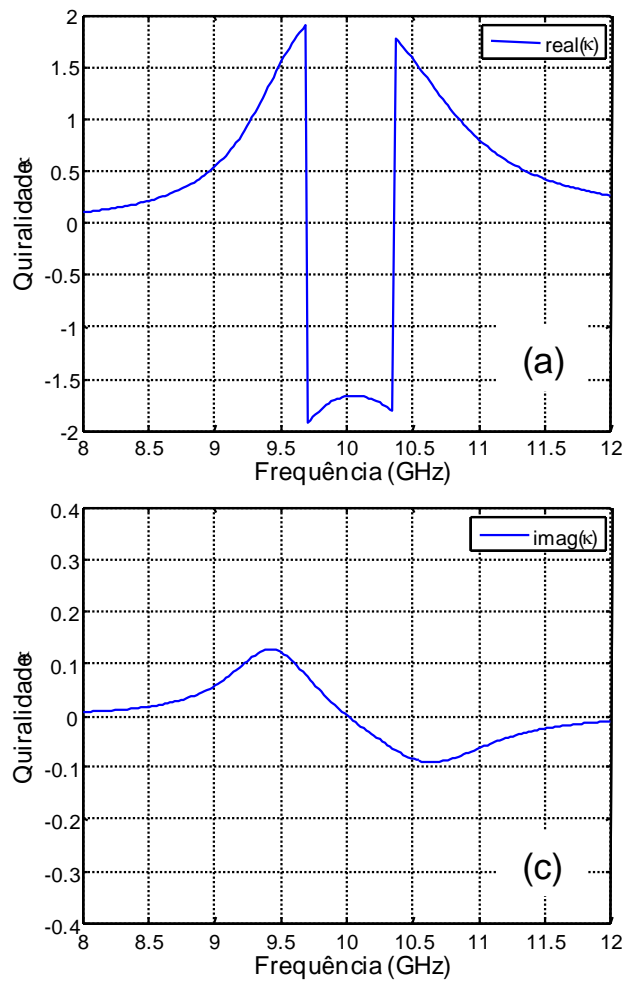

Experimental
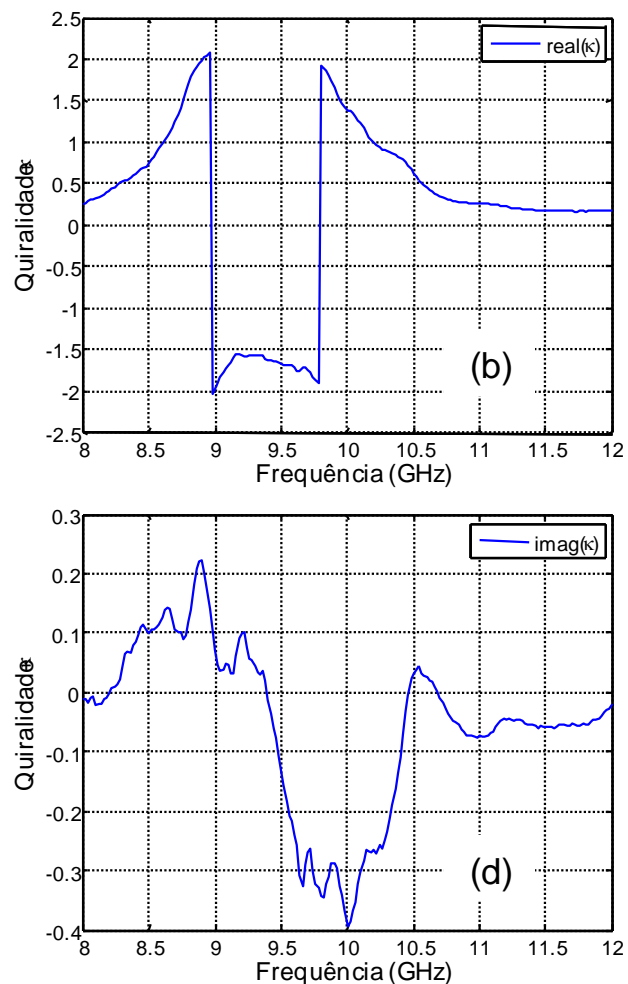

Figura 43 - Valores simulados e experimentais da quiralidade complexa para a estrutura em ressoadores em "U" em filme de alumínio: (a) Valores simulados parte real da quiralidade; (b) Valores experimentais parte real da quiralidade; (c) Valores simulados da parte imaginária da quiralidade; (d) Valores experimentais da parte imaginária da quiralidade.

As Figura 43 (a) e (b) mostram os valores reais da quiralidade (numéricos e experimentais), responsáveis pela birrefringência circular do meio, enquanto as Figura 43 (c) e (d) mostram os valores imaginários da quiralidade, medidos e simulados, responsáveis pelo dicroísmo circular do metamaterial.

O índice de refração complexo para ondas RCP e LCP foi obtido a partir do método de extração de parâmetros. Os gráficos de sua parte real e imaginária são mostrados na Figura 44. 
Parte Real

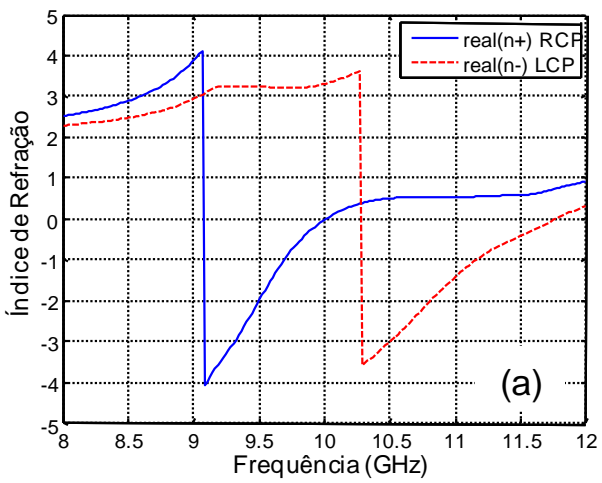

Parte Imaginária

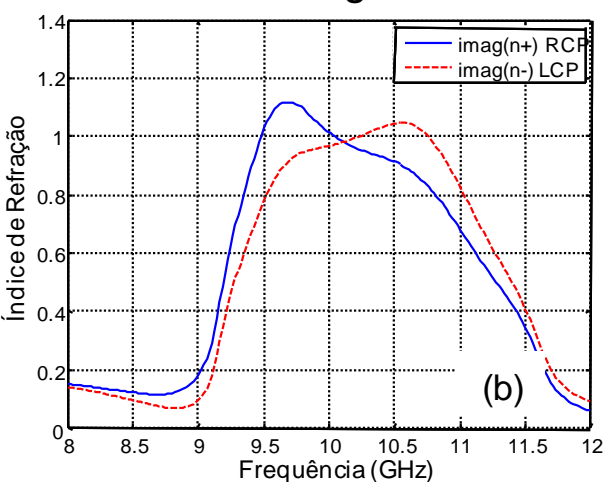

Figura 44 - Valores simulados da parte real e imaginária dos índices de refração para ondas RCP e LCP da estrutura em ressoadores em "U" em filme de alumínio:(a) Parte real dos índices de refração para RCP e LCP; (b) Parte imaginária dos índices de refração para RCP e LCP

A Figura 44 mostra as curvas da parte real e imaginária do índice de refração para ondas RCL e LCP. Pode-se notar primeiramente na Figura 44-(a) que as partes reais de $n+$ e $n$ - são diferentes em toda a faixa de frequência por consequência da birrefringência circular do meio e são os responsáveis pelas diferentes curvas de fase dos coeficientes de transmissão das ondas RCP e LCP transmitidas através da estrutura quiral (Figura 41 (c) e (d), respectivamente). Além disso, verifica-se a existência de valores negativos de índice de refração para $n+e n-$ em torno de 9,5 $\mathrm{GHz}$ e $10,5 \mathrm{GHz}$, respectivamente.

A Figura 44-(b) apresenta os gráficos da parte imaginária no índice de refração para ondas RCP e LCP. As curvas são diferentes e não se sobrepõem completamente, indicando que as perdas são diferentes para RCP e LCP, proporcionando assim, o efeito dicroísmo circular nessa estrutura. 


\section{3 - Ressoadores EM “CRUZ” EM SUBStRato de FR4}

O metamaterial quiral baseado em ressoadores de cobre em forma de cruz em substrato de FR4 foi adaptado de [24], e a célula unitária projetada apresenta as dimensões: $\mathrm{a}_{\mathrm{x}}=\mathrm{a}_{\mathrm{y}}=11 \mathrm{~mm} ; \mathrm{L}=10,2 \mathrm{~mm} ; \mathrm{w}=0,8 \mathrm{~mm} ; \varphi_{0}=30^{\circ} ; \varphi=40^{\circ} ; \mathrm{t}=1,6$ mm; como mostradas nas Figura 45(a) e (b). A estrutura completa foi construída na placa de FR4, como mostrado na foto da Figura 45(c)

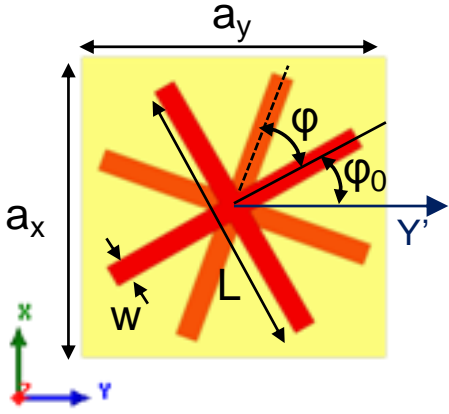

(a)

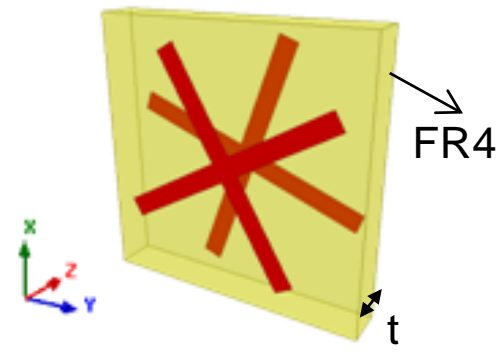

(b)

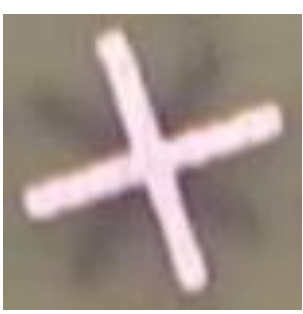

(c)

Figura 45 - Célula quiral unitária baseada em ressoadores em cruz com substrato em FR4:(a) Vista frontal: Dimensões: $a_{x}=a_{y}=11 \mathrm{~mm} ; \mathrm{L}=10,2 \mathrm{~mm} ; \mathrm{w}=0,8 \mathrm{~mm} ; \varphi_{0}=30^{\circ} ; \varphi=40^{\circ}$ (b) Vista em perspectiva: $\mathrm{t}=1,6 \mathrm{~mm}$; (c) Célula em placa construída em FR4

No processo de caracterização numérica e experimental deste modelo foram obtidos os quatro parâmetros de transmissão lineares ( $T_{x x}, T_{x y}, T_{y x}$ e $\left.T_{y y}\right)$ e suas curvas de magnitude são mostradas na Figura 46. 
Simulação
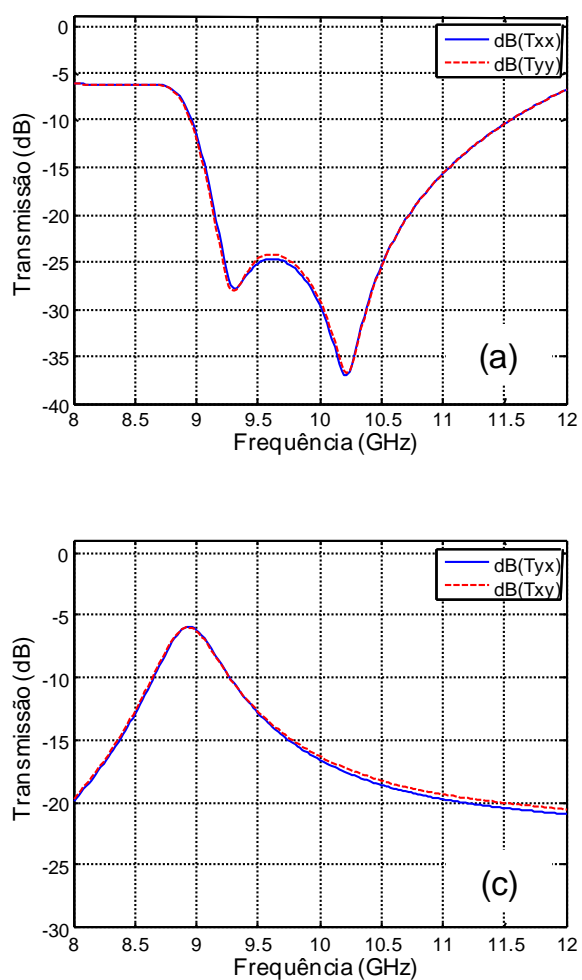

Experimental
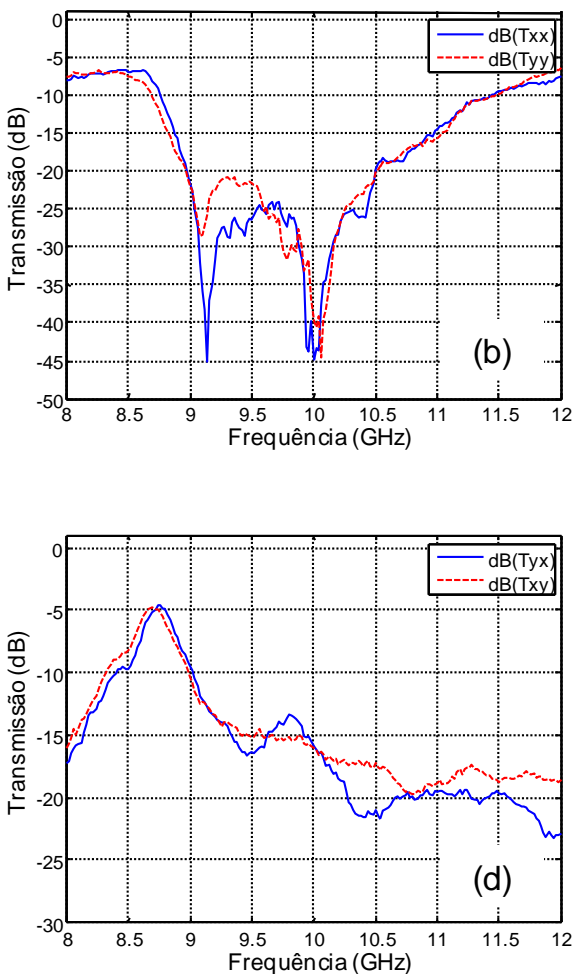

Figura 46 - Medidas numéricas e experimentais da magnitude dos coeficientes de transmissão lineares para ressoadores em forma de cruz em substrato de FR4:(a) Valores simulados de $T_{x x}$ (azul, contínua) e $T_{y y}$ (vermelha, tracejada); (b) Valores experimentais de $\mathrm{T}_{\mathrm{xx}}$ (azul, contínua) e $\mathrm{T}_{\mathrm{yy}}$ (vermelha, tracejada); (c) Valores simulados de $\mathrm{T}_{\mathrm{yx}}$ (azul, contínua) e $\mathrm{T}_{\mathrm{xy}}$ (vermelha, tracejada); (d) Valores experimentais de $\mathrm{T}_{\mathrm{yx}}$ (azul, contínua) e $\mathrm{T}_{\mathrm{xy}}$ (vermelha, tracejada)

A estrutura quiral em formato de cruz possui simetria rotacional de $90^{\circ}$ e por isso as magnitudes de $T_{x x}$ e $T_{y y}$ são iguais em toda a faixa de frequência, como pode ser visto nas Figura 46(a) e (b). O mesmo acontece com a magnitude dos coeficientes de transmissão cruzada $T_{y x}$ e $T_{x y}$ (Figura 46(c) e (d), respectivamente).

A partir dos coeficientes de transmissão linear, foram calculados os coeficientes de polarização circular $\left(T_{++}\right.$e $\left.T_{--}\right)$, cujos gráficos de amplitude e fase são mostrados a seguir na Figura 47. 

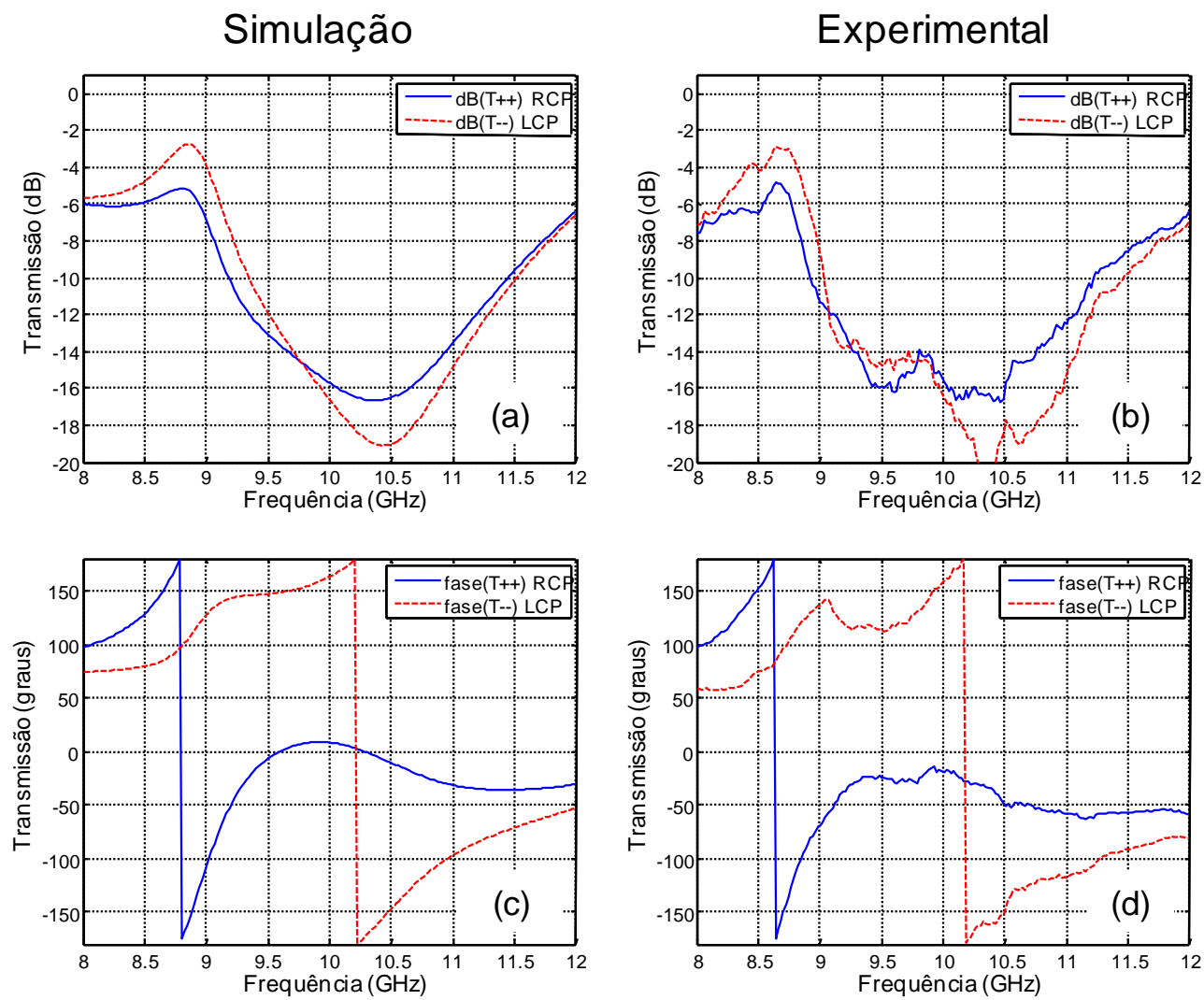

Figura 47 - Valores simulados e experimentais da magnitude e da fase dos coeficientes de transmissão circulares para ressoadores em forma de cruz em substrato de FR4:(a) Valores simulados da magnitude de $\mathrm{T}_{++}$(RCP) (azul, contínua) e $\mathrm{T}_{\text {.. }}$ (LCP) (vermelha, tracejada); (b) Valores experimentais da magnitude de $\mathrm{T}_{++}$(RCP) (azul, contínua) e $\mathrm{T}_{\text {. }}$ (LCP) (vermelha, tracejada); (c) Valores simulados da fase de $T_{++}$(RCP) (azul, contínua) e T.. (LCP) (vermelha, tracejada); (d) Valores experimentais da fase de $\mathrm{T}_{++}$(RCP) (azul, contínua) e T.- (LCP) (vermelha, tracejada);

Por meio das curvas mostradas nas Figura 47(a) e (b), pode-se verificar diferença entre as curvas de magnitude dos coeficientes de transmissão para RCP e LCP, indicando a existência do efeito de dicroísmo circular e, consequentemente, elipticidade na onda transmistida. A diferença nas curvas de fase, por sua vez, indica o fenômeno da birrefringência circular (Figura 47(c) e (d))

A partir desses valores, utilizando-se as equaçoes (21) e (23), foram então calculados o ângulo de azimute $\theta$ e a elipticidade $\eta$, como mostrado na Figura 48. 
Simulação
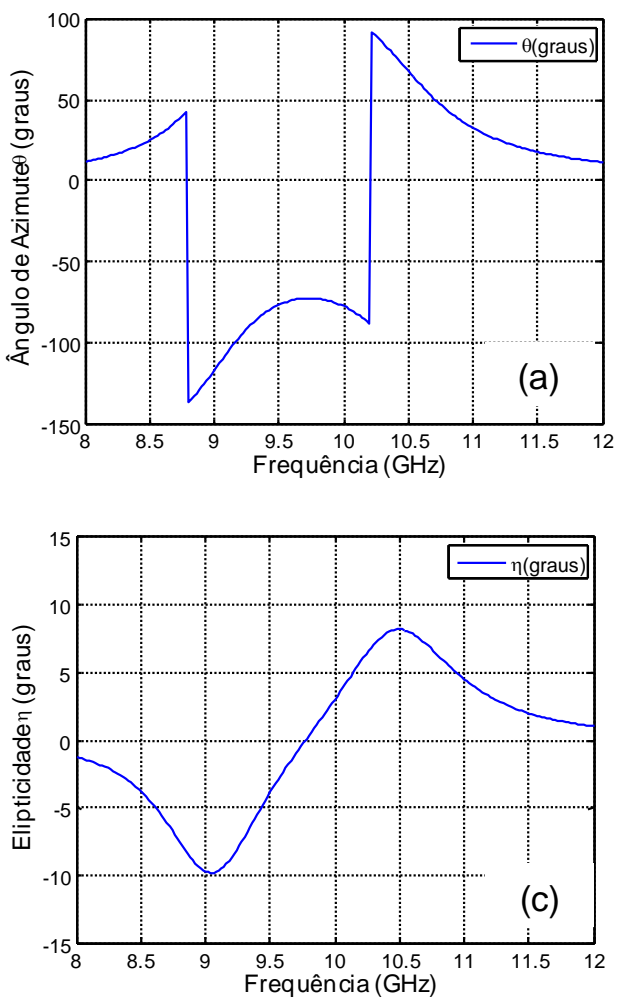

Experimental
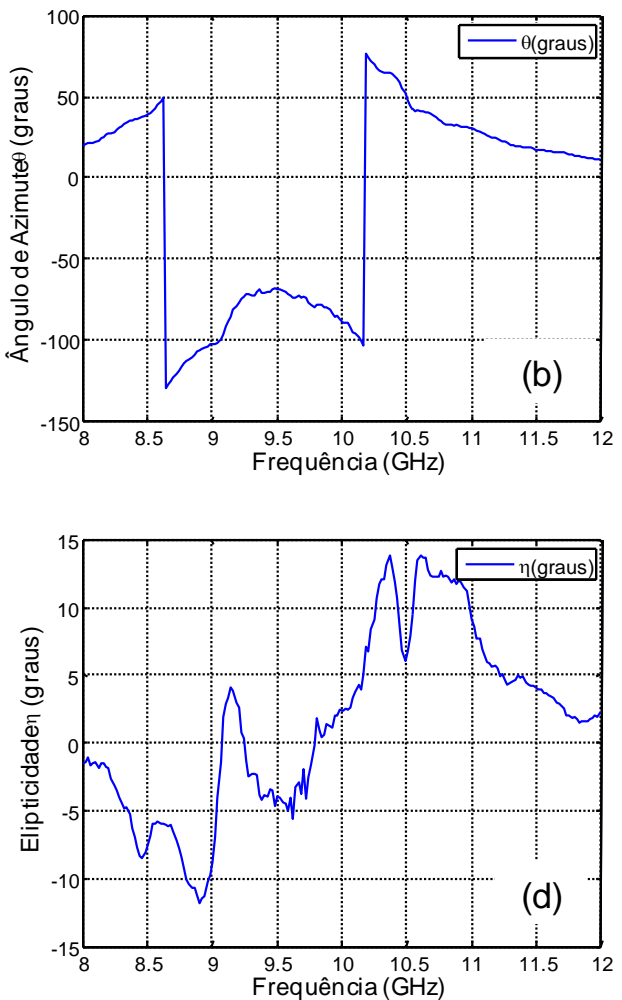

Figura 48 - Valores simulados e experimentais do ângulo de azimute $\theta$ e da elipticidade $\eta$ para a estrutura em ressoadores em forma de cruz em substrato de FR4:(a) Valores simulados do ângulo de azimute $\theta$; (b) Valores experimentais do ângulo de azimute $\theta$; (c) Valores simulados da elipticidade $\eta$; (d) Valores experimentais da elipticidade $\eta$.

Nas curvas do ângulo de azimute $\theta$ (Figura 48(a) e (b)), podem ser verificados valores máximos de rotação de campo de $\theta=100^{\circ}$ nas frequências próximas a 10 $\mathrm{GHz}$ e $\theta=-140^{\circ} \mathrm{em}$ torno de $8,8 \mathrm{GHz}$.

Nos gráficos da elipticidade (Figura 48(c) e (d)), os valores máximos de elipticidade ocorrem nas frequências em torno de $9 \mathrm{GHz}$ e $10,5 \mathrm{GHz}$, apresentando os valores de $\eta=-10^{\circ}$ e $\eta=-8^{\circ}$, respectivamente. 
Simulação
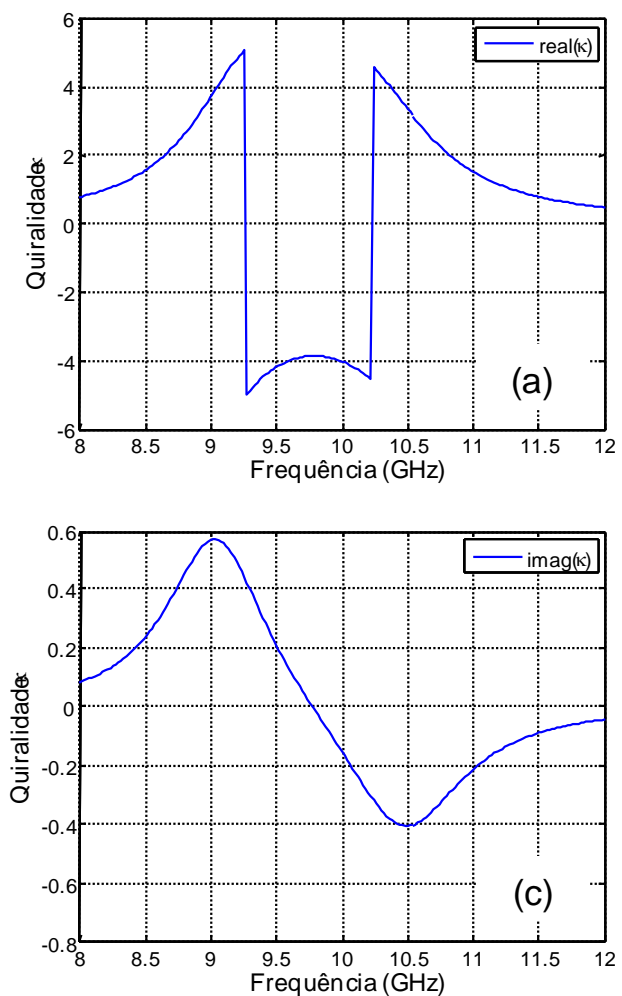

Experimental
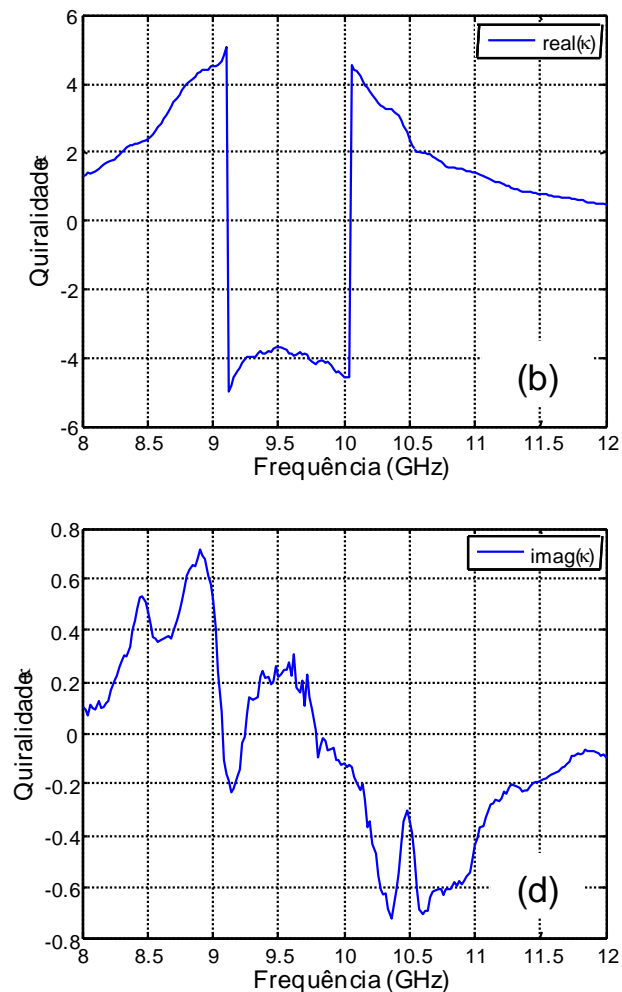

Figura 49 - Valores simulados e experimentais da quiralidade complexa para ressoadores em forma de cruz em substrato de FR4:(a) Valores simulados parte real da quiralidade; (b) Valores experimentais parte real da quiralidade; (c) Valores simulados da parte imaginária da quiralidade; (d) Valores experimentais da parte imaginária da quiralidade.

Nas Figura 49 (a) e (b) são apresentadas as curvas teórica e experimental da parte real da quiralidade, responsáveis pela birrefringência circular e pela rotação de campo da onda transmitida.

As Figura 49 (c) e (d), mostram as curvas referentes à parte imaginária da quiralidade (teórica e experimental), responsáveis pelo dicroísmo circular e elipticidade da onda transmitida.

Os valores de índices de refração para ondas RCP e LCP, por sua vez, foram calculados pelo método de extração de parâmetros e são mostrados na Figura 50. 
Parte Real

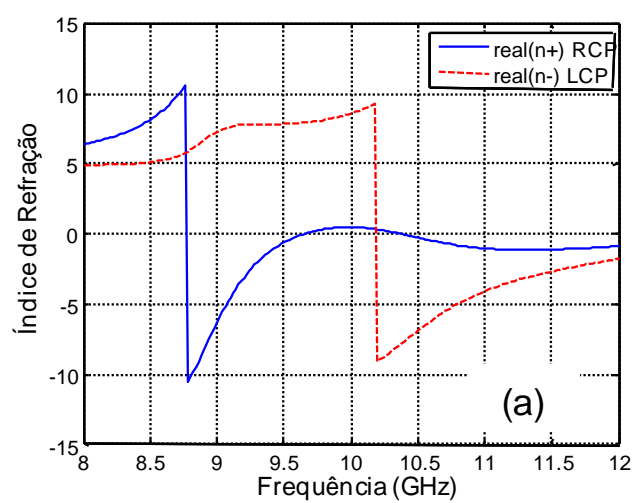

Parte Imaginária

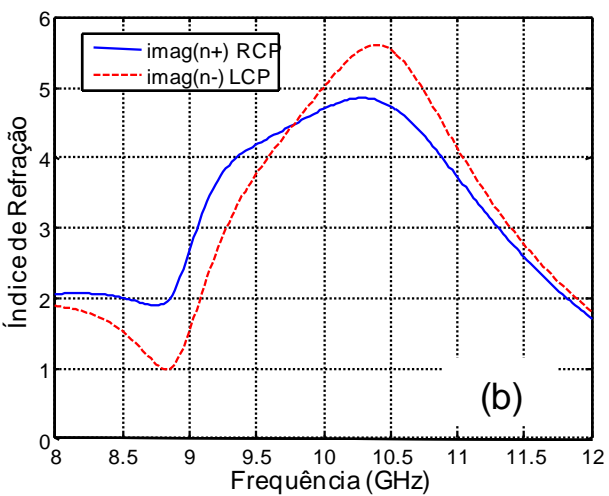

Figura 50 - Valores simulados da parte real e imaginária dos índices de refração para ondas RCP e LCP da estrutura com ressoadores em forma de cruz em substrato de FR4:(a) Parte real dos índices de refração para RCP e LCP; (b) Parte imaginária dos índices de refração para RCP e LCP

Os gráficos da parte real e imaginária do índice de refração para ondas RCL e LCP são mostrados na Figura 50.

Verifica-se na Figura 50 (a), que as partes reais de $n+$ e $n$ - são diferentes em toda a faixa de frequência, por consequência da birrefringência circular do meio. Além disso, são responsáveis pelas diferentes curvas de fase dos coeficientes de transmissão das ondas RCP e LCP (Figura 47 (c) e (d), respectivamente). Verificase ainda a existência valores negativos de índice de refração em para $n+e n-e m$ torno de $9 \mathrm{GHz} 10,5 \mathrm{GHz}$, respectivamente.

Na Figura 50-(b) são apresentados os gráficos da parte imaginária no índice de refração para ondas RCP e LCP. As curvas são diferentes, indicando diferentes atenuações para cada tipo de polarização (dicroísmo circular), o que explica as diferentes magnitudes dos coeficientes de transmissão RCP e LCP (Figura 47 (a) e (b), respectivamente). 


\section{4 - Ressoadores em “Cruz” em Filme fino de Alumínio}

O metamaterial quiral baseado em ressoadores em forma de cruz foi adaptado de [24], para o filme fino de alumínio para o qual a célula unitária projetada apresentou as dimensões: $a_{x}=a_{y}=17 \mathrm{~mm} ; L=15,3 \mathrm{~mm} ; w=0,8 \mathrm{~mm} ; \varphi_{0}=45^{\circ} ; \varphi=$ $10^{\circ} ; \mathrm{t}=4 \mathrm{~mm}$; como mostradas nas Figura 51 (a) e (b). A estrutura completa foi construída com o filme de alumínio e um substrato de baixa densidade, como mostrado na foto da Figura 51 (c).

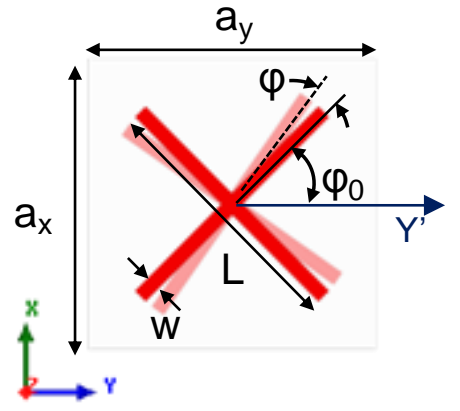

(a)

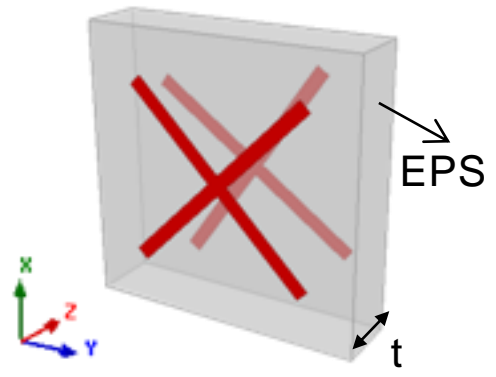

(b)

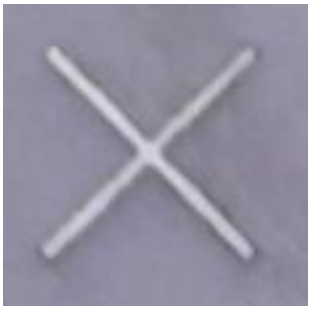

(c)

Figura 51- Célula quiral unitária baseada em ressoadores em cruz com substrato em FR4: (a) Vista frontal: Dimensões: $a_{x}=a_{y}=17 \mathrm{~mm} ; \mathrm{L}=15,3 \mathrm{~mm} ; \mathrm{w}=0,8 \mathrm{~mm} ; \varphi_{0}=45^{\circ} ; \varphi=10^{\circ}$ (b) Vista em perspectiva: $\mathrm{t}=4 \mathrm{~mm}$; (c) Célula construída em filme de alumínio com substrato de baixa densidade.

Esta estrutura em particular não se mostrou muito eficiente na prática devido ao tamanho de sua célula unitária $\left(a_{x}=a_{y}=17 \mathrm{~mm}\right)$, que é um pouco maior que meio comprimento de onda da frequência central da banda de operação $(10 \mathrm{GHz})$, sendo então muito grande para que o metamaterial seja considerado homogêneo.

A caracterização deste modelo foi então realizada inicialmente a partir dos quatro coeficientes de transmissão linear $\left(T_{x x}, T_{x y}, T_{y x}\right.$ e $\left.T_{y y}\right)$, que foram obtidos numérica e experimentalmente, e suas curvas de magnitude são mostradas na Figura 52. 
Simulação
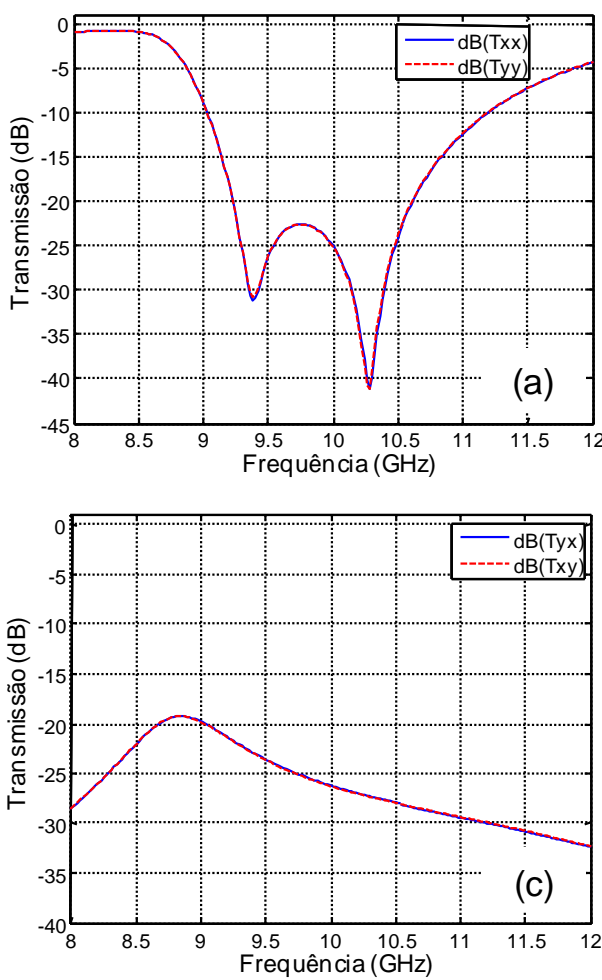

Experimental
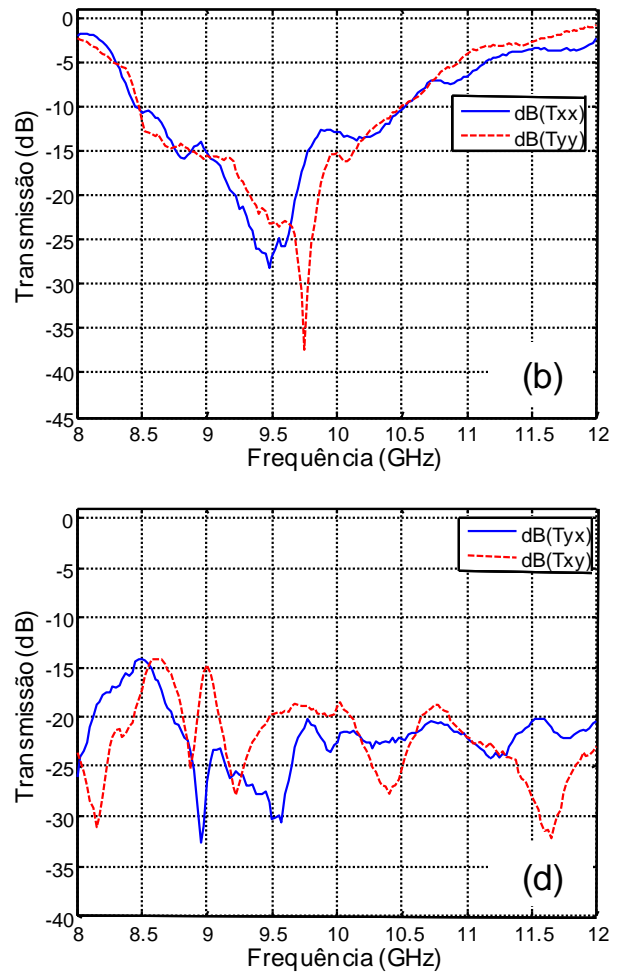

Figura 52 - Medidas numéricas e experimentais da magnitude dos coeficientes de transmissão lineares para ressoadores em forma de cruz em filme de alumínio:(a) Valores simulados de $T_{x x}$ (azul, contínua) e $T_{y y}$ (vermelha, tracejada); (b) Valores experimentais de $T_{x x}$ (azul, contínua) e $T_{y y}$ (vermelha, tracejada); (c) Valores simulados de $\mathrm{T}_{y x}$ (azul, contínua) e $\mathrm{T}_{x y}$ (vermelha, tracejada); (d) Valores experimentais de $T_{y x}$ (azul, contínua) e $T_{x y}$ (vermelha, tracejada)

Devido à simetria rotacional de $90^{\circ}$ que a estrutura quiral em formato de cruz possui, as magnitudes de $T_{x x}$ e $T_{y y}$ são iguais em toda a faixa de frequência, como mostram as Figura 52(a). O mesmo acontece com a magnitude dos coeficientes de transmissão cruzada $T_{y x}$ e $T_{x y}$ (Figura 52(c)). As curvas experimentais correspondentes não se sobrepõem completamente devido a erros inerentes às medidas.

Os coeficientes de polarização circular para RCP e LCP $\left(T_{++}\right.$e $\left.T_{--}\right)$foram calculados a partir dos coeficientes de transmissão linear e seus respectivos gráficos de amplitude e fase são mostrados a seguir na Figura 53. 
Simulação
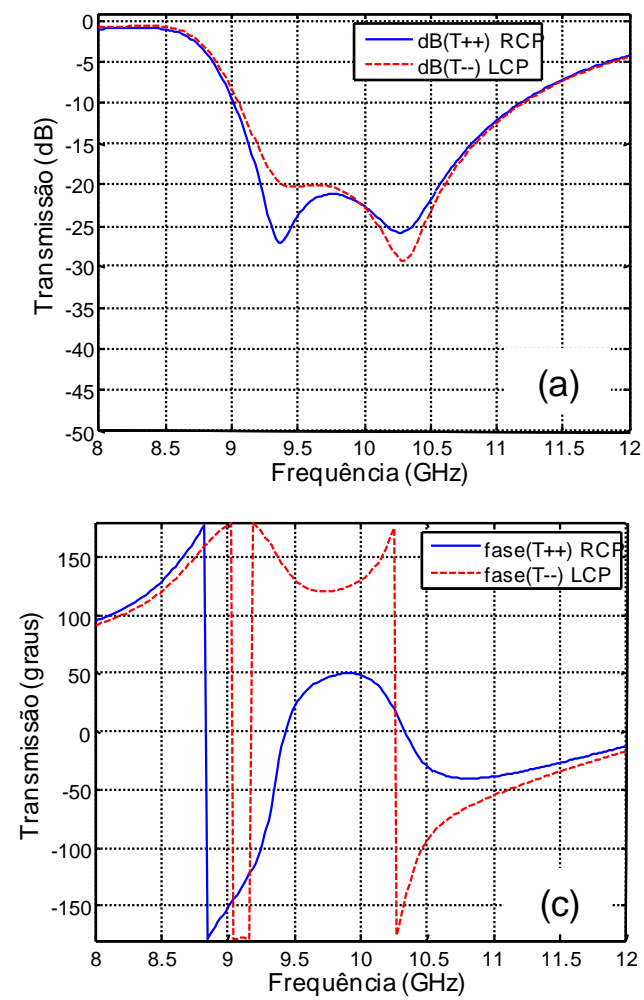

Experimental
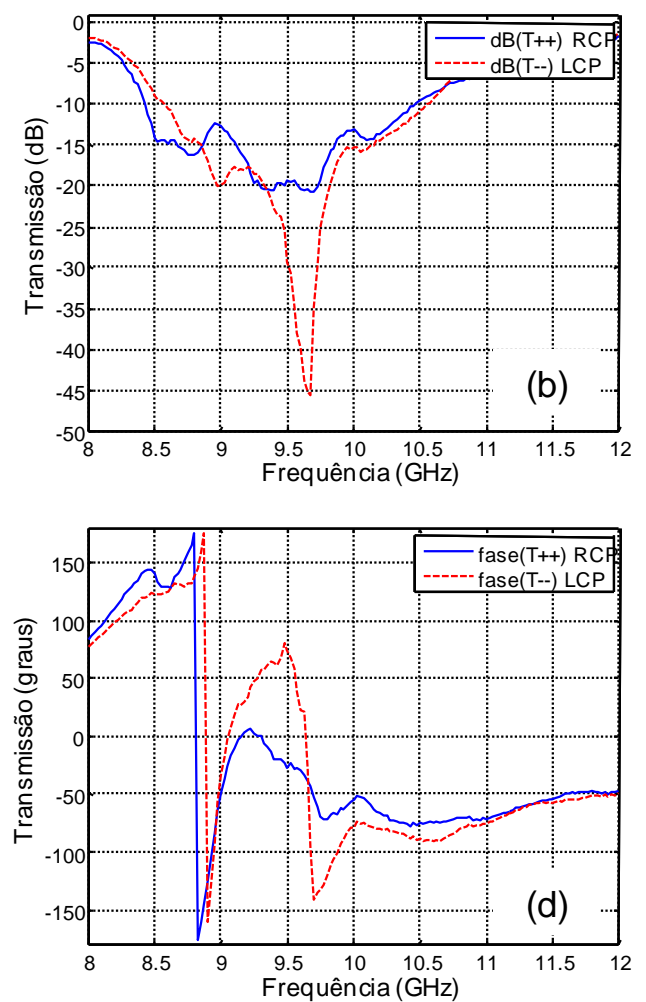

Figura 53 - Valores simulados e experimentais da magnitude e da fase dos coeficientes de transmissão circulares para ressoadores em forma de cruz em filme fino de alumínio:(a) Valores simulados da magnitude de $\mathrm{T}_{++}$(RCP) (azul, contínua) e $\mathrm{T}_{\text {.. }}$ (LCP) (vermelha, tracejada); (b) Valores experimentais da magnitude de $T_{++}(R C P)$ (azul, contínua) e $T_{\text {.. }}(\mathrm{LCP})$ (vermelha, tracejada); (c) Valores simulados da fase de $T_{++}$(RCP) (azul, contínua) e T.. (LCP) (vermelha, tracejada); (d) Valores experimentais da fase de $T_{++}$(RCP) (azul, contínua) e $T_{\text {.- }}$ (LCP) (vermelha, tracejada);

Nas Figura 53(c) e (d) pode-se verificar a diferença entre as curvas de fase da transmissão das ondas RCP e LCP em alguns pontos da faixa de frequência, indicando efeitos de birrefringência circular.

Nas Figura 53(a)e (b), há a sobreposição das curvas de magnitude da transmissão de RCP e LCP, exceto em alguns pontos na região de ressonância, indicando efeitos de dicroísmo circular nessas frequeências.

A partir das equações (21) e (23) foram então calculadas o ângulo de azimute $\theta$ e a elipticidade $\eta$, como mostrados na Figura 54. 
Simulação
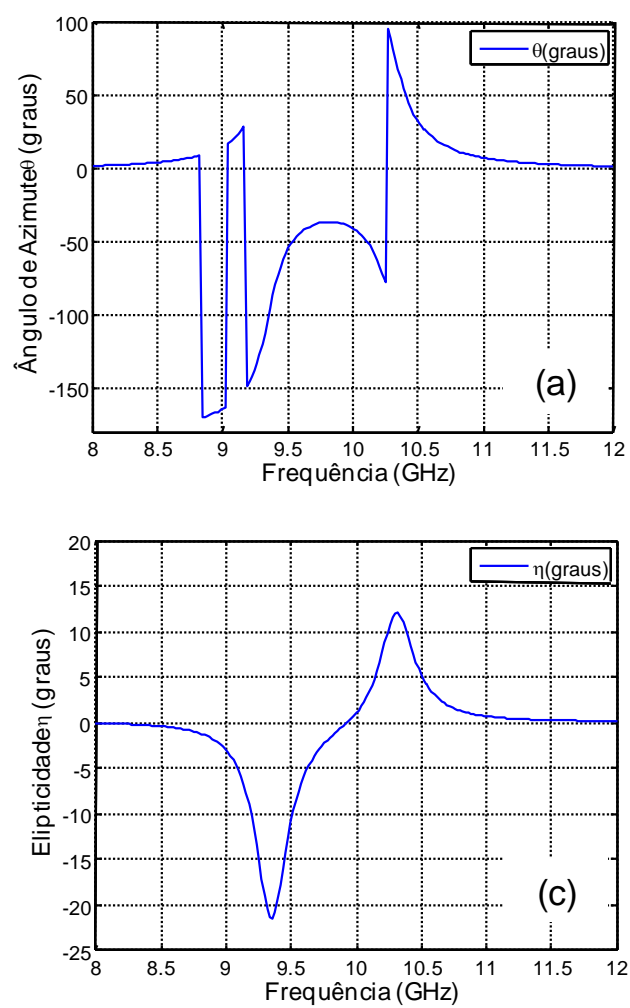

Experimental
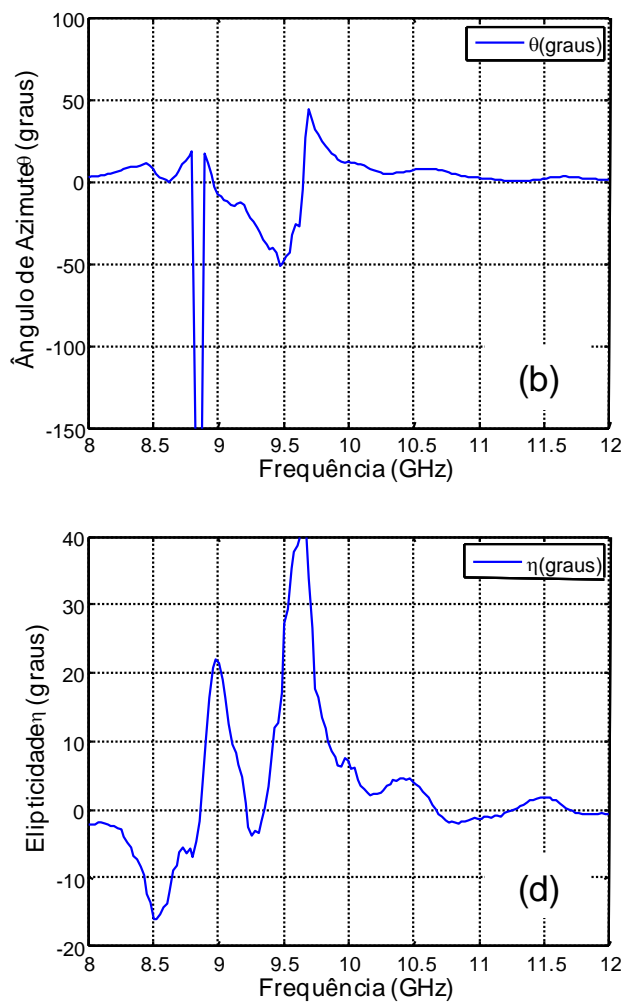

Figura 54 - Valores simulados e experimentais do ângulo de azimute $\theta$ e da elipticidade $n$ para a estrutura em ressoadores em forma de cruz em filme fino de alumínio: (a) Valores simulados do ângulo de azimute $\theta$; (b) Valores experimentais do ângulo de azimute $\theta$; (c) Valores simulados da elipticidade $\eta$; (d) Valores experimentais da elipticidade $\eta$.

Na curva simulada do ângulo de azimute $\theta$, mostrada na Figura 54 (a), podem ser verificados valores máximos de rotação de campo da ordem de $100^{\circ}$ nas frequências próximas a $10,4 \mathrm{GHz}$, e $\theta=-120^{\circ}$ em torno de $9,5 \mathrm{GHz}$. O resultado experimental correspondente (Figura 54 (b)), no entanto, não está como o esperado devido às limitações das medidas experimentais com esse modelo de célula quiral que possui tamanho muito superior ao ideal para ser considerado um material homogêneo para a onda propagante.

Os valores simulados da elipticidade (Figura 54(c)) indicam valores máximos de $\eta=13^{\circ}$ e $\eta=-21^{\circ}$ nas frequências de ressonância. No resultado experimental correspondente, porém, verifica-se um valor máximo de $\eta=40^{\circ}$, decorrente da grande diferença entre as curvas de magnitude RCP e LCP. Esse valor surge em virtude dos erros de medidas que fazem com que $T_{++}$e $T_{--}$apresentem 
magnitudes diferentes em alguns pontos gerando, assim, valores maiores de elipticidade.

Simulação
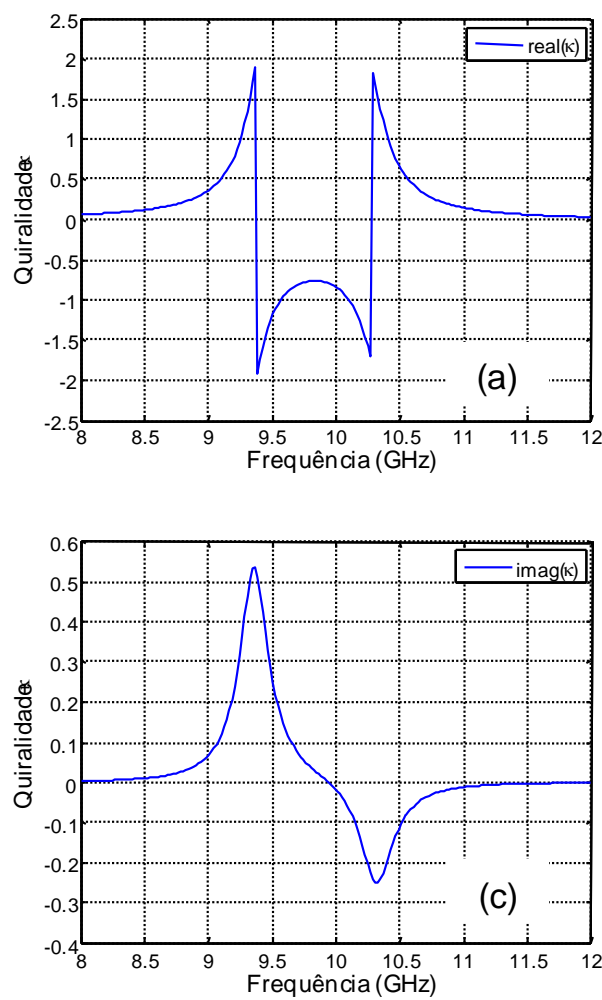

Experimental
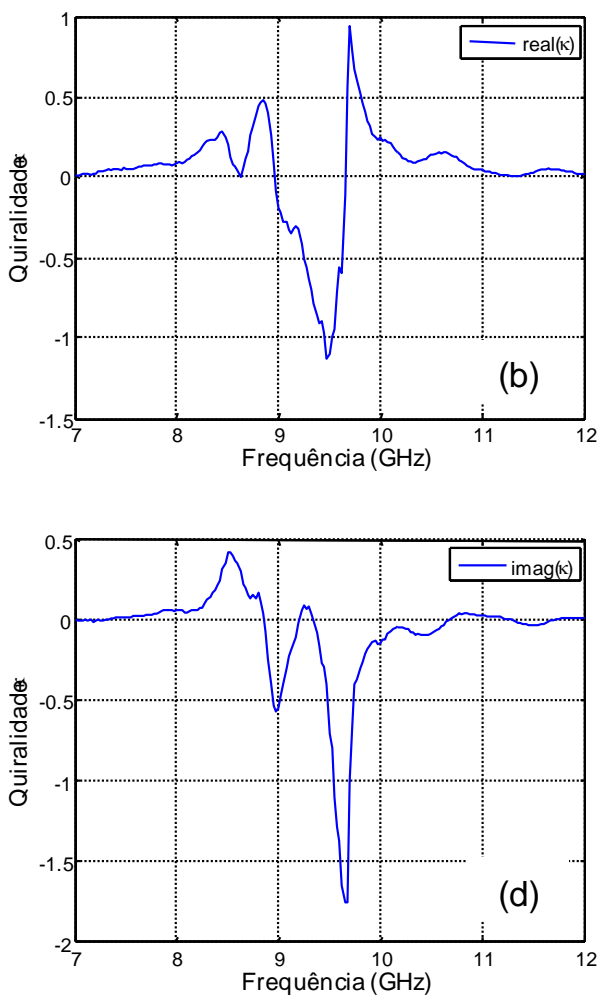

Figura 55 - Valores simulados e experimentais da quiralidade complexa para ressoadores em forma de cruz em filme de alumínio: (a) Valores simulados parte real da quiralidade; (b) Valores experimentais parte real da quiralidade; (c) Valores simulados da parte imaginária da quiralidade; (d) Valores experimentais da parte imaginária da quiralidade.

Os valores simulados da parte real da quiralidade são mostrados na Figura 55-(a) Eles são proporcionais à rotação de campo da onda transmitida sendo, portanto, responsáveis pelo fenômeno da birrefringência circular no metamaterial quiral.. O resultado experimental correspondente, Figura 55 (b), não ficou como esperado devido (em princípio) a três motivos: às limitações das medidas, às grandes dimensões dos ressoadores quirais, e à não homogeneidade do meio efetivo. O mesmo pode ser concluído com respeito ao resultado experimental da parte imaginária da quiralidade (Figura 55 (c) e (d)).

A partir no método de extração de parâmetros, o índice de refração complexo para ondas RCP e LCP foi obtido e os gráficos simulados de sua parte real e imaginária são mostrados na Figura 56. 
Parte Real

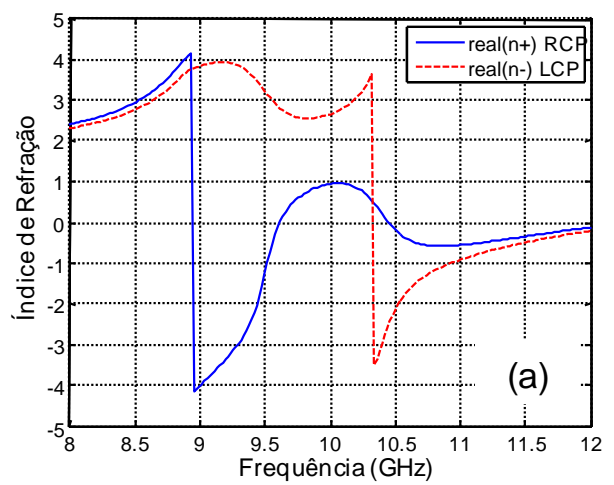

Parte Imaginária

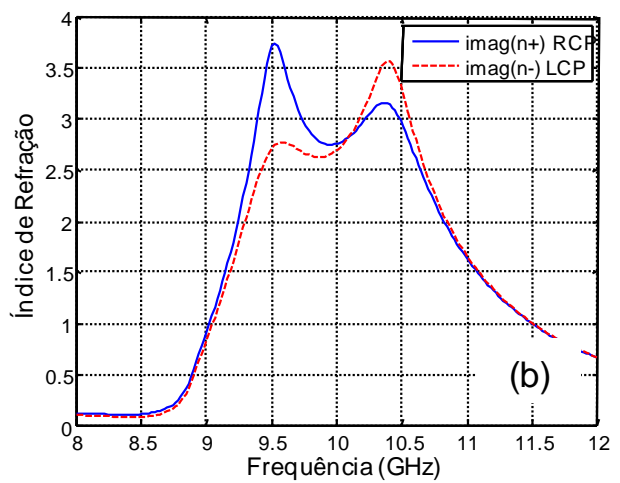

Figura 56 - Valores simulados da parte real e imaginária dos índices de refração para ondas RCP e LCP da estrutura com ressoadores em forma de cruz em filme de alumínio:(a) Parte real dos índices de refração para RCP e LCP; (b) Parte imaginária dos índices de refração para RCP e LCP.

A Figura 56 (a) mostra os valores reais dos índices de refração para ondas RCP e LCP. Por serem curvas diferentes elas indicam o efeito de birrefringência circular do metamaterial em questão. Nota-se ainda valores de índices de refração negativos para RCP e LCP em frequências em torno de $9,3 \mathrm{GHz}$ e $10,5 \mathrm{GHz}$

$\mathrm{Na}$ Figura 56 (b), as curvas da parte imaginária dos índices de refração $\mathrm{n}+\mathrm{e}$ n- não são completamente idênticas, indicando assim, efeitos de dicroísmo circular neste material. Por conta disso, as atenuações nas amplitudes das ondas RCP e LCP foram diferentes, como foi visto nas curvas da Figura 52 (a). 


\section{5 - RESSOADORES DE TRÊS HASTES CURVADAS EM FR4}

Ressoadores quirais formados por hastes curvadas com ângulos de $120^{\circ}$ entre si vêm sendo explorados neste trabalho como candidatos a metamateriais quirais. Essa configuração permite uma maior concentração de campo em suas extremidades favorecendo, assim, um maior acoplamento eletromagnético entre as estruturas localizadas em ambas as faces do substrato. Sua célula unitária apresenta os seguintes parâmetros geométricos: $a_{x}=a_{y}=7,5 \mathrm{~mm} ; L=1,5 \mathrm{~mm} ; r=$ $1,5 \mathrm{~mm}, \mathrm{w}=0,7 \mathrm{~mm} ; \varphi=30^{\circ} ; \mathrm{t}=1,6 \mathrm{~mm}$; como indicados na Figura 57 (a) e (b). A estrutura completa foi construída em placa de FR4 cobreada, como mostrado na foto da Figura 57 (c)

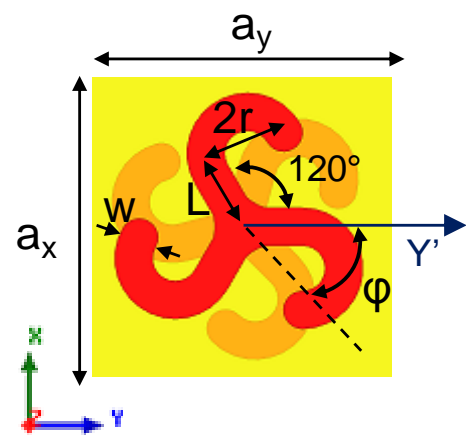

(a)

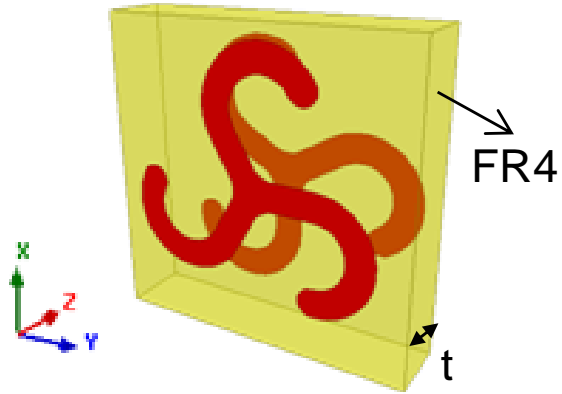

(b)

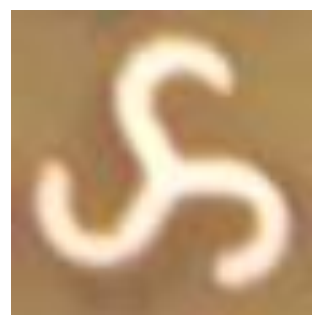

(c)

Figura 57 - Célula quiral unitária baseada em ressoadores de hastes curvadas em FR4: (a) Vista frontal: Dimensões: $a_{x}=a_{y}=7,5 \mathrm{~mm} ; L=1,5 \mathrm{~mm} ; r=1,5 \mathrm{~mm}, w=0,7 \mathrm{~mm} ; \varphi=30^{\circ} ;$ (b) Vista em perspectiva: $\mathrm{t}=1,6 \mathrm{~mm}$; (c) Célula na placa construída em FR4.

A partir das simulações e medidas experimentais, foram obtidos os quatro parâmetros de transmissão lineares $\left(T_{x x}, T_{x y}, T_{y x}\right.$ e $\left.T_{y y}\right)$ e suas curvas de magnitude são mostradas na Figura 58. 
Simulação
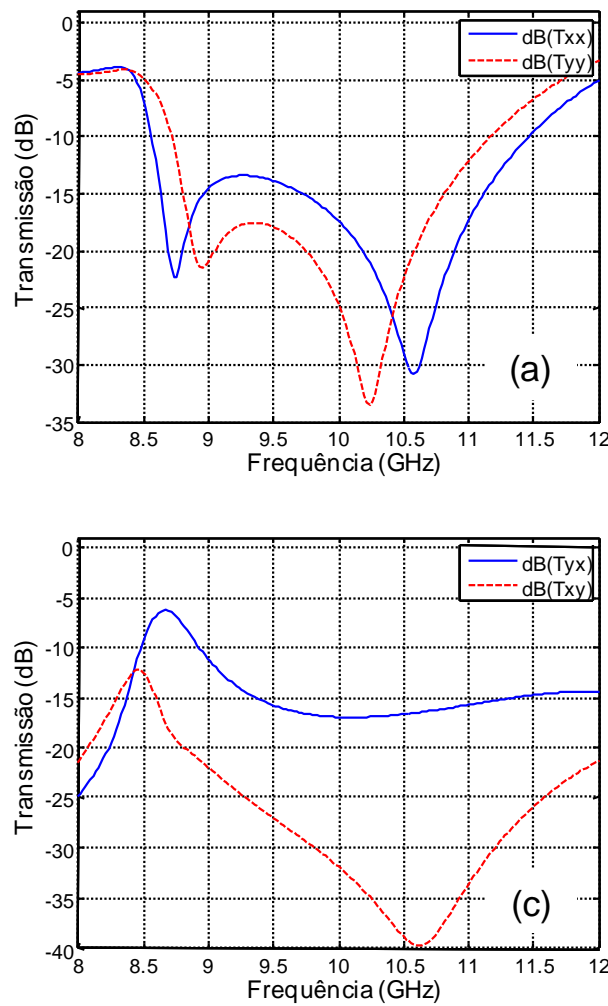

Experimental
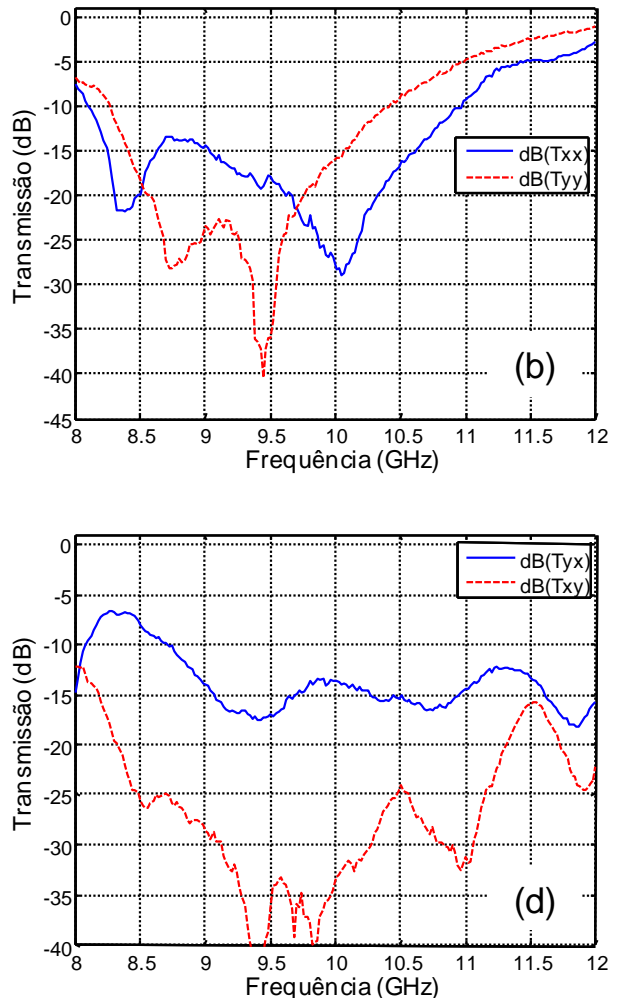

Figura 58 - Medidas numéricas e experimentais da magnitude dos coeficientes de transmissão lineares para ressoadores em forma de hastes triplas curvadas em substrato de FR4: (a) Valores simulados de $\mathrm{T}_{\mathrm{xx}}$ (azul, contínua) e $\mathrm{T}_{\mathrm{yy}}$ (vermelha, tracejada); (b) Valores experimentais de $T_{x x}$ (azul, contínua) e $T_{y y}$ (vermelha, tracejada); (c) Valores simulados de $T_{y x}$ (azul, contínua) e $T_{x y}$ (vermelha, tracejada); (d) Valores experimentais de $\mathrm{T}_{\mathrm{yx}}$ (azul, contínua) e $\mathrm{T}_{\mathrm{xy}}$ (vermelha, tracejada)

Uma vez que o ressoador formado por três hastes curvadas não possui simetria rotacional de $90^{\circ}$, mas sim de $120^{\circ}$, essa célula quiral apresenta imagens diferentes se orientada no eixo $x$ ou no eixo y. Por esse motivo, é de se esperar que o metamaterial apresente diferentes valores para os coeficientes complexos de transmissão linear $T_{x x}$ e $T_{y y}$, como pode ser verificado nos resultados teóricos e experimentais das Figura 58(a) e (b), respectivamente. O mesmo pode ser verificado para os coeficientes de transmissão de polarização cruzada $T_{x y}$ e $T_{y x}$ (Figura 58 (c) e (d)) 
Simulação
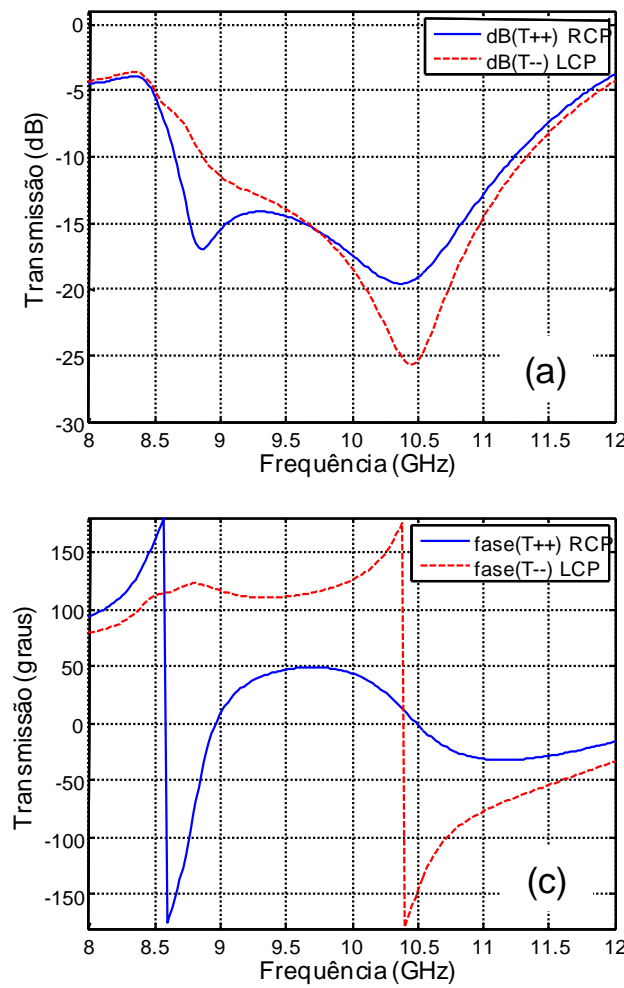

Experimental
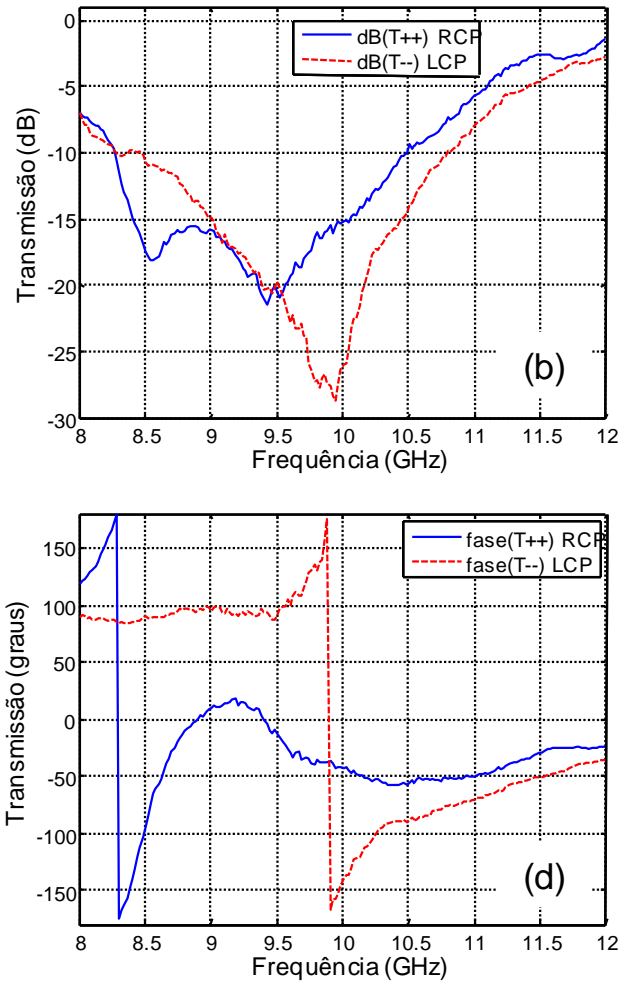

Figura 59 - Valores simulados e experimentais da magnitude e da fase dos coeficientes de transmissão circulares para ressoadores em forma de hastes triplas curvadas em substrato de FR4:(a) Valores simulados da magnitude de $T_{++}$(RCP) (azul, contínua) e $T_{\text {.- }}$ (LCP) (vermelha, tracejada); (b) Valores experimentais da magnitude de $T_{++}$(RCP) (azul, contínua) e T.. (LCP) (vermelha, tracejada); (c) Valores simulados da fase de $\mathrm{T}_{++}$(RCP) (azul, contínua) e T.. (LCP) (vermelha, tracejada); (d) Valores experimentais da fase de $\mathrm{T}_{++}(\mathrm{RCP})$ (azul, contínua) e T.. (LCP) (vermelha, tracejada);

A Figura 59 mostra que o metamaterial baseado em ressoadores de hastes triplas apresenta dicroísmo e birrefringencia circular, o que pode ser verificado, respectivamente, pelas diferentes curvas de magnitude e fasedos coeficientes de transmissão para RCP $\left(T_{++}\right)$e LCP $\left(T_{--}\right)$. Para quantificar esses fenômenos, foram então calculados 0 ângulo de azimute $\theta$ e a elipticidade $\eta$, como mostrado na Figura 60. 
Simulação
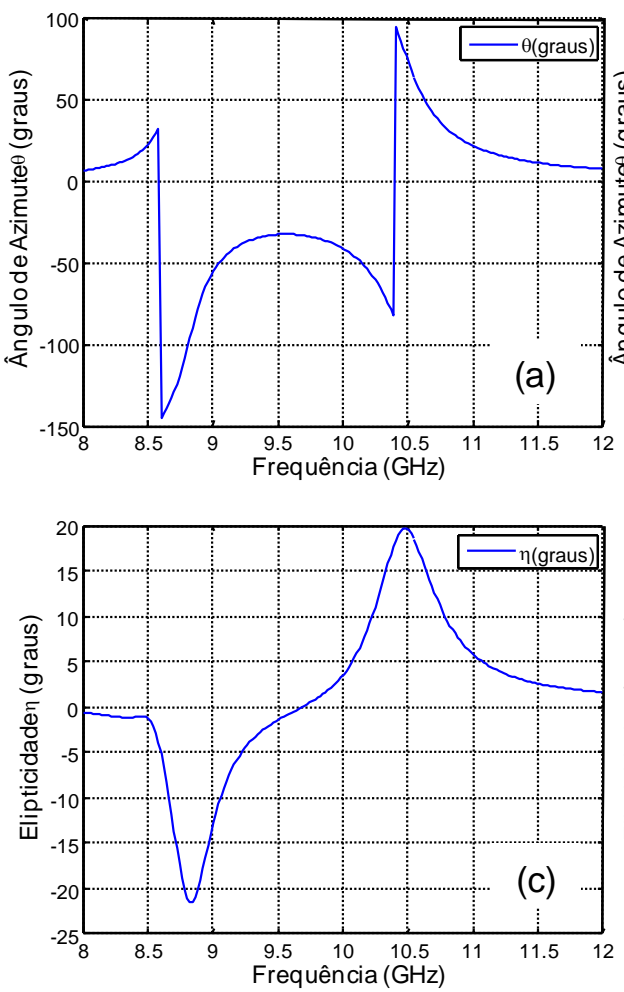

Experimental
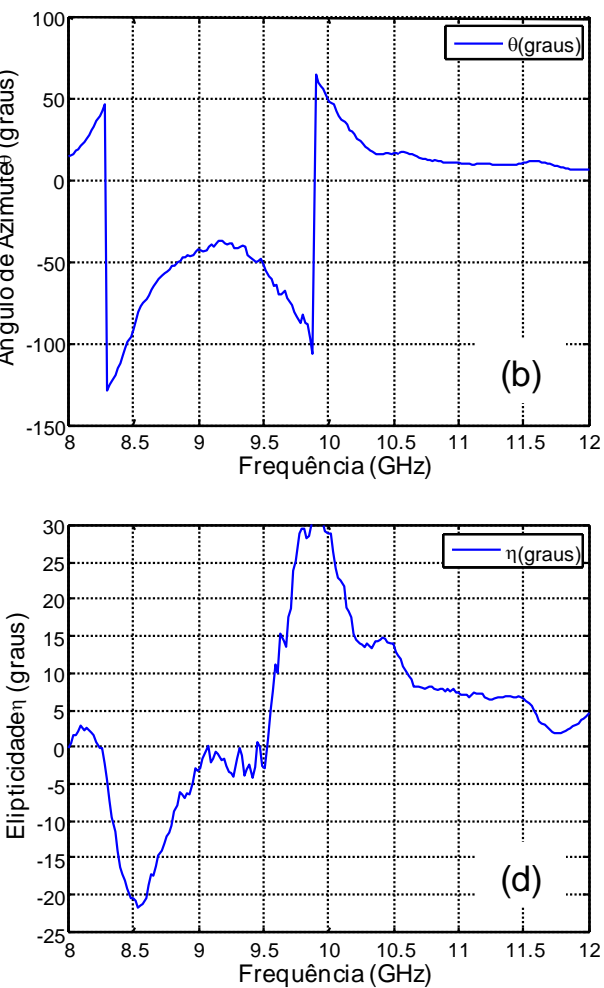

Figura 60 - Valores simulados e experimentais do ângulo de azimute $\theta$ e da elipticidade $\eta$ para a estrutura em ressoadores em forma de hastes triplas curvadas em substrato de FR4:(a) Valores simulados do ângulo de azimute $\theta$; (b) Valores experimentais do ângulo de azimute $\theta$; (c) Valores simulados da elipticidade $\eta$; (d) Valores experimentais da elipticidade $\eta$.

As Figura 60 (a) e (b) mostram as curvas do ângulo de azimute $\theta$ da simulação e da medida experimental, em que podem ser verificados valores máximos de rotação de campo de $\theta=100^{\circ}$ nas frequências próximas a $10 \mathrm{GHz}$ e $\theta=$ $-150^{\circ} \mathrm{em}$ torno de $8,5 \mathrm{GHz}$.

Nas curvas de elipticidade (Figura 60 (c) e (d)), os valores máximos ocorrem nas frequências entre $8,5 \mathrm{GHz}$ e $9 \mathrm{GHz}$, apresentando os valores de $\eta=-22^{\circ}$ e $\eta=$ $20^{\circ}$, respectivamente.

O cálculo da quiralidade complexa foi feito a partir da equação (24) e dos coeficientes de transmissão simulados e medidos. As curvas da sua parte real e imaginária são mostradas na Figura 61. 

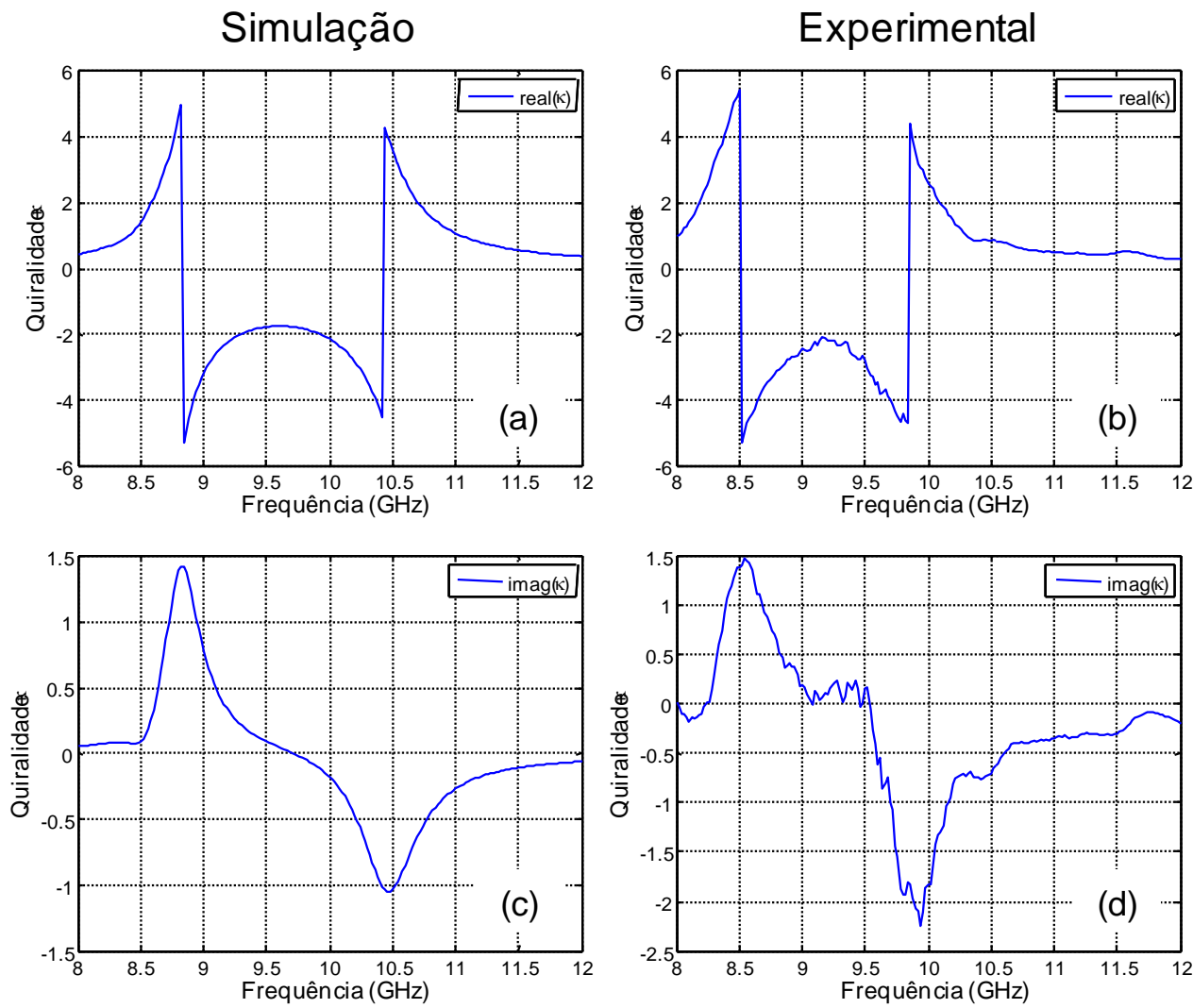

Figura 61- Valores simulados e experimentais da quiralidade complexa para a estrutura em ressoadores em forma de hastes triplas curvadas em substrato de FR4: (a) Valores simulados parte real da quiralidade; (b) Valores experimentais parte real da quiralidade; (c) Valores simulados da parte imaginária da quiralidade; (d) Valores experimentais da parte imaginária da quiralidade.

As Figura 61 (a) e (b) mostram a parte real da quiralidade teórica e experimental, respectivamente, responsável pelo efeito de birrefringência circular do meio quiral artificial.

Nas Figura 61 (c) e (d) são apresentadas as curvas teórica e experimental da parte imaginária da quiralidade, a qual é responsável pelo efeito de dicroísmo circular do metamaterial em questão.

O índice de refração para cada polarização RCP e LCP foi calculado e os gráficos de sua parte real e imaginária são mostrados a seguir na Figura 62. 

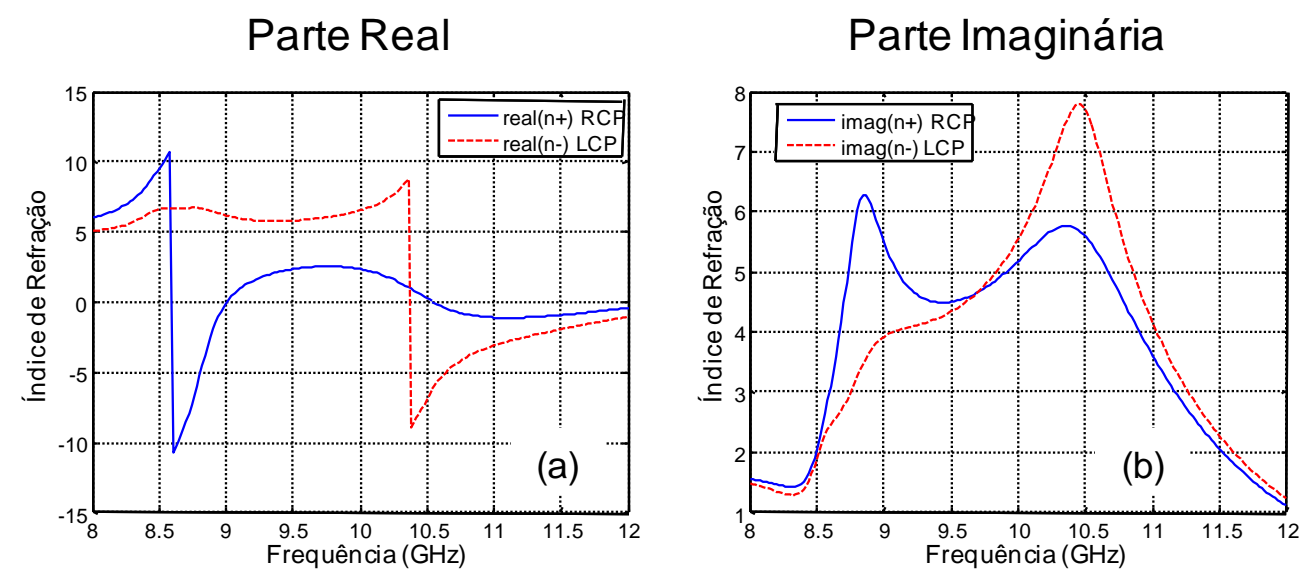

Figura 62 - Valores simulados da parte real e imaginária dos índices de refração para ondas RCP e LCP da estrutura em ressoadores em forma de hastes triplas curvadas em substrato de FR4:(a) Parte real dos índices de refração para RCP e LCP; (b) Parte imaginária dos índices de refração para RCP e LCP.

A parte real de $n+$, bem como a de $n$-, é mostrada na Figura 62(a). A diferença entre as curvas indica o efeito da birrefringência circular, que resulta em diferentes velocidades das ondas RCP e LCP no material. Verifica-se ainda a existência de faixas de índice de refração negativo entre 8,6 GHz e $9 \mathrm{GHz}$ para RCP e a partir de $10,5 \mathrm{GHz}$ para ondas LCP. 


\section{6 - RESSOAdORES DE TRÊS HASTES CURVADAS EM FILME DE ALUMÍNIO}

A célula quiral formada por três hastes curvadas foi modelada tendo resultado na célula unitária mostrada nas Figura 63 (a) e (b), cujos parâmetros geométricos são: $a_{x}=a_{y}=12 \mathrm{~mm} ; L=2,4 \mathrm{~mm} ; r=2,4 \mathrm{~mm}, w=0,6 \mathrm{~mm} ; \varphi=30^{\circ} ; t=4 \mathrm{~mm}$. $A$ estrutura completa foi construída em filme de alumínio com substrato de baixa perda, como mostrado na foto da Figura 63 (c)

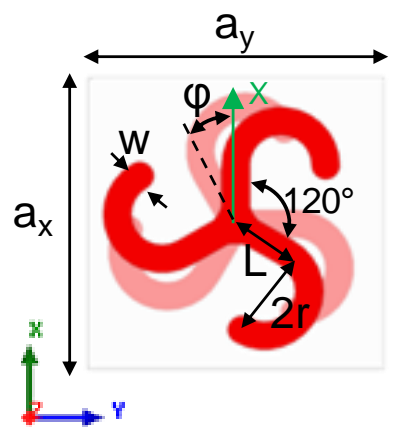

(a)

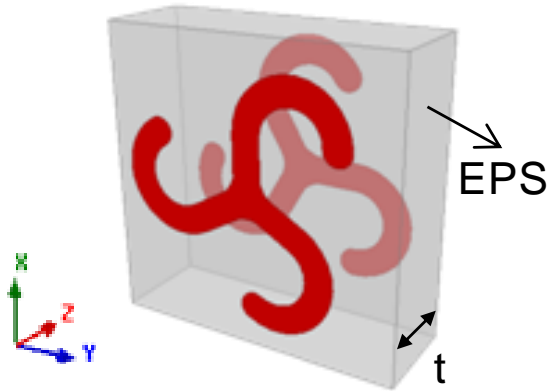

(b)

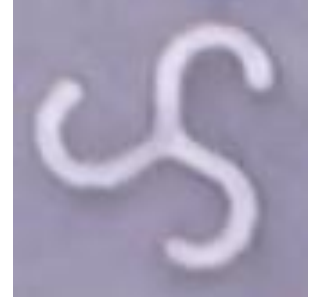

(c)

Figura 63 - Célula quiral unitária baseada em ressoadores de hastes curvadas em filme de alumínio:(a) Vista frontal: Dimensões: $a_{x}=a_{y}=12 \mathrm{~mm} ; \mathrm{L}=2,4 \mathrm{~mm} ; \mathrm{r}=2,4 \mathrm{~mm}, \mathrm{w}=0,6 \mathrm{~mm} ; \varphi=$ $30^{\circ}$; (b) Vista em perspectiva: $\mathrm{t}=4 \mathrm{~mm}$; (c) Célula construída em placa de filme de alumínio.

A partir da célula projetada e construída, foram obtidos inicialmente os parâmetros $T_{x x}, T_{x y}, T_{y x}$ e $T_{y y}$. Os resultados obtidos para suas magnitudes são mostrados na Figura 64. 
Simulação
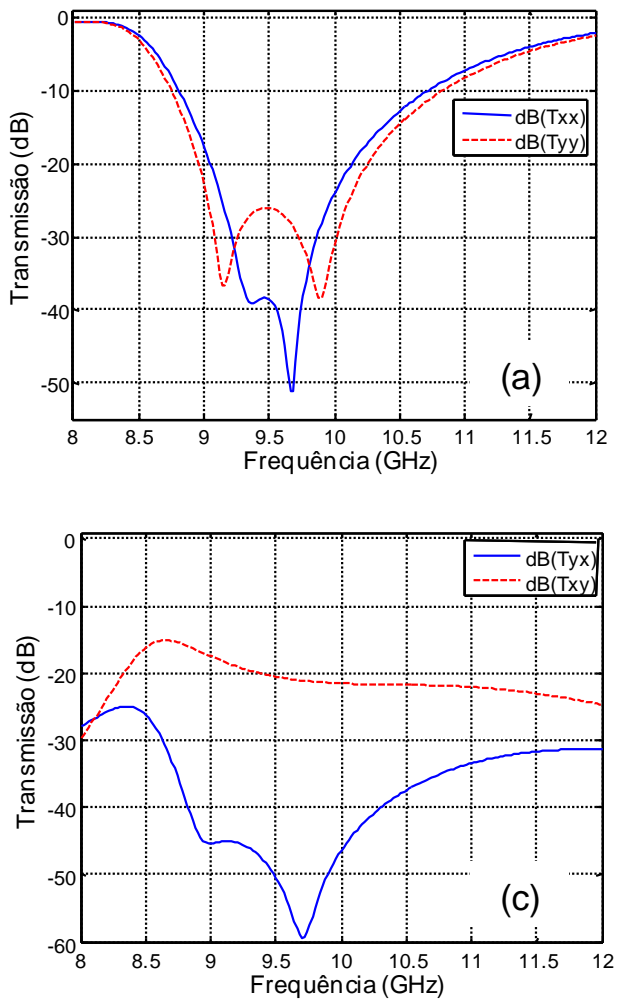

Experimental
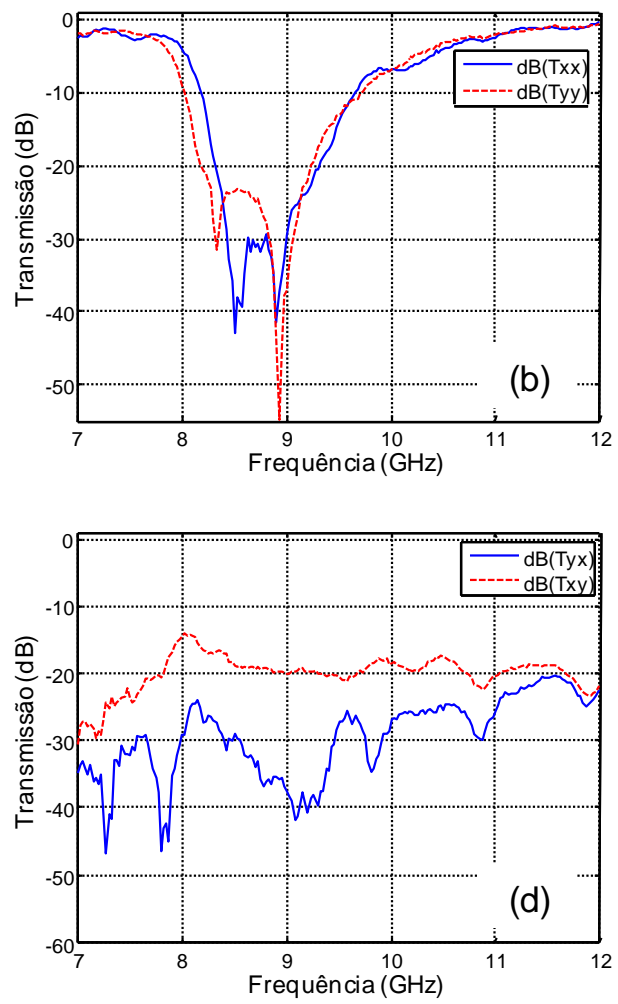

Figura 64 - Medidas numéricas e experimentais da magnitude dos coeficientes de transmissão lineares para ressoadores em forma de hastes triplas curvadas em filme fino de alumínio:(a) Valores simulados de $\mathrm{T}_{\mathrm{xx}}$ (azul, contínua) e $\mathrm{T}_{\mathrm{yy}}$ (vermelha, tracejada); (b) Valores experimentais de $T_{x x}$ (azul, contínua) e $T_{y y}$ (vermelha, tracejada); (c) Valores simulados de $T_{y x}$ (azul, contínua) e $T_{x y}$ (vermelha, tracejada); (d) Valores experimentais de $T_{y x}$ (azul, contínua) e $T_{x y}$ (vermelha, tracejada)

Como esse modelo de célula quiral apresenta imagens diferentes se orientado ao longo do eixo $\mathrm{x}$ ou do eixo $\mathrm{y}$, ele apresenta diferentes valores para os coeficientes complexos de transmissão linear $T_{x x}$ e $T_{y y}$, como pode ser verificado nas curvas simuladas e experimentais das Figura 64 (a) e (b), respectivamente. $\mathrm{O}$ mesmo pode ser verificado para os coeficientes de transmissão de polarização cruzada $T_{x y}$ e $T_{y x}$ (Figura 64 (c) e (d)) 
Simulação
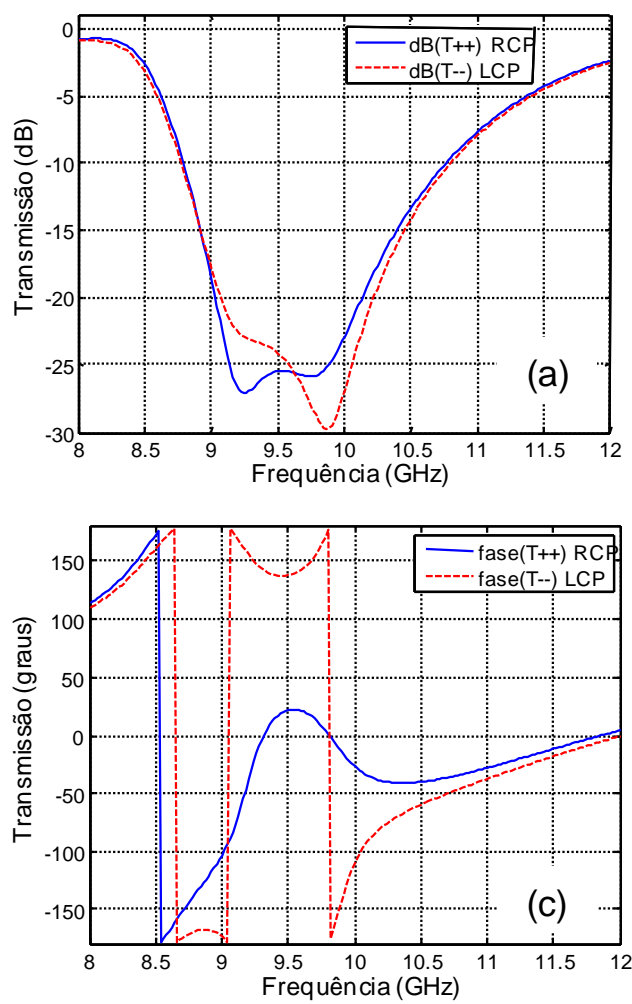

Experimental
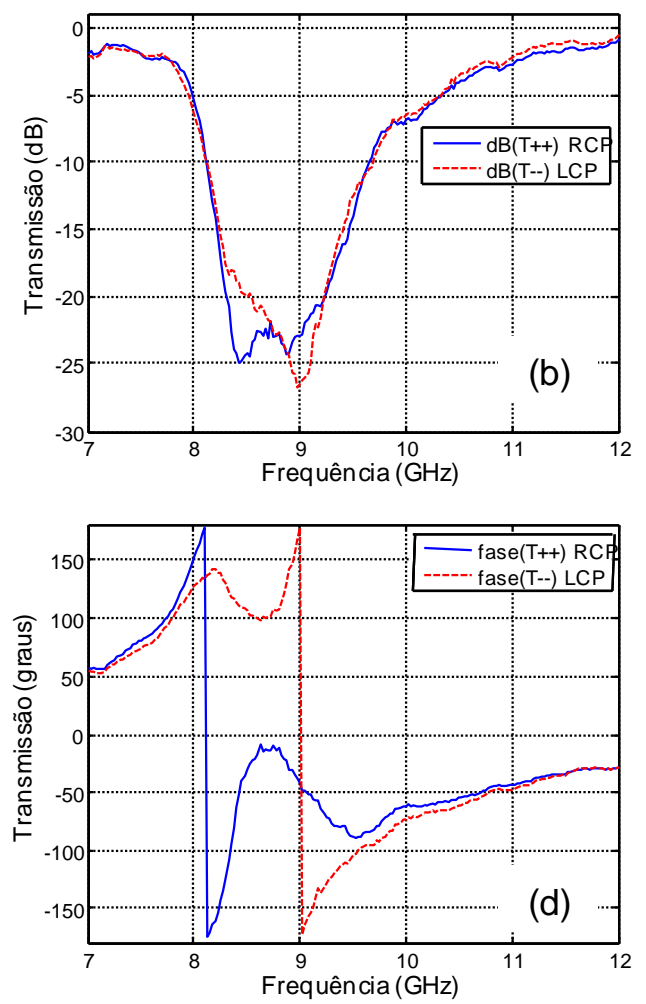

Figura 65 - Valores simulados e experimentais da magnitude e da fase dos coeficientes de transmissão circulares para ressoadores em forma de hastes triplas curvadas em filme fino de alumínio:(a) Valores simulados da magnitude de $T_{++}$(RCP) (azul, contínua) e $T_{\text {.- }}$ (LCP) (vermelha, tracejada); (b) Valores experimentais da magnitude de $\mathrm{T}_{++}$(RCP) (azul, contínua) e $T_{\text {.. }}$ (LCP) (vermelha, tracejada); (c) Valores simulados da fase de $T_{++}$(RCP) (azul, contínua) e T.. (LCP) (vermelha, tracejada); (d) Valores experimentais da fase de $\mathrm{T}_{++}(\mathrm{RCP})$ (azul, contínua) e T.. (LCP) (vermelha, tracejada);

Por meio das curvas das diferentes fases dos coeficientes de transmissão circular, pode-se verificar o efeito da birrefringência circular pela diferença entre as curvas de fase da transmissão das ondas RCP e LCP (Figura 65 (c) e (d)). $O$ efeito do dicroísmo circular deste tipo de metamaterial para o substrato de filme de alumínio é mais sutil, mas pode ser notado nas pequenas diferenças entre as curvas de magnitude da transmissão de RCP e LCP (Figura 65 (a) e (b), respectivamente). A partir desses valores, utilizando-se as equaçoes (21) e (23), foram então calculados o ângulo de azimute $\theta$ e a elipticidade $\eta$, como mostrado na Figura 66 . 
Simulação
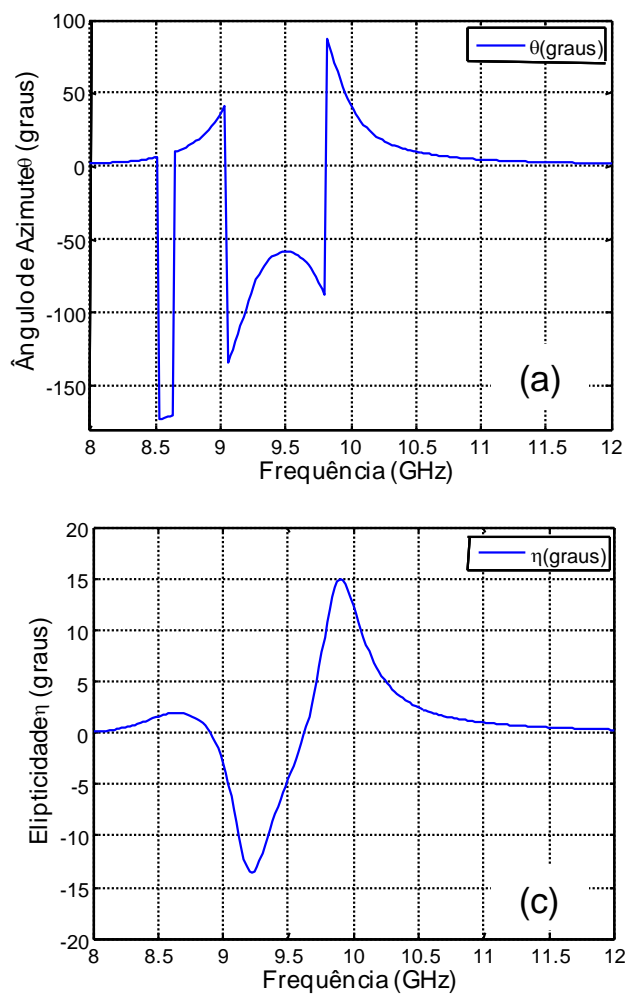

Experimental
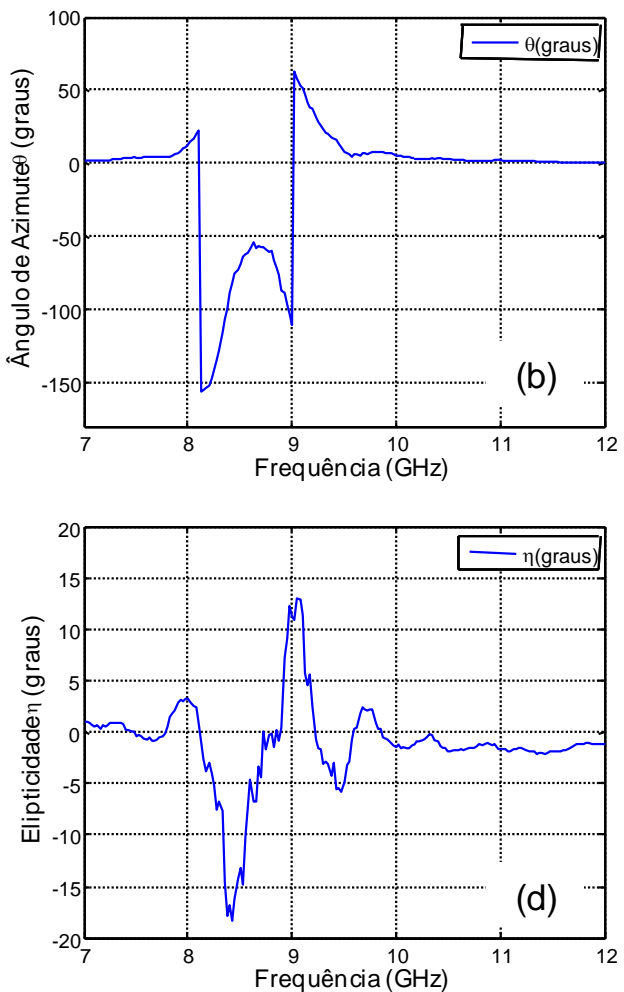

Figura 66 - Valores simulados e experimentais do ângulo de azimute $\theta$ e da elipticidade $\eta$ para a estrutura em ressoadores em forma de hastes triplas curvadas em filme fino de alumínio:(a) Valores simulados do ângulo de azimute $\theta$; (b) Valores experimentais do ângulo de azimute $\theta$; (c) Valores simulados da elipticidade $\eta$; (d) Valores experimentais da elipticidade $\eta$.

As curvas para o ângulo de azimute $\theta$ obtidos teórica e experimentalmente são mostradas, respectivamente, nas Figura 66 (a) e (b)). Na curva teórica podem ser verificados valores máximos de rotação de campo de $\theta=90^{\circ}$ nas frequências próximas a $10 \mathrm{GHz}$, e $\theta=-150^{\circ} \mathrm{em}$ torno de $8,5 \mathrm{GHz}$.

A elipticidade (Figura 66 (c) e (d)) exibe valores entre $\eta=-15^{\circ}$ a $\eta=15^{\circ} \mathrm{em}$ ambos os gráficos teórico e prático.

A quiralidade do metamaterial foi calculada por meio da equação (24) e os resultados são mostrados na Figura 67. 
Simulação
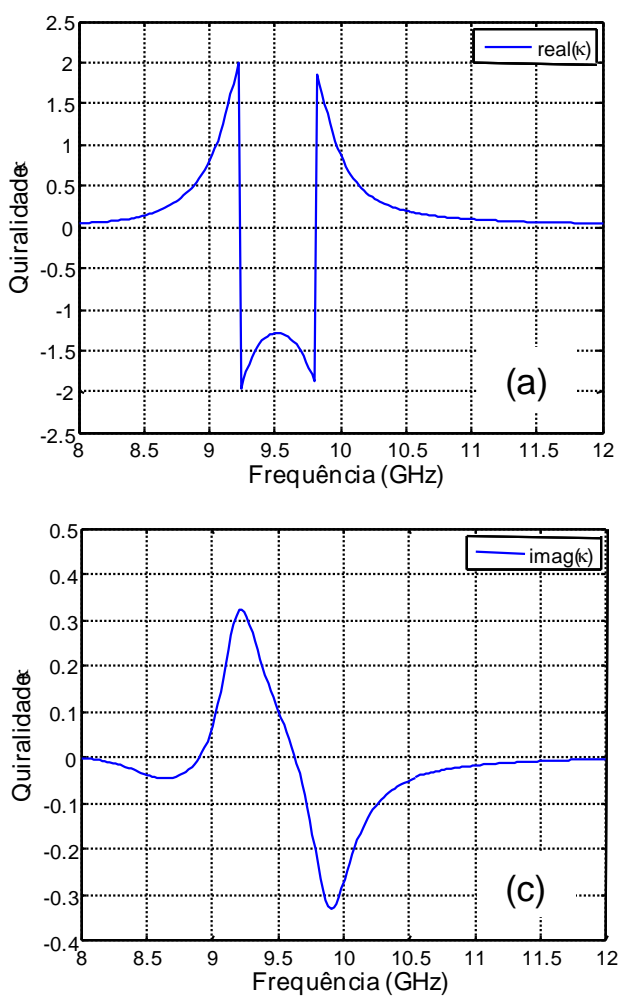

Experimental
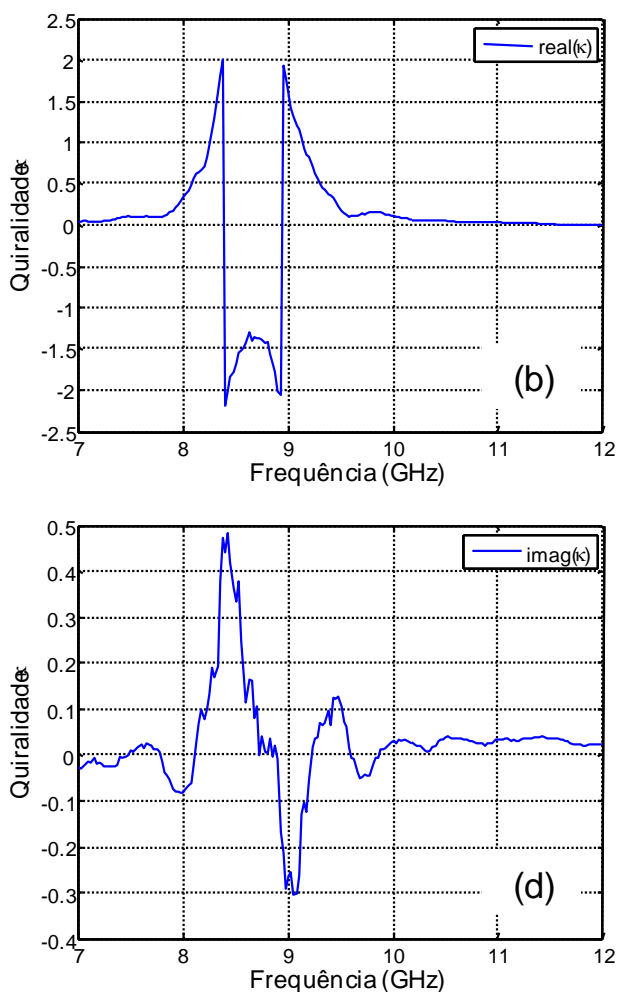

Figura 67 - Valores simulados e experimentais da quiralidade complexa para a estrutura com ressoadores em forma de hastes triplas curvadas em filme fino de alumínio:(a) Valores simulados parte real da quiralidade; (b) Valores experimentais parte real da quiralidade; (c) Valores simulados da parte imaginária da quiralidade; (d) Valores experimentais da parte imaginária da quiralidade.

Os resultados teóricos e experimentais para a parte real da quiralidade são mostrados nas Figura 67 (a) e (b), respectivamente. Por sua vez, os resultados teóricos e experimentais para a parte imaginária da quiralidade são mostrados nas Figura 67 (c) e (d), respectivamente.

O índice de refração desse modelo de metamaterial foi extraído a partir dos coeficientes de transmissão e reflexão simulados, e as curvas obtidas são mostradas na Figura 68. 


\section{Parte Real}

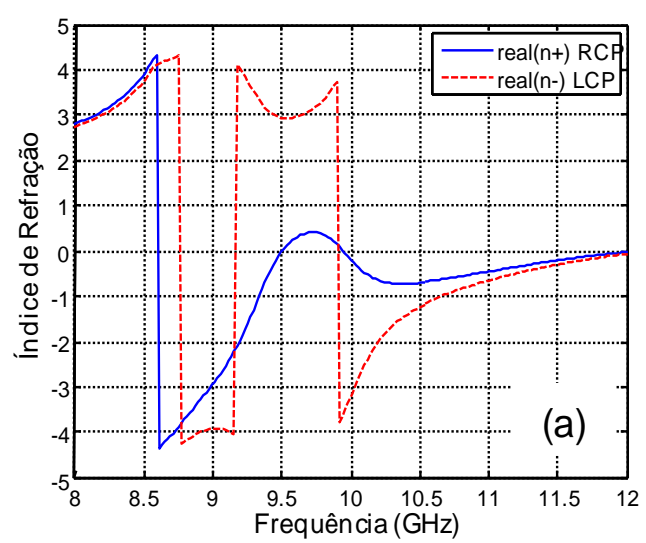

Parte Imaginária

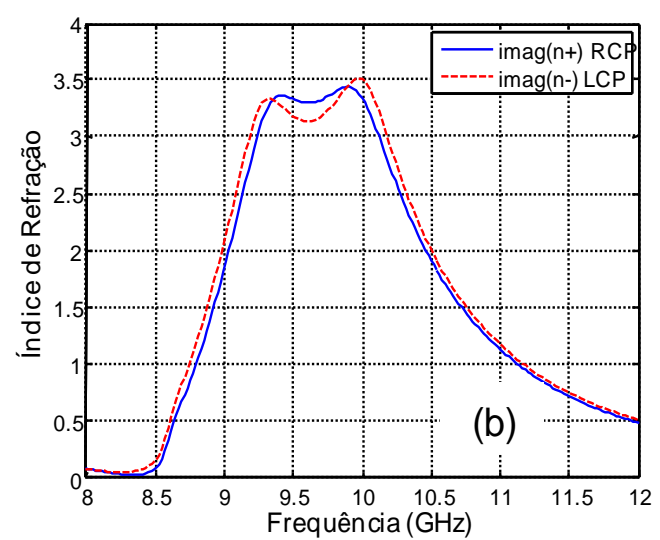

Figura 68 - Valores simulados da parte real e imaginária dos índices de refração para ondas RCP e LCP da estrutura em forma de hastes triplas curvadas em filme fino de alumínio:(a) Parte real dos índices de refração para RCP e LCP; (b) Parte imaginária dos índices de refração para RCP e LCP.

$\mathrm{Na}$ Figura 68-(a) pode-se verificar a diferença entre as partes reais dos índices de refração, evidenciando o efeito da birrefringência circular do metamaterial quiral. Nota-se ainda refração negativa para ondas RCP e LCP em torno de $9 \mathrm{GHz}$ e $10 \mathrm{GHz}$, respectivamente.

A parte imaginária de $\mathrm{n}+$, bem como de $\mathrm{n}$-, é mostrada na Figura 68 (b), em que se verifica uma diferença entre as curvas em alguns pontos. Isso implica em um efeito de dicroísmo circular, proporcionando diferentes atenuações nas ondas RCP e LCP nesse metamaterial como sugerem as curvas de transmissão vistas nas Figura 65 (a) e (b). 


\section{6 - DiscuSSÕES DOS RESULTADOS}

De um modo geral, as curvas experimentais estiveram de acordo com as curvas das simulações. Todas as estruturas demonstraram efeitos de quiralidade, rotação de campo e índices de refração negativos, inclusive as estruturas construídas pelo método proposto neste trabalho.

As diferenças entre os dados medidos e simulados aparecem devido aos seguintes efeitos:

- nas análises computacionais, o arranjo periódico de ressoadores é considerado infinito por causa das condições de contorno, enquanto na prática, o metamaterial possui um tamanho limitado;

- as placas de metamateriais podem apresentar pequenos defeitos no processo de fabricação, como desalinhamentos dos ressoadores pelas diferentes dilatações térmicas entre o papel transfer utilizado e as superfícies metálicas dos substratos causados com a alta temperatura na etapa de prensagem. (Vide Apêndice I e II)

- nas simulações a onda eletromagnética incidente é perfeitamente plana, enquanto que nas medidas práticas com antenas, a onda emitida não é perfeitamente plana;

- as antenas utilizadas não apresentavam precisão suficientes satisfatória, além disso, não foi utilizado nenhum recurso focalizador do feixe de microondas;

- as medidas experimentais foram feitas sem o uso de câmara anecoica. Sendo assim, os resultados podem estar contaminados por interferências externas ou até mesmo pelas próprias reflexões do sinal nas paredes e móveis do laboratório;

- os substratos utilizados na prática podem apresentar valores de permissividades ligeiramente diferentes dos valores utilizados nas simulações, causando assim, uma pequena diferença translacional entre os respectivos gráficos; 
No caso particular da estrutura com ressoadores em forma de cruz em filme de alumínio, as medidas experimentais ficaram completamente fora do esperado devido às grandes dimensões dos ressoadores, que são quase da ordem do comprimento de onda na frequência de operação. Isso faz com que o metamaterial deixe de ser considerado homogêneo. Além disso, por ser fabricado em uma placa de tamanho definido de $150 \times 150 \mathrm{~mm}$, o metamaterial ficou constituído por poucos ressoadores resultando, assim em uma baixa densidade de células. As simulações computacionais, no entanto, exibiram boas respostas devido à periodicidade infinita proporcionada pelas condições de contorno do programa. Por outro lado, os outros modelos de células se mostraram mais compactos e exibiram respostas esperadas. 


\section{7 - APLICAÇÕES EM BIOSSENSORES}

Nas Figura 69 e Figura 70 são mostradas as duas células unitárias quirais investigadas para o biossensor. Cada célula unitária é formada por três camadas, sendo duas camadas de material dielétrico (FR4) e, entre elas, uma camada que representa a amostra biológica a ser analisada (analito). Em ambos os casos, dois ressoadores metálicos localizam-se nas interfaces das placas do dielétrico que estão em contato com o analito. A primeira estrutura (Figura 69) consiste de um arranjo de três segmentos em ângulo de $120^{\circ}$ (hastes triplas curvadas). As extremidades das três hastes foram curvadas de modo a maximizar o efeito de rotação de campo. A segunda estrutura (Figura 70), adaptada de [24] consiste de uma estrutura de fios cruzados.

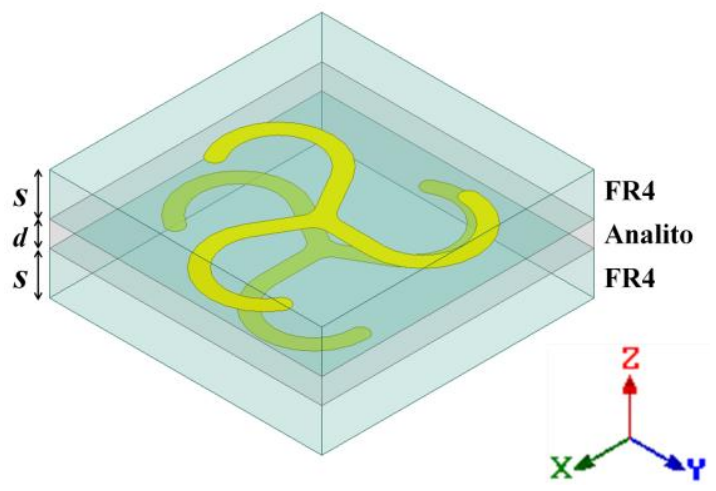

Figura 69 - Vista em 3D das células unitárias de hastes triplas curvadas, cujas dimensões são: $s=$ $1.6 \mathrm{~mm}$ e $d=1.2 \mathrm{~mm}$.

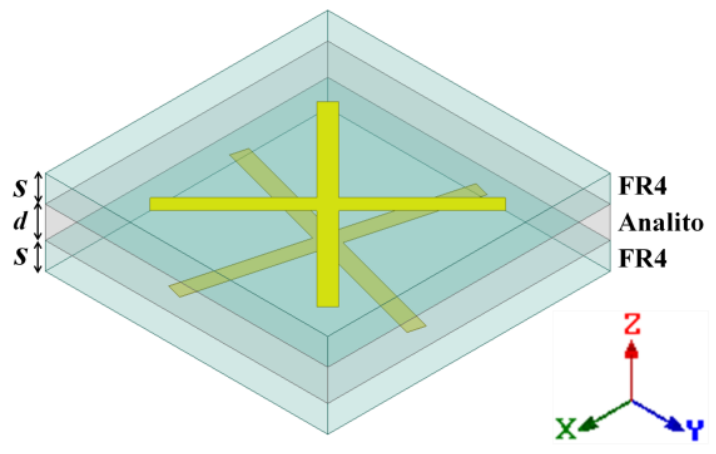

Figura 70 - Vista em 3D das células unitárias de fios cruzados, cujas dimensões são: $s=1.6 \mathrm{~mm}$ e $d$ $=1.8 \mathrm{~mm}$. 
Nas Figura 71 e Figura 72 são apresentados mais detalhes das células unitárias para os casos propostos. Cada estrutura possui dois ressoadores idênticos, porém, posicionados com um ângulo $\varphi$ de diferença entre si. É exatamente este ângulo que permite a rotação de campo e, portanto, deve ser otimizado para melhorar o desempenho da estrutura.

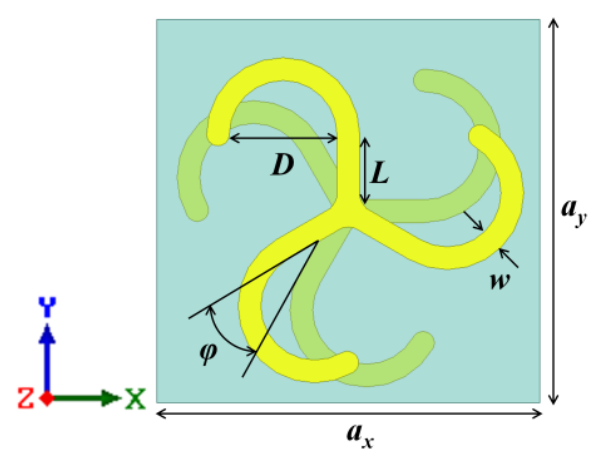

Figura 71 - Vista superior da célula de hastes triplas curvadas, cujas dimensões são: $L=1.6 \mathrm{~mm}, D=$ $3.2 \mathrm{~mm}, a_{x}=a_{y}=8 \mathrm{~mm}, w=0.5 \mathrm{~mm}, \varphi=30^{\circ}$.

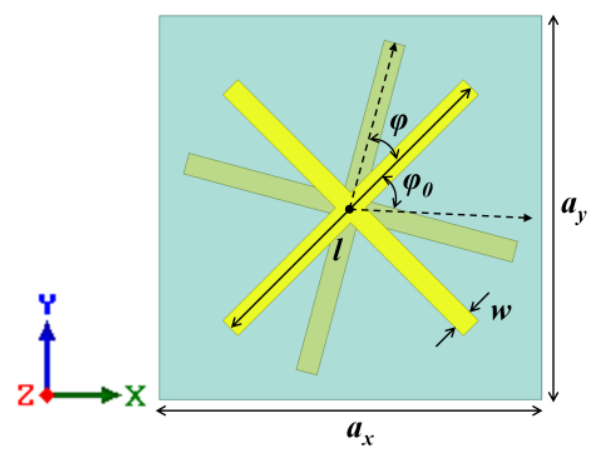

Figura 72 - Vista superior da célula de fios cruzados, cujas dimensões são: $I=16 \mathrm{~mm}, w=1 \mathrm{~mm}, \varphi=$ $30^{\circ}, \varphi_{0}=45^{\circ}$.

As simulações computacionais foram realizadas no software Ansoft High Frequency Structure Simulator (HFSS), baseado no método de elementos finitos. Cada uma das células unitárias foi configurada com condições de contorno periódicas resultando, assim, na análise de um arranjo infinito de dupla periodicidade nos eixos $x$ e $y$. Foi considerada uma fonte de excitação de onda plana se propagando na direção do eixo $z$, configurando uma incidência perpendicular à estrutura.

Por meio de análises paramétricas, as dimensões das estruturas foram ajustadas de modo que a ressonância ocorra na frequência analisada de $1,7 \mathrm{GHz}$ obtendo-se, assim, o maior ângulo de azimute possível para essa frequência. 
A constante dielétrica do substrato de FR4 foi considerada como um valor fixo de $\varepsilon_{r}=4,4$ e sua tangente de perdas $\tan \delta=0,02$. No intuito de reduzir o custo computacional da simulação, os ressoadores metálicos receberam a condição de contorno de Condutor Elétrico Perfeito (PEC) uma vez que, operando na faixa de micro-ondas, os metais se comportam como tal.

O material biológico analisado foi uma solução aquosa de glicose que, a partir de suas propriedades dielétricas, pode ser representada na simulação numérica. A permissividade elétrica relativa da solução de glicose, em função da sua concentração, é dada por [53]:

$$
\varepsilon_{g}=\left(\varepsilon_{w}^{\prime}+c \delta^{\prime}\right)-j\left(\varepsilon_{w}^{\prime \prime}+c \delta^{\prime \prime}\right)
$$

em que $\varepsilon_{w}$ é a permissividade da água pura para $1,7 \mathrm{GHz}$ e $25{ }^{\circ} \mathrm{C} \quad\left(\varepsilon_{w}^{\prime}=77,75 \mathrm{e}\right.$ $\left.\varepsilon_{w}^{\prime \prime}=6,4\right) ; c$ é o valor da concentração de glicose (em $\left.\mathrm{mg} / \mathrm{ml}\right)$; e $\delta$ é o coeficiente que indica o acréscimo na permissividade da solução quando a concentração aumenta em uma unidade $\left(\delta^{\prime}=0,0577\right.$ e $\left.\delta^{\prime \prime}=0,0015\right)$. A Eq. (47) é válida para concentrações na faixa de 0 a $300 \mathrm{mg} / \mathrm{ml}$.

O funcionamento do sensor está baseado no fato de que a variação da concentração de glicose modifica o valor da permissividade da camada de analito alterando, assim, o grau de interação entre os ressoadores. Portanto, como a resposta do metamaterial quiral depende dessa interação, haverá uma variação do acoplamento de campo e, consequentemente, da rotação do azimute de polarização da onda propagante. Dessa forma, a concentração de glicose pode ser inferida por meio do estado do azimute da onda transmitida.

As simulações com o sensor foram realizadas analisando-se estruturas de hastes triplas e de fios cruzados ilustradas nas Figura 69 e Figura 70, respectivamente. Em cada situação, incidiu-se uma onda plana de $1,7 \mathrm{GHz}$ sobre o metamaterial e variou-se a concentração de glicose da camada de analito, no intervalo de 0 a 300 $\mathrm{mg} / \mathrm{ml}$ (com passos de $10 \mathrm{mg} / \mathrm{ml}$ ). A partir da onda transmitida mediu-se, então, o ângulo de azimute $\theta$ em função da concentração da solução.

Nas Figura 73 e Figura 74 são apresentados os resultados das simulações das estruturas das Figura 69 e Figura 70, respectivamente. As curvas mostram a variação 
da rotação do azimute de polarização em função da concentração de glicose.

Essa análise foi realizada para diferentes distâncias $d$ entre os ressoadores quirais, definida aqui como a espessura da camada de analito. Os valores de $d$ foram escolhidos a partir de análises paramétricas de cada estrutura, de forma que a faixa de operação de cada uma delas ficasse dentro do intervalo de concentração de glicose de interesse (0 a $300 \mathrm{mg} / \mathrm{ml}$ ). Na Figura 73, para a estrutura com configuração de hastes triplas, o valor de $d$ foi variado entre 1,0 e $1,5 \mathrm{~mm}$. Na Figura 74, para a estrutura com configuração de fios cruzados, o valor de $d$ foi variado entre 1,5 e 2,2 mm.

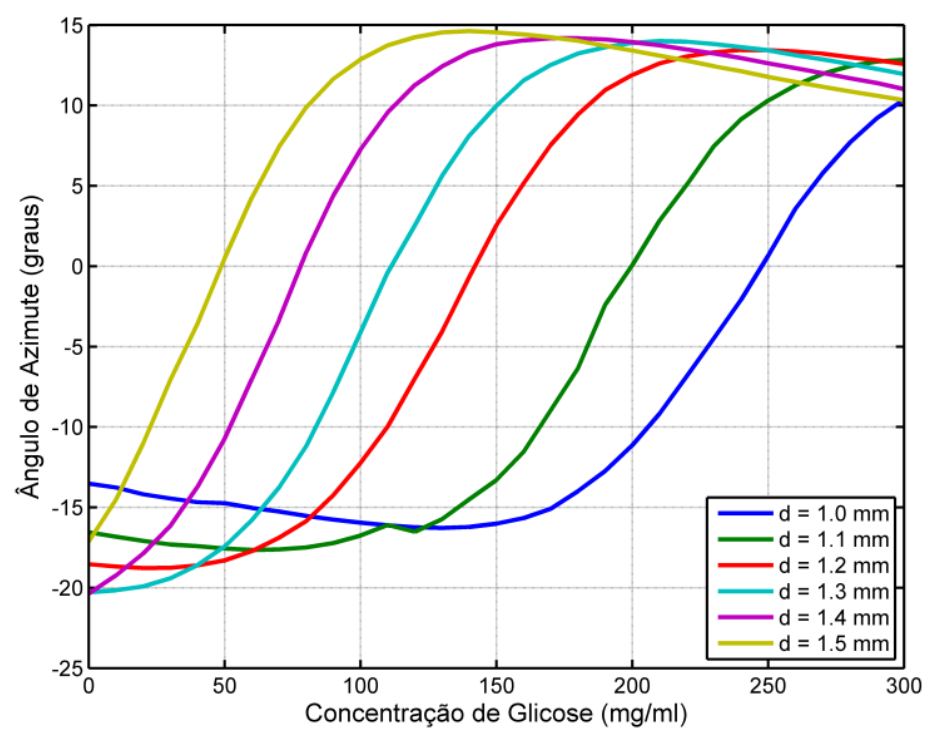

Figura 73 - Ângulo de azimute $\theta$ em função da concentração de glicose de 0 a $300 \mathrm{mg} / \mathrm{ml}$ para a configuração de hastes triplas. 


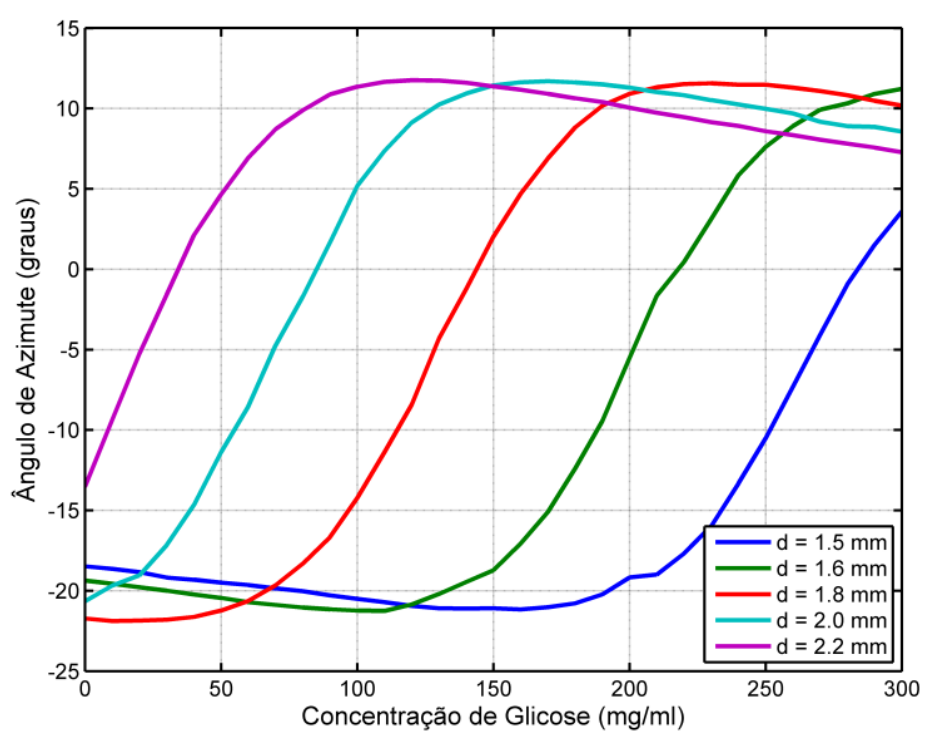

Figura 74 - Ângulo de azimute $\theta$ em função da concentração de glicose de 0 a $300 \mathrm{mg} / \mathrm{ml}$ para a configuração de fios cruzados.

Para ambas as estruturas, verificou-se a ocorrência de faixas dinâmicas lineares de boa sensibilidade. Como exemplo, considere a faixa de concentração de 50 a $100 \mathrm{mg} / \mathrm{ml}$, onde pode-se verificar um comportamento linear do ângulo de azimute com a concentração. A sensibilidade do sistema é calculada a partir da relação $\Delta \theta / \Delta c$. Para a configuração de hastes triplas com $d=1,4 \mathrm{~mm}$, a sensitividade é 0,36 (graus. $\mathrm{ml} / \mathrm{mg}$ ). Para a configuração de fios cruzados com $d=2 \mathrm{~mm}$, a sensitividade é 0,33 (graus. $\mathrm{ml} / \mathrm{mg}$ ), sugerindo ambas configurações de inclusões como candidatas para operação neste tipo de sensor. A configuração de hastes triplas, por sua vez, possui um potencial maior de aplicação por apresentar mais graus de liberdade em sua geometria. É importante observar que a estrutura sugerida em [53] apresenta uma sensibilidade $\Delta S_{11} / \Delta c=0,00004(\mathrm{ml} / \mathrm{mg})$.

Finalmente, ainda de acordo com os gráficos das Figura 73 e Figura 74, verifica-se que aumentando-se o valor da separação $d$, as faixas dinâmicas de cada curva são deslocadas para regiões de menor concentração de glicose. Esse artifício pode ser utilizado para escolher em qual faixa de concentração se deseja trabalhar. Nota-se que na região linear de cada curva, o ângulo de azimute aumenta conforme a concentração de glicose aumenta. 


\section{Capítulo 6 - Conclusões}

Este trabalho desenvolveu uma nova técnica de fabricação de metamateriais para a faixa de micro-ondas, a qual foi aplicada na confecção de metamateriais quirais para caracterização experimental. Para isso, células quirais foram previamente modeladas para operarem na faixa de $8 \mathrm{GHz}$ a $12 \mathrm{GHz}$ para serem construídas em dois tipos de substratos: o tradicional FR4 e o filme fino de alumínio desenvolvido pela primeira vez neste trabalho. Ambos os métodos foram comparados e o novo processo foi validado. Além disso, o novo substrato proposto se mostrou um forte candidato para trabalhos futuros com aplicações que exigem flexibilidade, baixas perdas e diferentes formatos, podendo ser também usados na confecção de outros tipos de metamateriais.

As medidas experimentais foram feitas pelo método do espaço livre com antenas cornetas, sendo que a para a calibração do sistema utilizou-se o método TRL. As estruturas metamateriais quirais caracterizadas apresentaram as principais propriedades dessa classe de materiais: birrefringência e dicroísmo circular e foram verificados ainda valores negativos de índice de refração em todas as estruturas.

Por fim, este trabalho aborda pela primeira vez a aplicação de estruturas quirais planares na faixa de micro-ondas para medidas de concentração de glicose em uma amostra aquosa. Foram analisadas duas configurações distintas para as inserções com o objetivo de definirmos critérios como faixa dinâmica, sensibilidade, e perdas de inserção. Os resultados indicaram que a utilização de metamateriais quirais proporciona uma boa sensibilidade para o novo sensor, demonstrando que nesse caso, a rotação de campo pode de fato ser utilizada como transdutor. 


\section{REFERÊNCIAS}

1. Smith, D. R., Pendry, J. B. e Wiltshire, M. C. K., "Metamaterials and negative refractive index", Science 305 788-92, 2004.

2. Soukoulis, C. M., Kafesaki, M. e Economou, E. N., "Negative-index materials: new frontiers in optics" Adv. Mater. 18 1941-52, 2006.

3. Dolling G, Enkrich C, Wegener M, Zhou J F, Soukoulis C M and Linden S 2005 "Cut-wire pairs and plate pairs as magnetic atoms for optical metamaterials" Opt. Lett. 30 319, 2005.

4. Shalaev V M "Optical negative-index metamaterials," Nature Photon 1 41-8, 2007.

5. Zhou J, Koschny T, Kafesaki M, Economou E N, Pendry J B and Soukoulis C $M$ "Saturation of magnetic response of split-ring resonators at optical frequencies" Phys. Rev. Lett. 95 223902, 2005.

6. Bose, J. C. "On the rotation of plane of polarisation of electric waves by a twisted structure" Proc. R. Soc. 63 146-52, 1898.

7. Ziolkowski, R. W. e Engheta, N., "Introduction, History and Selected Topics in Fundamentals Theories of Metamaterials" em N. Engheta e R. W. Ziolkowski, Metamaterials: Physics and Engineering Explorations, New York: Wiley-IEEE Press., 2006.

8. Veselago, V. G., The electrodynamics of substances with simultaneously negative values of $\varepsilon$ and $\mu$ Sov. Phys.-Usp. 10 509-14, 1968.

9. Pendry $J$ B, Holden $A J$, Stewart $W J$ and Youngs I "Extremely low frequency plasmons in metallic mesostructures" Phys. Rev. Lett. 76 4773-6, 1996.

10. Pendry, J. B., A. J. Holden, D. J. Robbins, and W. J. Stewart, "Low frequency plasmons in thin-wire structures," J. Phys.: Condens. Matter, Vol. 10, No. 22, 4785-4809, 1998.

11.Pendry, J. B., Holden, A. J., Robbins, D. J. e Stewart, W. J., "Magnetism from conductors and enhanced nonlinear phenomena," IEEE Trans. Microw. Theory Tech. 47 2075, 1999. 
12. Smith, D. R., Padilla, W. J., Vier D. C., Nemat-Nasser S. C. e Schultz S., "Composite medium with simultaneously negative permeability and permittivity", Phys. Rev. Lett. 84 4184-7, 2000.

13. Pendry, J. B., "Negative refraction makes a perfect lens", Phy. Rev. Letters, Vol. 85, No. 18, 3966-3969, 30, Oct. 2000.

14. Cartwright, J. "Defeating diffraction", Physics World, Maio de 2012.

15. Schurig, D. et al. "Metamaterial electromagnetic cloak at microwave frequencies," Science 314, 977-980, 2006.

16.J. B. Pendry, D. Schurig, and D. R. Smith, "Controlling Electromagnetic Fields," Science 312, 1780-1782, 2006.

17.D. Rainwater et al., "Experimental Verification of Three-Dimensional Plasmonic Cloaking in Free-Space," New Journal of Physics, Vol. 14, 013054, 2012.

18. J. C. Soric, et al., "Demonstration of an ultralow profile cloak for scattering suppression of a finite-length rod in free space," New J. Phys., 2013.

19. R. W. Ziolkowski and A. D. Kipple, "Application of Double Negative Materials to Increase the Power Radiated by electrically Small Antennas", IEEE Transactions on Antennas and Propagation, vol. 51, no. 10, pp. 2626-2640, October 2003.

20.R. W. Ziolkowski, "Metamaterials-Based Antennas: Research and Developments", IEICE Trans. Electron, Vol. E89-C, no.9, pp. 1267-1275, September 2006.

21. L. C. P. S. Lima, L. V. Muniz, T. C. Vasconcelos, F. D. Nunes and B. V. Borges, "Design of a dual-band monopole antenna enclosed in a 2D-chiral metamaterial shell", Metamaterials'2012: The Sixth International Congress on Advanced Electromagnetic Materials in Microwaves and Optics, 2012, Saint Petersburg. Proceedings of the Metamaterials 2012 Congress. p. 730-732, 2012.

22. J.J yang, M. Huang and J. Sun, "Double Negative Metamaterial Sensor Based on Microring Ressonator", IEEE Sensor Journal, vol. 11, no. 10, pp. 22542259, 2011.

23. L. V. Muniz, L. C. P. S. Lima, T. C. Vasconcelos, F. D. Nunes and B. V. Borges, "Rotação do Azimute de Polarização em Metamateriais Quirais como 
um Transdutor para Aplicações em Biossensores". MOMAG 2012 - 15 SBMO Simpósio Brasileiro de Micro-ondas e Optoeletrônica e o 10 CBMag Congresso Brasileiro de Eletromagnetismo (MOMAG 2012), João Pessoa, PB, 2012.

24.Zhou, J. et al., "Negative refractive index due to chirality," Phys. Rev. B 79, 121104, 2009.

25. Li, Z. et al., "Chiral metamaterials with negative refractive index based on four 'U' split ring resonators,' Appl. Phys. Lett. 97, 081901, 2010.

26. Tretyakov, S., Nefedov, I., Sihvola, A., Maslovski, S. e Simovski, C., "Waves and energy in chiral nihility," J. of Electromagn. Waves and Appl., vol. 17, no. 5, pp. 695-706, 2003.

27. Fedotov, V. A. et al., "Asymmetric propagation of electromagnetic waves through a planar chiral structure," Phys. Rev. Lett. 97, 167401, 2006.

28.Zhang S, Park Y S, Li J, Lu X, Zhang W and Zhang X., "Negative refractive index in chiral metamaterials," Phys. Rev. Lett. 102 023901, 2009.

29. Wang B, Zhou J, Koschny $T$ and Soukoulis C M, "Nonplanar chiral metamaterials with negative index" Appl. Phys. Lett. 94 151112, 2009.

30. Plum, E., Fedotov, V. A. e Zheludev, N. I., "Optical activity in extrinsically chiral metamaterial," Appl. Phys. Lett. 93, 191911, 2008

31.Demir, V., A. Z. Elsherbeni, E. Arvas, "FDTD formulation for dispersive chiral media using the $Z$ transform method," IEEE Trans. Antennas Propag., Vol. 53, 10, 2005.

32. Kong, J. A., "Electromagnetic Wave Theory", John Wiley \& Sons, New York, 1986.

33. Orfanidis, S. J. "Electromagnetic Waves and Antennas," (http://www.ece.rutgers.edu/ orfanidi/ewa/), 2004.

34. A.Yariv and P. Yeh, "Optical waves in crystals", Wiley 1984

35. Lindell I V, Sihvola A H, Tretyakov S A and Viitanen A J "Electromagnetic Waves in Chiral and Bi-isotropic Media," (Boston, MA: Artech House Publishers), 1994.

36.Wang, B., Zhou, J., Koschny T., Kafesaki, M. e Soukoulis, C. M., "Chiral metamaterials: simulations and experiments," J. Opt. A: Pure Appl. Opt., vol. 11, 2009. 
37. Zhao R., Koschny T. and Soukoulis C. M. "Chiral metamaterials: retrieval of the effective parameters with and without substrate", Opt. Express 18 1455367, 2010.

38. Gonzalez, G. "Microwave Transistor Amplifiers: Analysis and Design", Prentice Hall, 1997.

39. Pozar D. M., "Microwave Engineering", $3^{\text {a }}$ Edição, John Wiley \& Sons, Pág 193, 2004.

40. Ansoft HFSS (High Frequency Structure Simulator), versão 15.0, Ansoft Corporation <www.ansoft.com>.

41.M. Choi, et al., "A terahertz metamaterial with unnaturally high refractive index", Nature 470, 369, 2011

42. Tao $\mathrm{H}$. et al., "Terahertz metamaterials on free-standing highly-flexible polyimide substrates", J. Phys. D, Appl. Phys., vol. 41, no. 23, 2008.

43. Tao H., et al., Flexible Terahertz Metamaterials: Towards a Terahertz Metamaterial Invisible Cloak, IEEE International Electron Devices Meeting, San Francisco, CA, December 15-17, 2008.

44. Ragi P. M. et al., "Flexible split-ring resonator metamaterial structure at microwave frequencies," Microwave and Optical Technology Letters, 54, 2012

45. Liu, L., S. M. Matitsine, Y. B. Gan, K. N. Rozanov, "Effective permittivity of planar composites with randomly or periodically distributed conducting fibers," J. Appl. Phys., Vol. 98, 63512, 2005.

46. Ghodgaonkar, D. K., Varadan, V. V., and Varadan, V. K.: A Free-Space Method for Measurement of Dielectric Constants and Loss Tangents at Microwave Frequencies, IEEE Trans. Instrum. Meas., 37, 789-793, June, 1989.

47. Ghodgaonkar, D. K., Varadan, V. V. and Varadan, V. K. "Free-space measurement of complex permittivity and complex permeability of magnetic materials at microwave frequencies," IEEE Transactions on Instrumentation and Measurements," Vol. 39, pp. 398-394, 1990.

48. Balanis, C. A., "Teoria de Antenas: Análise e Síntese", vol. 2, Rio de Janeiro: LTC, pp. 106-145, 2009. 
49. Agilent Technologies, Inc. "Free Space Materials Measurement Seminar", Disponível em <http://www.home.agilent.com/upload/cmc_upload/All/ FreeSpaceSeminarRev2.pdf>, 2005

50. Biju K. J., et al., "A simple free-space method for measuring the complex permittivity of single and compound dielectric materials," Microw. Opt. Technol. Lett., Vol. 26, 117-119, 2000.

51. Agilent Technologies, "Network Analysis Applying the 8510 TRL Calibration for Non-Coaxial Measurements", Product Note 8510, 2001.

52. Curran, J., Rochford, K., "TRL calibration for non-coaxial measurements", Hewlett-Packard Company. Disponível em : www.hparchive.com/ seminar_notes/a-215.pdf

53. Kim, J., Babajanyan, A., Hovsepyan, A., Lee, K. e Friedman, B., "Microwave dielectric resonator biosensor for aqueous glucose solution," Rev. Sci. Instrum. 79, 086107, 2008 


\section{APÊNDICE I - CONFECÇÃo dAS PLACAS META- MATERIAIS PLANARES}

\section{Placas de FR4}

O processo de confecção de uma placa metamaterial, partindo-se da placa virgem até o metamaterial definitivo, é feito basicamente em duas etapas: transferência térmica e corrosão química.

$\mathrm{Na}$ primeira parte do processo, o desenho da estrutura projetada deve ser transferido para a face metalizada da placa virgem.

Para isso, o layout do arranjo de células paródicas é impresso primeiramente em um papel transfer próprio para transferências em superfícies, como ilustrado na Figura 75 (a), e cuja impressão deve ser feita utilizando impressoras a LASER, as quais utilizam tinta em pó do tipo toner. Em seguida, como pode ser visto na Figura 75 (b), o papel transfer é posicionado na placa e ambos são colocados em uma prensa térmica durante o tempo de 50 segundos a uma temperatura de $200^{\circ} \mathrm{C}$.

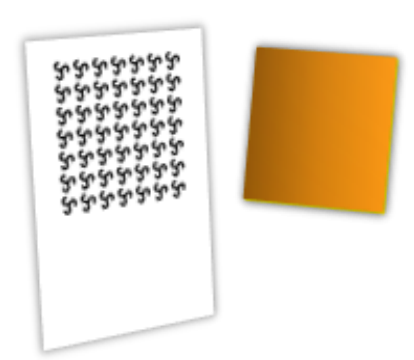

(a)

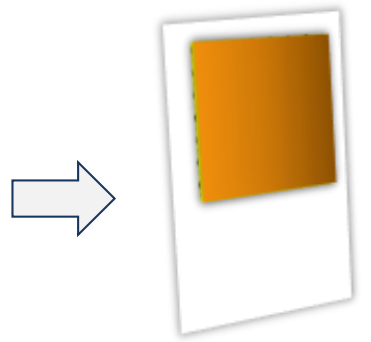

(b)
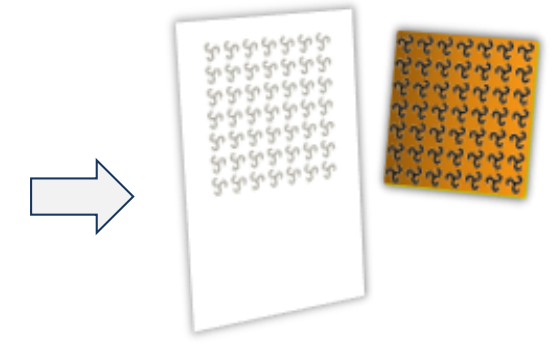

(c)

Figura 75 - Transferência térmica- (a) Papel transfer e placa de FR4 metalizada; (b) Posicionamento do papel transfer na placa e transferência térmica, (c) placa com o layout transferido.

O modelo da prensa térmica utilizada é mostrado na Figura 76, onde podem ser vistas suas duas posições de operação. Na prensa, o papel e a placa são pressionados um contra o outro e, devido à alta temperatura, a tinta sai do papel e se fixa na placa de metal. Assim, ao final dessa primeira etapa, retira-se o papel transfer e tem-se então uma placa metalizada parcialmente coberta pelo desenho da 
estrutura metamaterial, como mostrado na Figura 75 (c). Como a imagem do layout naturalmente se inverte ao ser transferida para a placa, a impressão no papel transfer deve então ser previamente espelhada.

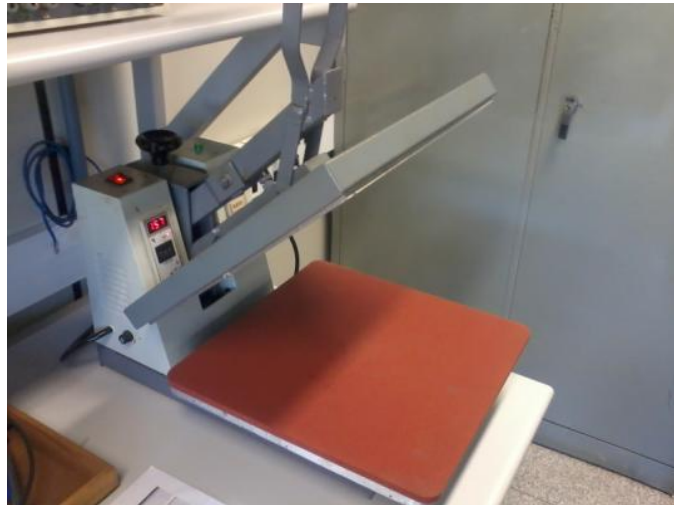

(a)

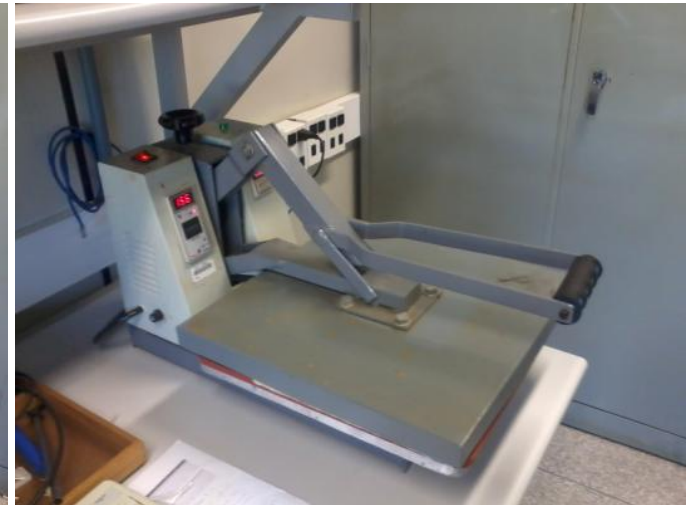

(b)

Figura 76 - Prensa térmica manual utilizada no processo de transferência em duas posições de operação.(a) prensa com mesa de compressão aberta; (b) mesa de compressão fechada durante o processo de transferência térmica

Por fim, no caso de metamateriais biplanares, em placas de dupla face, o mesmo procedimento de transferência também deve ser feito no lado oposto da placa, com o seu respectivo layout devidamente posicionado.

No segundo passo da confecção do metamaterial, a placa é submetida a um processo corrosão química. A placa, ilustrada na Figura 77 (a), é mergulhada em uma solução ácida de Percloreto de Ferro $\left(\mathrm{FeCl}_{3}\right)$, como mostrado na Figura 77 (b), a qual é corrosiva para o cobre exposto, porém não afeta o substrato de FR4 nem a tinta da impressão. Sendo assim, a corrosão faz com que parte do cobre seja removida da placa, restando metal apenas nas regiões protegidas pela tinta. Esta etapa tem duração de aproximadamente 30 minutos e, no final do processo, após retirar a placa do ácido e lavá-la com esponja de aço e sabão, verifica-se que restaram apenas os ressoadores metálicos dispostos sobre o substrato de FR4, como mostrado na Figura 77 (c). 


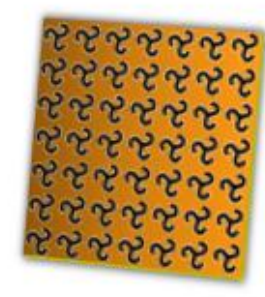

(a)

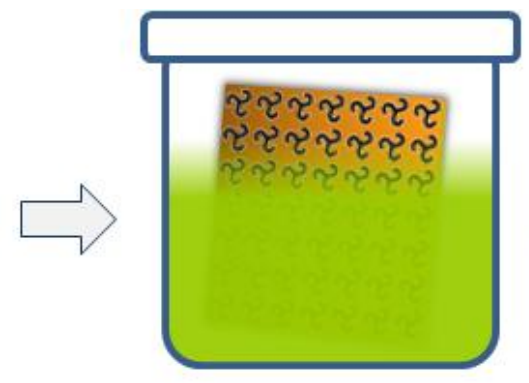

(b)

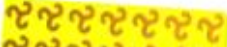

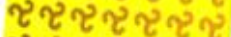

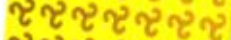

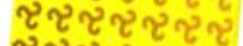

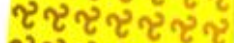

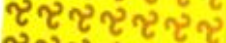

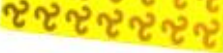

(c)

Figura 77 - Processo de corrosão: (a) placa a ser corroída; (b) placa imersa no ácido; (c) placa após a corrosão.

$\mathrm{Na}$ Figura 78, é mostrada uma fotografia da placa metamaterial finalizada (Figura 78 (a)), assim como uma imagem mais detalhada dos ressoadores metálicos (Figura 78 (b)). Com isso, o metamaterial está finalizado e, portanto, pronto para ser caracterizado.

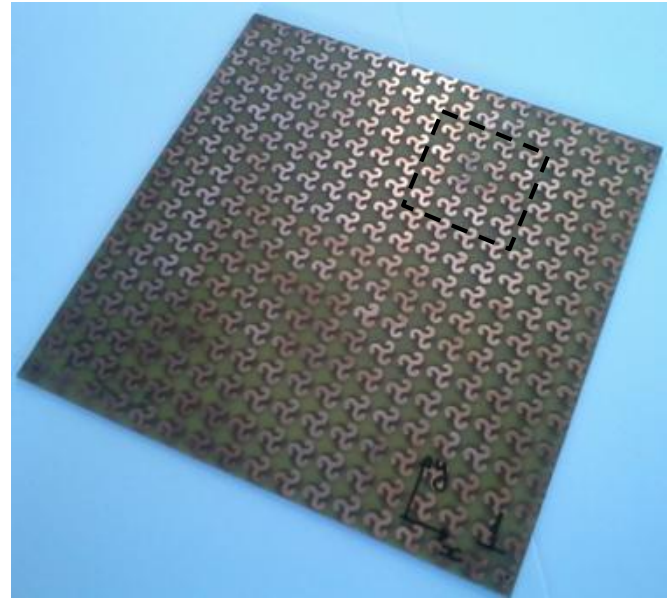

(a)

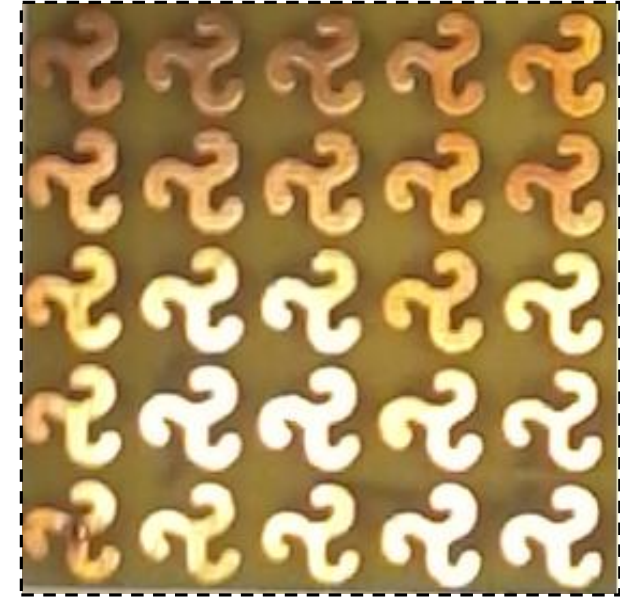

(b)

Figura 78 - Placa metamaterial pronta (a) Placa metamaterial pronta; (b) Detalhe ampliado. 


\section{ApÊndice II - Placas em Filme flexível de ALUMÍNIO}

A construção de metamateriais em filme fino de alumínio é feita em etapas como: construção na folha metalizada, a transferência do layout da estrutura para a face metalizada e corrosão química.

O processo de criar a placa de circuito impresso flexível consiste em aderir o filme de alumínio em um pedaço de folha de plástico auto-adesivo, como ilustrado na Figura 79 formando, assim, um substrato flexível de dielétrico com uma face metalizada.

\section{CONSTRUÇÃo dA PLACA DE CIRCUITO FLEXÍVEL}

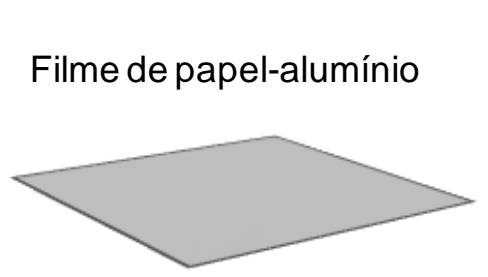

(a)
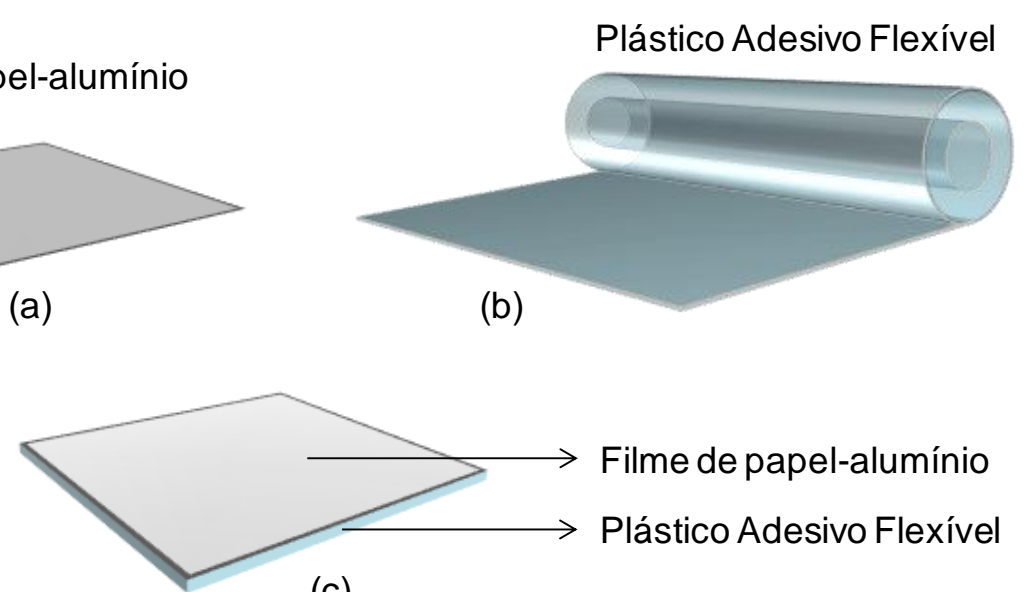

(c)

Figura 79 - Processo de confecção da placa de circuito impresso flexível: (a) filme de alumínio $(50 \mu \mathrm{m})$; (b) plástico auto-adesivo; (c) placa pronta

\section{TRANSFERÊNCIA TÉRMICA}

O processo de construção da placa flexível foi ilustrado anteriormente para apresentar uma ideia mais direta da técnica. Contudo, verificou-se que a maneira mais eficaz de construir o metamaterial nesse método é realizar primeiramente a transferência térmica para a face do filme de alumínio (ainda sem o plástico) e 
somente após isso ter sido feito, aderir o plástico ao alumínio, no lado oposto ao que recebeu a transferência do layout dos ressoadores.

A etapa da transferência térmica, por sua vez, é semelhante à ilustrada no método usado para placas de FR4 e cobre. O desenho do metamaterial é impresso em um papel transfer, que é devidamente posicionado no filme de alumínio e ambos são levados a uma prensa térmica que aquece e pressiona o conjunto, provocando a transferência da tinta do papel para o metal. A temperatura utilizada nesse caso foi a de $150^{\circ} \mathrm{C}$ e o tempo de $45 \mathrm{~s}$.

Nesta etapa, deve-se tomar um cuidado especial com as diferentes dilatações térmicas do metal e do papel, pois isso pode provocar rugosidades e falhas na transferência. Para se evitar problemas desse tipo, verificou-se que a melhor maneira é aquecer inicialmente apenas a folha de alumínio durante 20 segundos na prensa térmica, fazendo com o filme metálico se dilate e, logo em seguida, posicionar rapidamente o papel transfer sobre o alumínio e acionar a prensa novamente sobre o conjunto, durante o tempo estipulado para a transferência. Após este processo, a face do metal apresentará o layout das estruturas do metamaterial, como mostrado na Figura 80

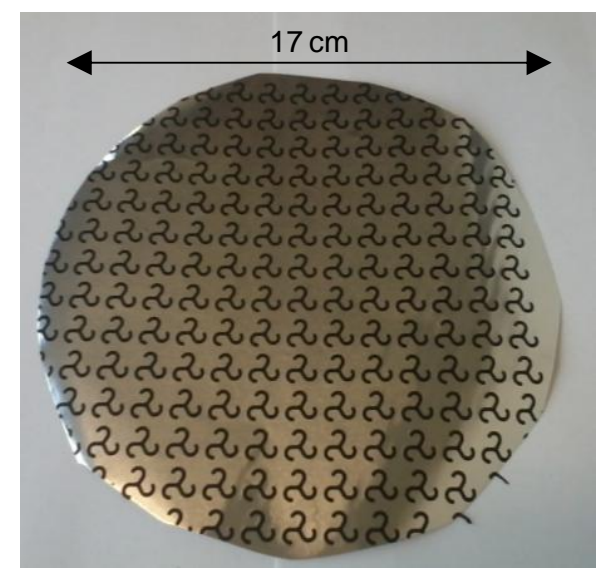

Figura 80 - Filme de alumínio com layout transferido

Após a transferência, pode-se, então, aderir o alumínio ao plástico autoadesivo e passar para a etapa final de corrosão. 


\section{CORROSÃo QUímICA}

De forma análoga ao método que utiliza o FR4, o filme flexível de alumínio deve ser imerso em uma solução ácida de Percloreto de Ferro para a corrosão. Entretanto, o ácido deve ser mais diluído para este processo, pois a sua reação química como alumínio é muito mais violenta, altamente efervescente e exotérmica. Para evitar este problema, deve-se diminuir sua concentração, adicionando mais água à solução (de duas a três vezes mais que a utilizada para corrosão de cobre em FR4). Após isso, ainda é recomendado fazer um teste com uma pequena amostra de alumínio.

Essa etapa dura cerca de 15 a 20 minutos e durante o processo é necessário a remoção do pó (produto da reação) que vai se formando ao longo do filme. Isso deve ser feito para que possibilite o contato entre o ácido e o metal que ainda falta ser corroído. Isso pode (e deve!) ser feito manualmente com o uso de luvas de proteção.

Assim, após a corrosão, a folha de plástico adesivo terá apenas os ressoadores, que não foram corroídos, por estarem protegidos pela tinta da impressão e transferência térmica. Deve-se lavar esta folha com sabão em água corrente para a remoção e neutralização de qualquer resquício de ácido.

Por fim, o filme flexível de ressoadores está pronto para ser aderido e adaptado a qualquer superfície adequada, como mostrado em detalhes na Figura 81.

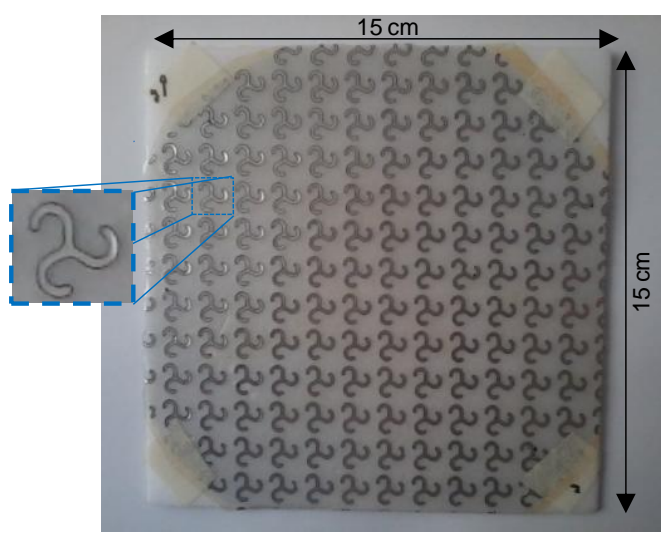

Figura 81 - Placa de metamaterial com filme de alumínio 


\section{ApÊndice III - Calibração TRL No ANALISAdoR DE REDES HP8720C.}

Procedimentos para calibração TRL (Thru, Reflect, Line) de antenas cornetas para medidas em espaço livre.

Ligar o Analisador de Redes na chave principal

$[\mathrm{ON} / \mathrm{OFF}]$

Configurações de display:

[MEAS $\rightarrow$ [S21] (mostrar na tela o parâmetro $S_{21}$ )

[FORMAT $] \rightarrow$ [LOG MAG ] (mostrar a magnitude do parâmetro S21 em dB)

Definindo a faixa de frequência e número de pontos

[START $] \rightarrow$ digitar o valor no teclado numérico $\rightarrow[\mathrm{G} / \mathrm{n}]$ (para frequências de $\mathrm{GHz}$ )

$[\mathrm{STOP}] \rightarrow$ digitar o valor no teclado numérico $\rightarrow[\mathrm{G} / \mathrm{n}]$ (para frequências de $\mathrm{GHz}$

[MENU] $\rightarrow$ [NUMBER OF $P$ POINTS $] \rightarrow$ usar a chave seletora para escolher o valor $\rightarrow[\mathrm{x} 1]$

Selecionando o modo de calibração TRL

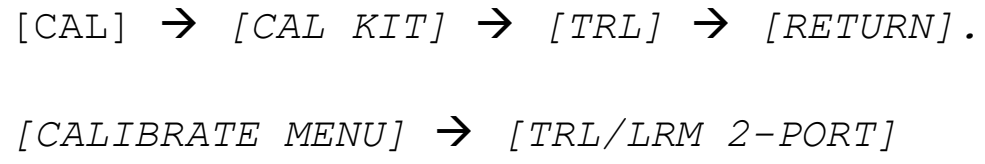




\section{THRU (Direto)}

Posicionar as antenas cornetas a distância entre si que seja a mesma para as medições. Pressionar o botão correspondente:

\section{[THRU]}

\section{REFLECT (Refletor)}

Inserir o espelho refletor entre as antenas, ajustar a posição das antenas se preciso, para compensar a espessura do espelho.

\section{[S11 REFL SHORT]}

\section{[S22 REFL SHORT]}

\section{LINE (Linha)}

Retirar o espelho, aumentar a distância entre as antenas em um quarto do comprimento de onda da frequência central da faixa de medida e pressionar os botões correspondentes:

\section{$[L I N E / M A T C H] \rightarrow[D O B O T H \quad F W D+R E V]$}

Feito isso, reposicionar as antenas para a distância inicial.

O analisador de redes ainda oferece uma quarta etapa para a calibração, chamada ISOLATION (isolação), mas esta pode ser omitida sem afetar o sucesso do procedimento. Para isso, pressionar os seguintes comandos:

\section{[ISOLATION] $\rightarrow$ [OMIT ISOLATION]}

Por fim, para finalizar a calibração TRL, pressionar o comando:

\section{[DONE TRL/LRM]}

Aguardar o analisador calcular os coeficientes de calibração e, enfim, salvar a calibração em um dos quatros registros do aparelho:

$\left[\begin{array}{lll}S A V E & R E G \\ X\end{array}\right] \quad(X=1,2,3$ ou 4$)$ 